NBER WORKING PAPER SERIES

\title{
BANK TIES AND BOND MARKET ACCESS: EVIDENCE ON INVESTMENT-CASH FLOW SENSITIVITY IN JAPAN
}

\author{
Patrick M. McGuire \\ Working Paper 9644 \\ http://www.nber.org/papers/w9644 \\ NATIONAL BUREAU OF ECONOMIC RESEARCH \\ 1050 Massachusetts Avenue \\ Cambridge, MA 02138 \\ April 2003
}

I would like to thank Gary Saxonhouse, Matthew Shapiro, Susanto Basu, and I. Serdar Dinc, all from the University of Michigan. In addition, I received many helpful comments from Anil Kashyap and the participants in the NBER/CEPR/Tokyo University CIRJE/EIJS Japan Project Meeting in Tokyo, Japan (Sept 13-14, 2002). I would also like to thank Fumio Hayashi from Tokyo University, for help with data preparation, and the Ministry of Economy, Trade, and Industry in Japan and the Economics Department of Tokyo University for use of their raw data. Any errors are my own. The views expressed herein are those of the authors and not necessarily those of the National Bureau of Economic Research.

(C)2003 by Patrick M. McGuire All rights reserved. Short sections of text not to exceed two paragraphs, may be quoted without explicit permission provided that full credit including Cnotice, is given to the source. 
Bank Ties and Bond Market Access: Evidence on Investment-Cash Flow Sensitivity in Japan Patrick M. McGuire

NBER Working Paper No. 9644

April 2003

JEL No. G3

\section{$\underline{\text { ABSTRACT }}$}

The banking literature has established that banks can alleviate information asymmetries between lenders and borrowers, while the Q literature has used cash flow sensitivity analysis to test whether financing constraints hinder investment. This paper investigates whether bank ties in Japan were costly for mature and healthy firms in the 1980's and 1990's, and whether banks continued to facilitate investment once non-bank financing options became available. Using the explicit bond issuing criteria to solve the endogenous firm-sorting problem, I measure the investment-cash flow sensitivity of Japanese firms, and find it lowest for those firms known to have faced bond market constraints. I then find that the spread in sensitivity was much larger for main bank client firms, once bond market access is controlled for. This result, coupled with results on the relative profitability and bond activity of bank-affiliated firms, is consistent with banks capturing the net benefits of relationship lending during the period of bond market deregulation.

Patrick M. McGuire

Bank for International Settlements

Centralbahnplatz $2 \mathrm{CH}-4002$

Basel, Switzerland

patrick.mcguire@bis.org 


\section{Introduction}

The relationship banking literature postulates that close bank ties can mitigate the asymmetric information and moral hazard problems that afflict public capital markets. Related with this, the $Q$ literature has interpreted excessive correlation between a firm's investment and its internal net worth as evidence of financing constraints. ${ }^{1}$ Combining these literatures, Hoshi, Kashyap, and Scharfstein (1991) (hereafter HKS91) investigate the investment-cash flow sensitivity of bank affiliated and independent firms in Japan, and provide evidence that strong ties helped to alleviate liquidity constraints. Since the Japanese asset market collapse, a body of work has emerged which focuses on the associated costs of "main banking". This paper builds on this literature by examining the investment-cash flow sensitivity of Japanese manufacturing firms, and uses the explicit bond issuing criteria in a simple test of whether firms enjoyed positive net benefits from close bank ties in the 1980's and 1990's.

While many have shown that banks can act as effective firm monitors, bank dependence may be costly to firms if banks use their market power to extract rents (Sharpe (1990) and Rajan (1992)). If close bank ties are costly for mature and healthy firms, should we still expect banks to facilitate investment? Do banks retain their ability to lower cash flow sensitivity when outside financing options are introduced? Can exogenous changes in the financing environment be used to determine which party enjoys the benefits of relationship banking? This paper addresses these questions, and highlights the importance of properly addressing endogenous firm-sorting issues in empirical investment- $Q$ work.

The empirical work on cash flow sensitivity has struggled with the problem of isolating financially constrained firms. ${ }^{2}$ Ideally, exogenous criteria indicative of financing constraints should be used to sort firms before comparing sensitivity across groups. Often, however, empirical work is forced to rely on behavioral characteristics which can lead to endogenous sample selection problems. Japan is a natural place to address this issue both because of its historical reliance on large domestic banks in corporate financing (the "Main Bank" system), and because of the government regulation of the capital markets for much of the post war period. ${ }^{3}$ Throughout the $1980 \mathrm{~s}$, firms had to meet explicit criteria set by the government in

\footnotetext{
${ }^{1}$ Fazzari, Hubbard and Petersen (1988), Oliner and Rudebusch (1992), Chirinko (1993), and Kaplan and Zingales (1997).

${ }^{2}$ See Hubbard (1998) for discussion.

${ }^{3}$ Reviewing the Japanese Main Bank system, Aoki (1994) noted, "In postwar Japan, the main bank system has been the main pillar of corporate monitoring and governance, compensating for the lack of more
} 
order to issue bonds in the domestic market. These bond criteria can be exploited in empirical work to isolate constrained firms, and serve as a partial solution to the endogeneity problem.

Using these criteria, I first show that sensitivity was lowest for those firms that were restricted from the bond market during the 1980's, a result very much at odds with the standard prediction in the $\mathrm{Q}$ literature. That is, the investment of firms known to have faced capital market restrictions was less sensitive to measures of internal net worth than that of firms with a wider range of financing options. This result survives several robustness tests, including controls for negative observations as outlined in Allayannis and Mozumdar (2001), and may indicate that sensitivity analysis is not an appropriate technique for identifying financing constraints. However, restricted firms were, by definition, bank-dependent, meaning the results presented here are consistent with both established theory with HKS91.

As effective firm monitors, banks may have facilitated the efficient use of capital, and helped firms to achieve and maintain their first-best investment path. On the other hand, high monitoring costs may have meant that firms paid a premium for bank financing. In a more sinister scenario, banks may have enjoyed information monopolies, or market power from the remaining capital controls, that allowed them to extract rents through higher interest rates, compensating balance requirements, or pressure to over-borrow (Weinstein and Yafeh (1998)). This is of particular concern because of the gradual nature of bond market deregulation; banks may have been able to capitalize on their market power over firms that did not meet the bond criteria. Thus, the results introduced above do not provide clear evidence on whether bank ties were a net benefit to firms. Sensitivity may have been lower for restricted firms because they enjoyed better access to funding (from close banks), but possibly with high "indirect" costs. Alternatively, sensitivity may have been driven by artificially high loan flows if firms were pressured to borrow.

Splitting the sample using both a standard proxy for main bank affiliation and the bond criteria sheds light on this issue. As in Hoshi et al. (1990b), this section implicitly hypothesizes that if firms enjoyed a positive net benefit from close bank ties, sensitivity should be lower for bank-affiliated firms, regardless of bond market access. In addition, there should be some ex post observable difference in performance between affiliated and independent firms that reflects the benefits of bank ties. If the net benefit accrued to banks (because of high monitoring costs or rent extraction) then bond-eligible, main bank client firms may

arm's-length market-oriented means such as the takeover mechanism, and probably obviating a need for them to develop." 
have had a stronger incentive to move to bond financing, even if this increased the likelihood of asymmetric information problems. In other words, the implications of higher sensitivity may have been more palatable to firms than the bank relationship.

The evidence presented here supports the latter case. For the four firm groups, sensitivity was highest for main bank client firms that had access to the bond market in the 1980s, and lowest for main bank client firms that did not. That is, the spread in sensitivity was larger for bank-affiliated firms than for independent firms once external financing options are introduced. In addition, bank-affiliated firms accessed the bond market more often, and with (slightly) larger issues than did independent firms, despite their lower profitability.

The results are consistent with banks capturing the rents from main bank ties. With deregulation, mature and healthy firms chose to reduce bank dependence, implying that internal financing (and its associated costs) was less than the cost of a main bank relationship. Importantly, these results do not imply that firms never benefited from having a main bank. Indeed, it is often argued that the bank centered financial system was an important factor behind Japan's rapid growth prior to the mid-1970's, and only became obsolete once Japan reached the technological frontier. The lack of outside financing options in this earlier period precludes the firm division proposed in this paper.

The remainder of this paper is organized as follows. Section 2 discusses the literature on cash flow sensitivity analysis, with emphasis on recent papers that question its validity, as well as the empirical work on main banking in Japan. Section 3 presents the empirical methodology, discusses the bond eligibility criteria in place in the 1980s, and describes the data. Section 4 presents the empirical results using standard cash flow sensitivity analysis, and robustness checks based on different firm sorting mechanisms, data samples, and model specifications. Section 5 concludes.

\section{Literature Review}

\subsection{Investment-Cash Flow Sensitivity}

The Modigliani-Miller theorem implies that a firm's financial structure does not matter for investment decisions. Absent financing constraints, all positive net-present-value investment projects are financed, and arbitrage within and across financial markets makes irrelevant the mix of finance sources. However, capital markets are not perfect, and information asym- 
metries may mean managers are unable to credibly convey the internal worthiness of their investment projects to public markets. ${ }^{4}$

Starting with Fazzari, Hubbard and Petersen (1988) (hereafter FHP88), a large literature has emerged that uses investment-cash flow sensitivity to investigate financing constraints. The central idea is as follows. Firms use a mixture of internal and external funds to finance investment, but financing constraints drive a wedge between the cost of these funds. With a large enough wedge, investment will vary not only with the availability of positive netpresent-value projects (as captured by Tobin's Q), but also with fluctuations in internal funds. ${ }^{5}$ Presumably, financing constraints can be measured by comparing the sensitivity of investment rates to cash flow across different classes of firms that are a priori assumed constrained. Firms that are the most constrained should display a higher sensitivity, as they are forced to use internal funds to maintain optimal investment. ${ }^{6}$

Several recent papers question the validity of this approach. Kaplan and Zingales (1997) (hereafter KZ97) reexamine the "constrained" firm group used in the FHP88 study, and show that within this group, sensitivity is highest for those firms that are the deemed unconstrained. They challenge the implicit assumption that the sensitivity of investment to cash flow increases monotonically with the degree of financing constraint, the so called "monotonicity hypothesis". ${ }^{7}$ They argue that the ambiguity of the theory which establishes the relationship between external financing constraints and the sensitivity of investment to internal funds implies that it is ultimately an empirical issue. Cash flow may act as a proxy for investment opportunities not captured by Tobin's Q, and do so differently for different groups of firms. Despite their findings, their analysis has been criticized because of small sample size. ${ }^{8}$

\footnotetext{
${ }^{4}$ Asymmetric information can cause the costs of internal and external finance to diverge (Greenwald, Stiglitz, and Weiss (1984), Myers and Majluf (1984)). Also see Bernanke and Gertler (1989, 1990), Jensen and Meckling (1976), and Hart and Moore (1995).

${ }^{5}$ See Hubbard (1998) and Chirinko (1993). Note that this methodology can detect financing constraints, but says nothing about their source (either agency costs or asymmetric information).

${ }^{6}$ FHP88 use dividend payouts to sort firms. Oliner and Rudebusch (1992) find sensitivity highest for young firms, and firms susceptible to insider trading. Schaller (1993) shows sensitivity is highest for young manufacturing firms with a dispersed ownership structure. Chirinko and Schaller (1995) use affiliation with a corporate group, firm age, and whether the firm is in the manufacturing sector.

${ }^{7}$ In their critique of FHP88, KZ97 use letters to shareholders and supplementary notes to track the incidence of liquidity problems and reclassify firms. In a simple model, they show that whether the monotonicity hypothesis is satisfied depends on the ratio of the second derivatives of the production and the financing cost functions.

${ }^{8}$ Fazzari, Hubbard, and Petersen (2000) defend the original FHP88 results by arguing that the KZ97
} 
Cleary (1999) reexamines this issue using a large sample of U.S. firms and a sorting index derived from six financial variables. In agreement with KZ97, he finds that unconstrained firms have the highest cash flow sensitivity. He draws support for this result from Mayer (1990), who empirically demonstrates that internal funds are the predominant source of financing for all firms (implying a correlation between liquidity and investment), and Jensen (1986), who argues that managers have an incentive to grow firms beyond their optimal size.

Recently, Allayannis and Mozumdar (2001) have overturned these critiques of cash flow sensitivity analysis. Using the data from both the KZ97 and Cleary (1999) studies, they investigate whether the results in each are driven by negative cash flow observations. They argue that firms with negative cash flow have driven investment down to its lowest possible level, making it unable to respond to further reductions (or small fluctuations) in cash flow. This reduces the investment-cash flow sensitivity for these observations. After correcting for this, they conclude that the Cleary (1999) results no longer hold, and the the KZ97 results are driven by a few influential observations and small sample size. Reaffirming the original FHP88 results, cash flow sensitivity is highest for those firms that are a priori assumed constrained.

The evidence to date suggests that sensitivity analysis may be useful in detecting financial constraints, but lacks the rigorous theoretical backing required to determine their source. In this paper, I present evidence using this approach for the purpose of reexamining Japanese main bank relationships, but rely on what are arguably exogenous criteria to sort firms. Further I show that the results presented here survive the robustness check proposed by Allyayannis and Mozumdar (2002).

\subsection{The Case of Japan}

"Main banking" has been at the core of the post war Japanese financial system, and as such has received considerable research attention. ${ }^{9}$ A substantial portion of this research has

model does not adequately capture the role of cash flow in investment decisions. Kaplan and Zingales (2000) reply to this critique by pointing out that the model analysis in Fazzari et al. (2000) fails to include second order effects.

${ }^{9}$ To name but a few in a large literature, Kaplan (1994), Kaplan and Minton (1994) and Morck and Nakamura (1999) analyze the appointment of outside directors from main banks to corporate boards. Prowse (1990) suggests that bank ownership can prevent wealth transfers from debt to equity holders, while Prowse (1992) shows that the top shareholders of main bank client firms do not take larger positions in cases where greater control might improve firm performance, presumably because banks have other means by which monitor management. Sheard (1989) argues that banks replace the takeover mechanism in arms-length 
focused on the investment-cash flow sensitivity of Japanese firms, typically in the context of assessing the benefits of affiliation with large domestic banks. In their seminal paper in both the Japan and Q literatures, HKS91 examine a panel of 145 manufacturing firms, and find that firms with strong bank ties exhibited significantly lower investment-cash flow sensitivity than did independent firms. Since main banks acquire inside knowledge of client firm's investment opportunities, the asymmetric information problems that force firms to rely on internal funds for investment are reduced.

While main bank client firms may enjoy access to capital, bank affiliation can be costly. Sharpe (1990) and Rajan (1992) argue that information monopolies or market power allow banks to extract rents. If a firm is known to be bank-affiliated, it may find it difficult to raise financing elsewhere since public capital markets may interpret this as bank refusal to extend credit because of some adverse private information. Thakor (1996) suggests that firms can seek financing from several sources to eliminate the threat of being held up or denied credit. ${ }^{10}$

In Japan, deregulation during the 1980's provided firms with alternative funding sources for the first time in the post war era. This expansion of non-bank financing options led to increased heterogeneity in capital structure across firms which researchers have been able to exploit in identifying the costs of bank affiliation. ${ }^{11}$ Hoshi et al. (1990b) examine the shift toward non-bank financing for a sample of 109 firms, and find sensitivity higher for firms that decreased their reliance on bank debt. This suggests that the net benefit to firms of bank affiliation may have been negative (at least in this period) since these firms presumably could have maintained close bank ties after deregulation. ${ }^{12}$

Others have also investigated whether firms enjoyed net benefits from close bank ties, particularly during the 1970's and 1980's. Horiuchi et al. (1988) found no evidence of risk sharing between banks and their client firms, while Caves and Uekusa (1976), Nakatani (1984), Kang and Shivdasani (1999) and Weinstein and Yafeh (1995, 1998) all show that

credit markets. Morck, Nakamura, and Shivdasani (2000) investigate the positive and negative effects of bank ownership on firm value. See Aoki (1994) for a thorough discussion of main banking in Japan. For a more recent treatment of the Japanese financial system, see Hoshi and Kashyap (2001).

${ }^{10}$ Ongena and Smith (2000) empirically show that multiple bank relationships can alleviate the hold-up problem, but that they limit the availability of credit.

${ }^{11}$ See Hoshi et al. (1993) and Hoshi and Kashyap (2001) for discussion on the development of the bond market.

${ }^{12}$ The authors speculate on the nature of the costs of bank affiliation. Banks may require higher rates of return because of reserve requirements, and may require a premium on loans, which are less liquid than publicly traded debt. In addition, firms may incur indirect costs if banks (as debt rather than equity holders) encourage excessively conservative investment policies. 
bank-affiliated firms performed worse than independents on a variety of profitability measures, suggesting that the benefits of bank relationships are not internalized by the firm. ${ }^{13}$

In a more direct test, Weinstein and Yafeh (1998) estimate a model where banks can influence firm investment through shareholding, and force firms to borrow as though their cost of capital is lower than it actually is. They argue that bank pressure induced artificially high loan flows and inefficient investment strategies that possibly led to the over-capitalization of client firms in the 1980's. Consistent with their story, the deregulation of the bond market led to a deterioration of the bank's traditional customer base during the 1980's. In addition, banks were initially prevented from entering the underwriting business, which meant fewer profit opportunities as banks were left with unused deposits. ${ }^{14}$ Regulated banks lacked the human capital to properly assess the risk of individual investment projects, and started lending to smaller, less well known firms, often based on land collateral values. Indeed, the bad loans that emerged after the market collapse have remained (undisclosed, for the most part) on the books of most Japanese banks. ${ }^{15}$ In such an environment, it is not inconceivable that banks pressured those firms over which they retained market power to borrow more than was economically efficient, particularly if the government implicitly guaranteed solvency.

More recently, Hayashi (2000) re-examines the HKS91 firm sample (with different data), and after excluding outliers, finds no significant difference in the cash flow sensitivity of bank-affiliated and independent firms. ${ }^{16}$ In fact, in some of the reported regressions, the point estimate on cash flow sensitivity for main bank firms is larger than for independent firms (although the difference is statistically insignificant). ${ }^{17}$ While this discrepancy may ultimately be driven by econometric technicalities, it does cast a shadow on the robustness

\footnotetext{
${ }^{13}$ Nakatani (1984) also finds that the variance of firm profitability is less for affiliated firms than for independent firms, suggesting that main banks serve as an "insurance policy" by implicitly committing to extend credit in times of financial distress in exchange for rents collected when the firm is healthy. This result is later challenged by Beason (1998).

${ }^{14}$ This restriction was relaxed in 1993 (Hoshi and Hamao (2000)). For a discussion of the "Big Bang" deregulation in the 1990s, see Hoshi and Kashyap (1999).

${ }^{15}$ Hoshi and Kashyap (1999) estimate the cost of the bad loan problem in the 1990 s to be roughly $7 \%$ of GDP, several times the size of the U.S. savings and loan crisis.

${ }^{16}$ The difference in the data used in the HKS91 and Hayashi (2000) studies is of some relevance here. HKS91 use data from the Nikkei needs database, which does not contain capital stock data by asset type. The JDB data used in the Hayashi (2000) study (and in this paper) contains a detailed breakdown of asset types and gross depreciation which allows for more accurate calculation of the real capital stock. For details on this issue, see the appendix of this paper and Hayashi and Inoue (1991).

${ }^{17}$ Hoshi (2000) counters the Hayashi (2000) critique by showing that if the data is corrected systematically, the earlier results still hold.
} 
of the original HKS91 results, and calls for further investigation.

Building on this literature, this paper investigates the investment-cash flow sensitivity of Japanese manufacturing firms in the 1980-96 period. While similar in spirit to Hoshi et al. (1990b), it makes use of a larger panel, uses the more detailed data described in Hayashi (2000), and uses the bond eligibility criteria as an exogenous firm sorting mechanism. In addition, it relies on recently developed empirical techniques, and carries the analysis of cash flow sensitivity and profitability into the 1990's when bond market deregulation was complete.

\section{$3 \quad$ Empirical Methodology}

The empirical procedure employed here is similar to that used in HKS (1990b, 1991) and Hayashi (2000), but incorporates alternative model specifications taken from recent papers in the $Q$ literature, and uses a variety of empirical methodologies in order to control for measurement error. The goal here is to (a) examine the relative sizes of cash flow sensitivity for firms with and without access to bond financing in order to establish the robustness of the HKS91 results, and (b) estimate sensitivity for main bank client firms after controlling for these outside financing options. As argued below, this latter query serves as a simple test of whether firms enjoyed positive net benefits from bank affiliation once bond financing became available.

\subsection{Model Specification}

The empirical analysis relies on the standard $Q$ equation from the dynamic optimization problem facing the firm each period, and I briefly review its derivation here. Firms are assumed to chose $I_{t}$ (investment net of sales of existing capital) subject to capital adjustment costs, and an accumulation constraint on capital, $K$.

Let $i$ index firms and $t$ index time periods. A general form of the cost of adjustment function is

$$
G\left(K_{i, t-1}, I_{i, t}\right)=\frac{\alpha}{2}\left[\frac{I_{i, t}}{K_{i, t-1}}-\beta \frac{I_{i, t-1}}{K_{i, t-2}}-\left(c+\nu_{i, t}\right)\right]^{2} K_{i, t-1}
$$

where $c$ is the (constant) target investment rate, and $\nu_{i, t}$ is a stochastic shock that contains both firm and period specific effects. $I_{i, t}$ is investment during period $t$, and $K_{i, t-1}$ is the capital stock at the beginning of period $t$. This functional form is a more general case of 
that most often used in the literature (where $\beta=0$ ), and is used in Love (2000) and Sekine (1999). Ideally, current investment should not depend on lagged investment. However, if firms find it difficult to cancel investment projects once they are started, investment rates will exhibit persistence across periods not explained by movements in $Q$. Also, a positive $\beta$ can capture some reductions in adjustment costs as firms learn to "work around" investment activity that normally upsets the production process. Since investment has been shown to be persistent over multiple periods, I test for this possibility by examining the size and significance of $\beta$.

The derivation of the standard investment equation requires that the conditions laid out by Hayashi (1982) hold, namely that production and adjustment costs are constant returns to scale, and that capital markets are perfect. The inclusion of regressors correlated with the internal net worth of the firm are a method of testing this last assumption. Only when financing constraints exist (and only if the "monotonicity hypothesis" as outlined in KZ97 holds) would we expect significant coefficients on such regressors.

Rearranging the first order conditions from the maximization of a dynamic profit function which contains the adjustment cost function specified above yields the standard equation in the literature, to which some measure of the firm's net worth is added as a regressor.

$$
\frac{I_{i, t}}{K_{i, t-1}}=c+\beta \frac{I_{i, t-1}}{K_{i, t-2}}+\frac{1}{\alpha}\left[\frac{P_{t}^{I}}{\left(1-\tau_{t}\right) P_{t}}\left(Q_{i, t}-1\right)\right]+\gamma_{c f} C F_{i, t}+\nu_{i}+\mu_{t}+\epsilon_{i, t}
$$

$Q_{i, t}$ is beginning of period average $q, C F_{i, t}$ is some measure of cash flow, $\tau_{t}$ is the corporate tax rate, $P_{t}$ and $P_{t}^{I}$ are the beginning of period output and capital prices, respectively, $c$ is the target investment rate, and $\alpha$ is the adjustment cost parameter.

In the derivation of equation 2 , the $\left(Q_{t}-1\right)$ on the right hand side is valid only under the assumption that there is no measurement error in the firm specific price ratio. Of course, the available data for capital and output prices is the same across industries, which precludes capturing firm level variation. Abel and Eberly (1996) suggest a correction for this by allowing the coefficient on the price ratio to deviate from $\frac{1}{\alpha}$. Thus, I insert a separate parameter, $\gamma_{p}$, on the regressor $\frac{P_{t}^{I}}{\left(1-\tau_{t}\right) P_{t}}$, which is expected to be negative.

A well documented problem in the literature is measurement error resulting from using average $Q$ in place of marginal $q{ }^{18}$ For Japan, the predominant concern was the asset appreciation that occurred during the late 1980s, which means that stock values used to

\footnotetext{
${ }^{18}$ See Erickson and Whited (2000) for a discussion of measurement error problems. Cummins et al. (1999) use earnings forecasts from securities analysts to construct more accurate measures of the fundamentals
} 
calculate the numerator of $Q$ may contain "bubble components". Goyal and Yamada (2001) have proposed a correction for this by deconstructing $Q$ into its fundamental and speculative parts. Thus, following their framework, $Q$ is regressed on two lags of sales growth and sales growth squared (in separate regressions for each year) and a full set of industry dummies. The predicted dependent variable from each regression is taken as fundamental $Q$, and the residuals as the non-fundamental part. ${ }^{19}$

Combining these modifications, the base estimation becomes

$$
\begin{aligned}
\frac{I_{i, t}}{K_{i, t-1}} & =c+\beta \frac{I_{i, t-1}}{K_{i, t-2}}+\frac{1}{\alpha}\left[\frac{P_{t}^{I}}{\left(1-\tau_{t}\right) P_{t}} Q_{i, t}^{f}\right]+\gamma_{n f}\left[\frac{P_{t}^{I}}{\left(1-\tau_{t}\right) P_{t}} Q_{i, t}^{n f}\right] \\
& +\gamma_{p} \frac{P_{t}^{I}}{\left(1-\tau_{t}\right) P_{t}}+\gamma_{c f} C F_{i, t}+\nu_{i}+\mu_{t}+\epsilon_{i, t}
\end{aligned}
$$

where $Q_{i, t}^{f}$ and $Q_{i, t}^{n f}$ are the beginning of period fundamental and non-fundamental parts of $Q$, respectively. For comparison with the literature, I estimate this equation using OLS and firm fixed-effects regressions in which $\beta$ is assumed to be zero, and $Q$, as opposed to its decomposition, is used as a regressor. Equation (3) is then estimated using the ArellanoBond GMM estimator, which allows for instrumentation of the current period regressors using lagged values.

\subsection{Data Description}

The firm data is from the financial database of the Japan Development Bank, which contains very detailed accounting data on all non-financial firms listed on the various stock exchanges in Japan from 1956 to 1997. The availability of price data restricts the sample to manufacturing firms, which is then balanced from 1980 to $1996 .{ }^{20}$ All firms that changed their

that affect the expected returns to investment. Gilchrist and Himmelberg (1998) assume the marginal productivity of capital follows a VAR process, and use numerous variables to forecast the future profitability of investment. Laeven (2001) simplifies this by assuming that the current period marginal productivity and financial variables proxy for $Q$.

${ }^{19}$ Using this technique, the coefficients on $Q$ are slightly larger and more significant than the standard case, but the relative sizes of the other parameters are preserved. In deconstructing $Q$, a variety of regressors were tried including lags (and squared lags) of Opperating Profits $/ K_{t-1}$, Opperating Profits $/ T A_{t-1}$, and Net Revenue $/ K_{t-1}$. These specifications did not alter the results.

${ }^{20}$ Firms in the mining, agriculture, and utility industries are dropped. The Japanese fiscal year ends in March. However many firms file late in the year, and in April and May (with few firms filing in the summer months), making June the appropriate month to divide the calendar data into fiscal years. Thus, the fiscal year (FY) for a particular observation is the previous year if the firm files before, and the current year if the firm files after June. 
accounting period over these years, firms with values of $Q$ above the 99.5 or below the 05 percentile, and firms with $I / K$ above the 99.5 percentile are dropped, leaving a final sample of 446 firms. $^{21}$

The construction of the variables used in the econometric analysis is similar to that in Hayashi and Inoue (1991), and a detailed description is available upon request. The JDB data contains a detailed breakdown of five depreciable asset types, as well as asset specific gross and current period depreciation. This allows for an estimate of the market value of assets sold or retired to be calculated, which means that the investment rate net of asset sales can be used. As discussed in Hayashi (2000), this (possibly) leads to more accurate capital stock and investment measures than studies that rely on data from the Nikkei data tapes, which contain only aggregate capital measures.

It is unclear whether or not land should be included in investment and the capital stock. Obviously, land is used in the productive process and should show up in the production function. However, land speculation during the asset appreciation period may have had nothing to do with production. Japanese law permits firms to carry land at historical rather than market value, and as a non-depreciable asset, the reported land values are very poor measures of both the physical land owned by the firm, and the portion of that land actually used in production. A perpetual inventory method is used to generate a measure of the market value of land based on Hoshi et al. (1990) and Hayashi and Inoue (1991). The problem with including this measure in the production function is that the rise in land prices over the 1980s was not necessarily based on its marginal productivity, which means the contribution of land would be over estimated. Thus, investment and the capital stock are constructed based on a separate recursive process for the five depreciable assets, and average $Q$ is adjusted for the market value of land by subtracting it from the firm's market capitalization in the numerator.

Figures 1 and 2 show the distribution of investment and Tobin's $Q$ for the sample of firms. Both $Q$ and $I / K$ are relatively flat during the 1980-87 period, before the asset inflation began. Starting in fiscal year 1988, both rose dramatically and peaked in 1990. From 1991 to 1993, both collapsed, before settling at lower levels in the 1994-96 period. For comparison, figure

\footnotetext{
${ }^{21}$ The elimination of firms based on extreme values of $I / K$ helps to rule out mergers and acquisitions. A constant accounting period is necessary because although the calculations of $K$ and $Q$ are unaffected, the investment level reported on the balance sheets may be downward biased in shorter periods, which will systematically change its correlation with $Q$.
} 
3 shows the distribution of total loan growth for all listed Japanese banks. ${ }^{22}$ Loan growth rose to $20 \%$ a year during the asset appreciation period, and then collapsed in the 1991-93 period, just as firm investment rates fell.

\subsection{Firm Sorting}

Following the literature, the sample was divided using a priori criteria that are indicative of financing constraints. Examples used elsewhere include dividend payout rates, firm age, firm size, or membership in a corporate group. However, criteria based only on firm characteristics, such as dividend payments for example, implicitly assume that such a "choice" variable is sufficiently correlated with the degree of financing constraints. Some firms may choose not to pay dividends for reasons that have nothing to do with financing constraints, and the lack of additional firm specific information usually means that these firms are incorrectly lumped into the "constrained" group. Fortunately (for this analysis), bond issues in Japan were heavily regulated throughout the 1980s, and this can be exploited as an exogenous firm sorting mechanism.

\subsubsection{Bond Eligibility Division}

The firm sorting technique is similar to that in Anderson and Makija (1999). First, the number of years between 1980 and 1990 in which a firm was eligible to issue secured convertible bonds was calculated based on the criteria in table $1 .{ }^{23}$ Firms were then divided into three groups based on the 33rd and 66th percentile of the total number of periods of eligibility using the sample of all listed manufacturing firms. The cutoff levels are one and four; thus, those firms that were eligible to issue bonds at most one period are considered "restricted" ( $\mathrm{R}$ firms), those that were eligible 2-4 periods are "semi-restricted" (S firms), and those that were eligible five or more periods are "unrestricted" (U firms). This yields $116 \mathrm{R}$ firms, 105 $\mathrm{S}$ firms, and $225 \mathrm{U}_{\text {firms. }}{ }^{24}$

\footnotetext{
${ }^{22}$ The data used to construct this figure uses all City, Trust, Long-Term Credit, and Regional banks available in the Nikkei Zaimu database.

${ }^{23}$ The criteria for secured convertible bonds is used because the criteria for other bond types was more severe. For example, the bottom of table 1 lists the criteria for secured strait bond issues.

${ }^{24}$ The sample is balanced over 1980-96, although the eligibility criteria were in place until 1990. It would be preferable to use the minimum credit rating requirement after 1990, but this data is not available. Furthermore, this may introduce an endogeneity problem since firms that could have issued bonds (after 1990) may have chosen not to, and thus would not have a credit rating. These firms would be incorrectly
} 
Using this sorting mechanism, $\mathrm{R}$ firms faced known financing constraints since, relative to $\mathrm{S}$ and $\mathrm{U}$ firms, they could not access the domestic bond market in the 1980s. ${ }^{25}$ Thus, if the monotonicity hypothesis holds, $\mathrm{R}$ firms should display higher investment-cash flow sensitivity than either S or U firms, and this difference should be largest in the 1980s when the bond restrictions were actually in place. ${ }^{26}$ This is the view as presented in the $Q$ and cash flow literature, but the situation in Japan requires a more subtle analysis.

If bank relationships did reduce financing costs through the acquisition of inside information or monitoring, $\mathrm{R}$ firms may have actually faced lower financing costs than firms that relied on arms-length debt financing. This is the central idea behind the HKS91 study and the subsequent Hayashi (2000) critique. ${ }^{27}$ On the other hand, the benefits of relationship banking may have accrued to banks if they extracted rents. If true, then internal financing, and the associated costs evidenced by higher sensitivity, may have been more palatable to firms than maintaining the bank tie. In addition, meeting the eligibility criteria increased the firm's bargaining power vis-a-vis the bank, and may have reduced the ability of the bank to influence the firm's loan position (Weinstein and Yafeh (1998)). Thus, cash flow sensitivity may appear lower for bank-dependent firms ( $\mathrm{R}$ firms) because investment responded to perverse loan flows which reduced its correlation with internal funds.

Table 3 breaks down by year the incidence of actual bond issues for each firm group. Two items are noteworthy. First, the share of $U$ firms that actually issued bonds increased from about $15 \%$ in 1980 , when deregulation began, to $43 \%$ by 1989 . Second, there is a jump in

included in the constrained group.

25 There are a few firms that issued bonds in periods in which they were supposedly ineligible to do so, either because they received special permission from the Kisaikai (bond underwriting cartel), or because the issues were floated on foreign markets. Unfortunately, the data does not provide any information on this. There are two ways to ensure that the results presented in later pages are not driven by these firm-year observations. First, any firm that had a bond issue in a period in which it was supposedly ineligible was eliminated. Second, firms were treated as eligible in such periods, which shifted a few toward the $\mathrm{S}$ and $\mathrm{U}$ groups. Neither of these robustness checks altered the results.

${ }^{26}$ As with all studies in this literature, there is a concern about whether firms self select by altering behaviour to target the eligibility criteria, thus making the sorting mechanism endogenous. This is difficult to analyze directly, but analysis of why firms failed provides convincing evidence that the use of these criteria is appropriate. Table 2 breaks down the criteria failure by year. The single largest failure reason was firm size, followed by low earnings per share. These are not really choice variables since firm managers are unlikely to be able to significantly alter firm size in the short run, and should be maximizing shareholder value each period regardless of bond eligibility.

${ }^{27}$ Since the division is not conditioned on whether firms actually issued bonds, then it is not necessarily the case that $U$ firms were bank-independent, as a firm could have been eligible all years, and yet never issued bonds. If bank ties imply lower financing costs, this would reduce the measured cost for the U group, and bias away from finding a significant role for banking relationships. 
the number of bond issues in 1989 and 1990 for R firms, while the number of $\mathrm{S}$ and $\mathrm{U}$ firms that issued bonds decreased dramatically in 1990 and again in 1992. This suggests that the regulations were binding for at least some firms.

Tables 4 and 5 present summary statistics using the eligibility division. U firms are larger based on any size measure (only real sales and total assets presented in the table). For all three firm groups, investment rates, $Q$, sales growth, operating profits, and cash flow all peak in 1988-90, which corresponds to the asset inflation period. In all four periods, U firms generally have the highest investment rates, $Q$, cash flow (normalized by $P^{I} K$ ), operating profits, and sales growth, although the differences across groups narrows in the 1990s as a result of the freer capital markets, as well as the market crash that reduced demand for all firms. What is important here is that on every measure used in other studies to divide firms into constrained and unconstrained groups (i.e., division based on size, bond issues, dividend payout rates, etc.), the relative ranking of the $\mathrm{R}, \mathrm{S}$, and $\mathrm{U}$ firms is preserved, even after the bond issuing criteria were lifted in 1990 .

The biggest difference across groups is their reliance on bank debt. The last panel of table 5 shows that mean bank debt over total liabilities was about $40 \%$ for $\mathrm{R}$ firms, but was less than half that for $\mathrm{U}$ firms, with an even larger difference in medians. This can be seen more clearly in figures 4 and 5. Figure 4 displays by year the mean outstanding bonds, and figure 5 displays the mean bank debt for each firm group, both normalized by total liabilities. All three firm groups reduced their dependence on banks from the early 1980s to the late 1980s, but more so for U and S firms. R firms actually increased their reliance on bank debt through about 1987, after which they too moved to bond financing in response to the relaxation of the eligibility criteria in that year (see table 1). After the asset market crash, bank financing again became more important for all firms groups and bond financing leveled off.

\subsubsection{Keiretsu Division}

The second firm division employed is membership in an industrial Keiretsu, or corporate grouping centered on one of the City Banks. ${ }^{28}$ Eight editions of Dodwell Marketing Consultant's Industrial Groupings in Japan were used to classify firms. Group membership may mitigate information problems since long-term relationships with other firms, as well as with

\footnotetext{
${ }^{28}$ This includes the Industrial Bank of Japan group which is technically not a City Bank.
} 
the group's bank, may introduce reputational effects that facilitate credible communication of investment projects to other members of the group. There were 250 independent firms (denoted I firms), and 196 group firms (denoted G firms).

All studies on Japanese main banking struggle to identify firms that have main bank relationships, and generally use published rosters as a starting point. ${ }^{29}$ Miwa and Ramseyer (2001) argue that the horizontal bank groups, or Keiretsu simply never existed, but rather "...began as a figment of the academic imagination, and they remain that today." In their view, firm rosters were conceived by Marxists committed to locating "domination" by "monopoly capital" in the 1960s, and became a key part of academic studies as scholars tried to "search for culture specific group behavior in Japan."

The restrictions on the bond market, however, were real, and make it easy to identify those firms that were bank-dependent out of necessity. If the effects of main banking were as pervasive as the literature would have us believe, then this looser definition of bank dependence should provide substantial evidence on the debate between HKS91 and Hayashi (2000), and is explored in section 4. Despite its frequent use in the literature, Keiretsu membership is not a perfect measure of main bank affiliation, as some firms may have business ties with other member firms, but actually rely primarily on non-bank financing. However, the use of the the bond issuing criteria in conjunction with Keiretsu membership is a partial solution to this problem since member, bank-dependent firms can be isolated. Thus, the R, S, and U firm groups created using the bond eligibility division are further divided based on Keiretsu membership. R (and S) firms that were Keiretsu member firms most likely had significant bank relationships, whereas member $U$ firms had the option of non-bank financing. The cross-group names are IR, IS, IU for independent restricted, semirestricted, unrestricted firms respectively, and GR, GS, and GU for the corresponding group firms. ${ }^{30}$

Keiretsu firms were generally larger when measured on sales and total assets (sample statistics omitted for brevity). However, there was virtually no difference in terms of $I / K$,

\footnotetext{
${ }^{29}$ Another publication is the Keiretsu no Kenkyu published by the Keizai Chosa Kyokai (Economic Survey Association). Both of these classify Keiretsu firms based loan structure, bank share holding, and historical factors. However, the Keiretsu no Kenkyu publication is problematic because it does not distinguish between horizontal (bank group) and vertical (subcontracting) groups. Using the Dodwell listing, less than $4 \%$ of the firms in the sample switch into or out of their Keiretsu group over the sample period. Rather than eliminate these, they are classified as group firms if they were listed for at least half the sample period, and independent otherwise.

${ }^{30}$ There are 60 IR, 61 IS, 129 IU, 56 GR, 44 GS, and 96 GU Firms.
} 
$Q$, and sales growth, although cash flow and operating profits were higher for independent firms firms in most periods. The biggest difference between the groups is again their relative reliance on bank debt. Bank debt normalized by total liabilities was generally about $5 \%$ higher for $\mathrm{G}$ firms than for I firms in all four periods. This difference in bank dependence is much smaller than when using the bond eligibility criteria, and suggests that the Keiretsu division by itself may be a noisy measure of main bank affiliation.

\section{Empirical Analysis}

Using a variety of empirical methodologies, the standard $Q$ equation including a cash flow term was estimated using a sample of 446 Japanese manufacturing firms for the 1980-90, and 1980-96 periods. In the OLS and fixed-effects regressions, $\beta$ is assumed to be zero (lagged $I / K$ term dropped) for empirical reasons, and for comparison with the standard equation in the literature. The results are presented in tables 6-18.

In the bottom panel of each table, equation 3 was estimated using a GMM estimator based on Arellano and Bond (1991), which allows for simultaneous determination of the explanatory and dependent variables. Thus, the explanatory variables can be assumed only "predetermined" instead of the stronger assumption of strict exogeneity required in OLS and fixed-effects models. This is accomplished by using a specified lag for each explanatory variable as instruments in a standard GMM estimation, which does not require assumptions about the distribution of the error term.

Firm fixed-effects are eliminated by first differencing the equation, and requires that all instruments be dated $t-2$ and earlier. ${ }^{31}$ GMM, and the use of lagged regressors as instruments, may be a significant improvement over the OLS and fixed-effects models since the coefficient on cash flow in these models may be driven by contemporaneous correlation with the error term. Controlling for this reduces the likelihood that cash flow measures simply proxy for future profitability not captured by $Q .{ }^{32}$

\footnotetext{
${ }^{31}$ In all GMM regressions, the price ratio is assumed strictly exogenous. In regressions where the coefficient on cash flow is estimated for the entire sample period, three first-differenced lags are used as instruments (although different lag structures yielded almost identical results). In regressions where the coefficient is estimated separately for each sub-period, a single first-differenced lag is used. All other regressors are instrumented with their entire past history $(t-2$ and earlier).

${ }^{32}$ The validity of the GMM model is tested using the Sargan test of over-identifying restrictions, and the $M$ test for second order serial correlation. The $p$-values for both tests are presented in each table. Heteroskedasticity consistent standard errors are reported for OLS and GMM regressions. Only with a
} 
It not clear what the correct definition of cash flow should be. Most papers in the literature use current period cash flow defined as end of period earnings minus dividend payments plus accounting depreciation (CF1). However, there is evidence that dividend payments are "sticky" since reputation effects may make it costly for firms to lower dividends even during periods of financial distress. Dividends are a choice variable, and thus should not necessarily be subtracted from earnings. Thus, I use a second measure of cash flow (CF2) defined as operating profits plus accounting depreciation minus taxes paid. In addition to adding back in dividend payments, the difference in these definitions is that non-operating revenue/expenses, extraordinary profits/losses, and special dispositions and provisions are excluded from profits. ${ }^{33}$

In all regression tables, rather than label the estimates as in equation 3, their corresponding variable names are used for simplicity. Thus, $L A G I K$ corresponds to $\beta$, and is the coefficient on the lagged investment term, PRAT corresponds to $\gamma_{p}$, and is the coefficient on the price ratio, $C F$ corresponds to $\gamma_{C F}$, and is the coefficient on cash flow normalized by $P_{t}^{I} K_{t-1}$, and $Q$ corresponds to $1 / \alpha$, and is the inverse of the adjustment cost parameter. In the GMM regressions, $Q$ and $Q^{n f}$ are the coefficients on the fundamental and non-fundamental parts of $Q$ (as described in section 3.1) respectively.

\subsection{Cash Flow Sensitivity-Bond Eligibility Division}

Cash flow sensitivity analysis, in its broadest sense, implies that $\mathrm{R}$ firms, which faced known financing constraints, should display higher sensitivity than $U$ firms. Previous empirical work on Japan, however, suggests a special role for Japanese banks in corporate governance. Since $\mathrm{R}$ firms are also, by definition, the most bank-dependent, the a priori expectation on the relative sizes of sensitivity across groups is ambiguous.

The top panel of table 6 presents the estimation of the base equation using the pooled sample, with $C F 1$ added as the cash flow measure. $Q$ is insignificant in the OLS model (with time and industry dummies), but becomes highly significant in the fixed-effects and

homoskedastic error term does the Sargan statistic follow an asymptotic chi-squared distribution. To correct for this, the $p$-values reported for the Sargan tests are from the two-step estimator, while the coefficients and robust standard errors are calculated with the one-step estimator. Arellano and Bond (1991) recommend using one-step estimators for inference, and several studies have found that the two-step standard errors downward biased in small samples.

${ }^{33}$ The special dispositions and provisions are somewhat peculiar to the Japanese accounting system. See the appendix for a discussion of these items. 
GMM regressions (time dummies included in both). Furthermore, the point estimate using GMM is over twice as large as the fixed-effects estimate, suggesting that the dissection of $Q$ into its fundamental and non-fundamental parts helps to correct for the effects of the asset appreciation period. That said, the estimates on $Q$ still imply unreasonably large adjustment costs, a common result in the literature. As expected, PRAT, the coefficient on the price ratio, is negative (and marginally significant) in all three models, and the point estimates of $C F$ are comparable to values found elsewhere, and are very significant.

Since passing the bond eligibility criteria implies a wider range of financing options, investment should be less sensitive to cash flow in those firm-year observations where the eligibility criteria were met. To test for this, the second panel of table 6 includes the interaction of $C F 1$ and a dummy for whether the firm was eligible in a particular year, with a corresponding coefficient, CFxELIG. Since $C F 1$ is also included, the total sensitivity for firm-year observations when the firm was eligible is the sum of $C F$ and CFxELIG. In all three regressions, $C F x E L I G$ is positive and significant, implying that sensitivity was higher when firms passed the eligibility criteria. ${ }^{34}$ The rest of this section explores alternative specifications to determine whether cash flow sensitivity is indeed higher for less bank-dependent firms.

Table 7 presents the results for each of the R, S, and U groups separately. Since R firms passed the eligibility criteria at most once, while $U$ firms passed at least 5 times during the 1980s, cash flow sensitivity should have been highest for R firms. All coefficients have the expected signs, and, again, the coefficient on $Q$ is larger after correcting for measurement error in the GMM estimation. The most striking result is the relative size and significance of the coefficients on cash flow (using CF1). In all three regressions, sensitivity was highest for $\mathrm{U}$ firms and lowest for R firms, with $\mathrm{S}$ firms falling somewhere in the middle. The differences in the point estimates, and the $t$ statistic ( $z$ statistic for GMM) for these differences, are listed in the last column, and are significant at standard levels. ${ }^{35}$

\footnotetext{
${ }^{34}$ Note, however, that the $p$-value of the Sargan test of over-identifying restrictions is quite low, implying that the instrument set is highly correlated with the residuals. Thus, one possible explanation for these odd results is that the OLS and fixed-effects models are biasing the coefficients on $C F 1$ because of its correlation with the error term, and, in this particular case, the GMM estimator has failed to reverse this bias.

${ }^{35}$ The regressions from table 7 were repeated using $C F 2$ in place of $C F 1$. Maintaining a certain level of dividends per share is one of the issuing criteria. Thus, if firms were targeting dividend rates for the purpose of issuing bonds, CF1 may distort sensitivity values. Since, presumably, U firms were better able to target the bond criteria because of their larger size, dividend payments may have been less discretionary than for $\mathrm{R}$ firms, which were more likely to have failed other criteria. This may have reduced the cash flow directed toward investment in a systematic way, and raise the sensitivity for these firms. However, the pattern in
} 
Table 8 presents the results after interacting the cash flow regressor $(C F 1)$ with a dummy for whether the firm issued bonds in a particular year. Like the eligibility dummy interaction in table 6 , the coefficients on this interaction term should be negative since $C F 1$ is included separately. Firms should rely on internal funds less in years when they issue bonds, thus reducing the correlation between cash flow and investment. ${ }^{36}$ This is not supported by the results. In all three regressions, $C F$ is significant, with $\mathrm{U}$ firms again displaying the highest sensitivity. In the OLS and fixed-effects regressions, the coefficient on the interaction term is positive and significant in the pooled regression (first column), as well as in each group regression. In the GMM regression, the coefficient is positive for both $\mathrm{R}$ and $\mathrm{S}$ firms, and significant for $\mathrm{R}$ firms. Again, the difference in the base cash flow term between $\mathrm{U}$ and $\mathrm{R}$ firms is everywhere significant at all standard levels.

If the theory underlying cash flow sensitivity analysis is correct, that is, the monotonicity hypothesis as formulated by FHP88 and KZ97 is actually satisfied, then some firm characteristic must explain why firms known to have been restricted had lower sensitivity. This difference was possibly bank dependence. In accordance with the original HKS91 results, bank affiliation reduces financing constraints, and is revealed in lower investment-cash flow sensitivity. By definition, $\mathrm{R}$ firms were more bank-dependent, and if bank relationships matter, the seemingly backward results are justified. The troubling aspect of this explanation is that unrestricted firms could have remained bank-dependent, a point first raised in Hoshi et al. (1990b). If banks were so good at solving asymmetric information problems, why did the largest and most profitable firms move to the bond market? Banks should have been more willing to lend to these firms, and yet these firms chose to reduce bank dependence. This is explored further in the next section.

A second possibility is that the incidence of negative cash flow observations drives the results. Allayannis and Mozumdar (2001) argue that firms with negative cash flow have driven investment down to its lowest possible level, making investment unable to respond to fluctuations in cash flow. This reduces sensitivity for those firm groups with the largest number of negative cash flow observations, and is an important robustness check since their work using U.S. data reversed the KZ97 and Cleary (1999) critiques, and empirically reaffirmed the validity of sensitivity analysis. This is of particular concern in this study because the bond eligibility criteria used in firm sorting does include performance thresholds. As

table 7 survives this robustness check, and these tables have been omitted for brevity.

${ }^{36}$ This also serves as a robustness check relating to the classification problem described in footnote 25 . 
shown in table 9, $\mathrm{R}$ firms had the highest incidence of negative cash flow observations in the 1980s. This may artificially lower the measured cash flow sensitivity for these firms, and thus would explain the "backward" results.

Table 10 presents the results where negative cash flow observations were separated from positive observations and given a separate coefficient. The pattern described above emerges for the positive cash flow observations, and, as expected, the coefficients on the negative observations are generally negative, but everywhere insignificant. The coefficients on positive cash flow observations are generally larger for all three firms groups relative to their corresponding values in table 7 , suggesting that the inclusion of negative cash flow observations does reduce sensitivity. However, this change is consistent across firm groups, and the differences in the coefficients on positive cash flow are significant in all three regressions.

A third possibility is that cash flow merely proxys for future profit opportunities not captured by $Q$. If true, $\mathrm{U}$ firms, with their higher sales growth and operating profits, would naturally display higher sensitivity. However, this seems unlikely. The sample statistics show that the large disparity between $\mathrm{R}$ and $\mathrm{U}$ firms (in terms of cash flow and operating profits) present in the 1982-87 period narrows considerably by the early 1990s. The level of $Q$ for R firms is on par with that for $U$ firms by the 1988-90 period, and remains so in the 1991-93 period. Sales growth for R firms is about one third that of $U$ firms in the earlier period, but is virtually equal across all three groups in the 1988-90 and 1991-93 periods. The year-by-year sample statistics (not presented) for $\mathrm{R}$ firms shows that the gap in $Q$, operating profits, and investment rates narrows consistently over the 1980s. In addition, the relationship between firm profits and the magnitude of sensitivity is not consistent. When the sample is split using main bank affiliation and bond eligibility, the sensitivity is actually larger for firm groups that do not have the highest profits or cash flow values. This point will be discussed in detail in the next section.

Other robustness checks that were conducted but not reported include:

1. Polynomials in $Q$ : Since $I / K$ may react non-linearly to movements in $Q$, or because cash flow measures may be proxying for future profit opportunities not captured by $Q$, squared and cubed terms of $Q$ were included in the base equation. The coefficient on $Q$ became slightly more significant, but the coefficients on the higher order terms were generally insignificant. In all specifications, the cash flow sensitivity pattern described above was preserved. 
2. Investment in Land: As described earlier, land is difficult to measure properly because of the discrepancy between the market and book values, and increases in market value in the 1980s were not necessarily correlated with changes in its marginal productivity. Nonetheless, the inclusion of the market value of land in $I$ and in $K$ (and thus $Q$ ) did not reverse the sensitivity pattern.

3. Firm Division: The three firms groups were redefined several times, each time adjusting the number of periods in which a firm had to be eligible to be included in a particular group. As the eligibility count was moved up for $\mathrm{R}$ firms, and down for $\mathrm{U}$ firms (squeezing out $\mathrm{S}$ firms), the differences in the coefficients on cash flow between the $\mathrm{R}$ and $\mathrm{U}$ firms narrowed. The difference increased slightly when those firms that were eligible at most once (currently included in the $\mathrm{R}$ group) were transferred to the $\mathrm{S}$ group.

4. Expanded Sample: The current sample was chosen by dropping those firms that changed their accounting period at least once between 1990-96. Dropping this restriction nearly doubles the sample, from 446 to 724 firms, with $188 \mathrm{R}$ firms, $173 \mathrm{~S}$ firms, and $363 \mathrm{U}$ firms. The pattern of the coefficients on $C F 1$ across groups was unaffected, although the coefficients on $Q$ were more often insignificant.

This section has presented evidence that either bank dependence matters, or cash flow sensitivity analysis is flawed. If the latter, then it is difficult to say anything concrete about the effect of bank ties on investment behavior. If the former is true, then it appears that the use of the bond eligibility criteria to determine bank dependence yields far more robust results than the "roster" definitions used elsewhere, and lends support to the original HKS91 empirical results (vis-a-vis Hayashi (2000)). However, the question of why the largest and most profitable firms left their banks needs to be addressed before concluding that lower cash flow sensitivity for bank-dependent firms implies that firms enjoyed a positive net benefit from close bank ties. Before turning to this issue, I briefly explore sensitivity in the 1990s after the bond market regulations were lifted.

Several scholars have tested for a credit crunch during the early 1990s under the suspicion that banks cut lending after the asset market crash. ${ }^{37}$ In the current analysis, higher cash

\footnotetext{
${ }^{37}$ Gibson $(1995,1997)$ uses a $Q$ model and bond ratings to show that firm investment did not react to bank health in 1994-95, and was only slightly affected in the 1991-92 period. Sekine (1999) inserts both
} 
flow sensitivity for any or all firm groups in the 1991-93 period would be indicative of a credit crunch. Table 11 presents the results where negative and positive cash flow observations are separated, and a separate coefficient is estimated for each of four time periods. $U$ firms consistently had higher sensitivity than $\mathrm{R}$ firms, even when negative cash flow observations are accounted for.

However, there is virtually no evidence of a credit crunch for this sample of firms. $\mathrm{R}$ and $\mathrm{S}$ firms were the smallest and the least profitable, and being relatively bank-dependent, had the most to lose from a contraction in lending. Yet for these groups, cash flow sensitivity decreased from the 1982-87 period to the 1994-96 period, and was smallest in the 1991-93 period. Overall, this is consistent with the bond market deregulation process that gradually evolved over the 1980s; these firms had the most to gain from deregulation, and their cash flow sensitivity falls accordingly. Although sensitivity does appear larger in the 1990s for U firms, the increase relative to the 1980s is small.

The important thing to note here is that the difference in the coefficients on cash flow between $\mathrm{U}$ and $\mathrm{R}$ firms remained significant in the 1990s, even though the bond eligibility criteria were lifted in 1990. This is consistent with figures 4 and 5 where it was shown that the relative reliance on bank debt across firm groups was preserved over this 16 year period.

\subsection{Keiretsu Membership and Bond Eligibility}

Why do the bond eligible firms display higher sensitivity? If bank affiliated firms enjoyed better access to capital, then these firms should be able to invest closer to their first-best level regardless of bond eligibility. However, if the costs of maintaining the relationship were large, or, as suggested by Weinstein and Yafeh (1998), if banks forced firms to over-borrow, firms may have willingly left their main banks. This section explores this issue by incorporating both the bond eligibility and the Keiretsu membership firm divisions.

Suppose there exists asymmetric information problems in the bond market, and these costs are similar for all eligible firms. The presence of such costs creates a role for internal funding of investment, as well as for banks that assume monitoring roles. If banks are a net benefit to firms, then firms with a main bank should have less need to rely on internal funds, and thus a lower investment-cash flow sensitivity, than firms without a main bank. Effective

bank and firm specific health measures into the $Q$ equation and shows that the coefficient on bank health measures became significant for small firms after 1993. 
monitoring (at least beyond monitoring by shareholders or the bond market) implies it is in the shareholder's interest for these firms to maintain their relationships with these banks even in the presence of outside financing options. Thus, cash flow sensitivity should be lower for GR, GS, and GU firms than for the corresponding IR, IS, and IU firms.

If, however, main banks push loans and extract rents in the process, then cash flow sensitivity should again be lower for GR firms than for IR firms, both of which are restricted from the bond market. Both sets of firms are bank-dependent, but only those with a main bank (GR firms) are pressured. These firms may enjoy better access to capital, but possibly only with large indirect costs. Thus, whether firms benefit from close bank ties or not is empirically indistinguishable based on results for IR and GR firms alone.

However, the implications are different for those firms with outside financing options, since these firms are in a better bargaining position to counter bank pressure. Eligible firms with a main bank may purposely reduce loan dependence in favor of bond financing, and turn to internal sources for marginal investment sooner than would an eligible firm without a main bank. This would occur if the costs of internal finance (including the costs incurred because of the unpredictability of internal finance) are lower than the rents extracted by the main bank when loans are extended. IU firms should have lower sensitivity than GU firms since IU firms do not have a main bank relationship, and therefore have less of a need to turn to internal financing once funding from the bond market is exhausted. This test gets at the heart of the original HKS91 and Hoshi et al. (1990b) studies because it attempts to identify not only bank-dependent firms, but do so after controlling for outside financing options.

\subsection{Profitability and Bank-Affiliation}

The following sample statistics shed considerable light on which of the above hypotheses more accurately describes the nature of main bank relationships. Figure 6 shows the mean total assets for GR, GU, IR, and IU firms (GS and IS firms are excluded from the figures for simplicity). Group firms, whether bond restricted or not, are larger than their corresponding independent firms, and the figures are net of yearly industry means to control for composition effects.

Figures 7, 8, and 9 track the earnings per share, profit, and "efficiency" rates of these firm groups (net of industry means). Figure 7 shows that earnings per share of GU firms was consistently lower than that of IU firms throughout the 1980s, and the difference increased 
during the asset appreciation period. During the the early 1980's, the earnings per share of both restricted groups, GR and IR firms, was similar. However, after the relaxation of the bond criteria in 1987, earnings per share rose for independent firms, but remained flat for group firms.

Figure 8 presents mean before tax profits normalized by total assets (net of industry means). Until 1990, group firms (GR and GU firms), although larger, were less profitable than their corresponding independent firm groups (IR and IU firms). This is consistent with the findings of Nakatani (1984) for the 1960's and 1970's, and Weinstein and Yafeh (1995, 1998) for the 1980s. After 1990, however, the differences disappear. Furthermore, the gap in profitability between the restricted (IR, GR) and unrestricted (IU, GU) firm groups narrowed considerably due to the rise in profitability for the former groups following the loosening of the bond eligibility criteria in 1987.

Most dramatic is the differences in productive efficiency between group and independent firms. Figure 9 presents the mean value added normalized by total assets for each group (net of industry means). ${ }^{38}$ Group firms are definitively less efficient than their corresponding independent firms, and, unlike the profitability measures, the differences do not disappear in the 1990s. This figure is consistent with claims Keiretsu member firms "over-capitalized".

Table 12 looks at the incidence and size of bond issues of eligible firms. The first two columns show the percentage of eligible firms, either independent or group, that actually issued bonds. ${ }^{39}$ The last four columns list the mean and median issue sizes (conditional on positive issue), and show that Keiretsu member firms had larger issues. What is striking is that in every year, a higher percentage of group firms accessed the bond markets with larger issues, despite their relatively worse performance.

Because this is a crucial point, tables 14 and 13 verify for the current sample that Keiretsu member firms were indeed less profitable prior to the lifting of the eligibility criteria, but tended to access the bond markets more often. In table 13, various profit measures are

\footnotetext{
${ }^{38}$ Value added is calculated using the method described in Keiei Bunseki Handbook (1987). The calculation is fairly involved, but proceeds generally as follows. Starting with gross sales, various portions of the selling and administrative expenses, cost of goods manufactured, inventory adjustments, and transfer payments are subtracted off to get the final value. Each of these components is adjusted so that only the nonlabor and non-depreciation components are subtracted off. The non-labor components of the cost of goods manufactured includes raw materials, the non-depreciation overhead expenses, and purchases of intermediate goods. Inventory is adjusted for sales/revaluations of both work in process and final goods inventories.

${ }^{39}$ In this table, all eligible firm-year observations are used making the total number of firms different for each year.
} 
regressed on controls for finance structure, firm size, sales trends, capital intensity, corporate governance, and a Keiretsu membership dummy. ${ }^{40}$ The top panel shows that in the 1980's, Keiretsu membership reduced firm profits, whether measured by operating profits normalized by total assets, or simply earnings per share. Other profit measures, or value added, yield similar results and have been omitted to save space. Two things are important. First, ownership by financial institutions is negative and generally significant above and beyond bank affiliation captured by the Keiretsu dummy. Second, in the bottom panel which presents the same regressions for the 1990s after the lifting of the issuing criteria, Keiretsu membership is generally insignificant.

Table 14 presents probit regressions where a dummy for actual bond issues is regressed on firm size, profitability, previous bond activity, dummies for eligibility group and Keiretsu membership, and corporate governance controls. Despite their lower profitability, membership in a Keiretsu increased the probability of a bond issue in the 1980s, but had no effect in the 1990s. The inclusion of other combinations of regressors that control for profitability, finance structure, and firm size all have the expected sign, but the sign and significance of the Keiretsu dummy is unaffected in for both the 1980s or 1990s.

Taken together, these results are quite revealing. First, the effects of Keiretsu membership on profitability and bond activity present in the 1980s disappeared in the 1990s. For the 1980s, why would firms that had a main bank need the bond market more often than independent firms? Potentially, this could be explained by differences in performance, as more profitable firms should be able to access the bond market with a lower premium. However, the very firms that issued the most often in the 1980s, and with the largest issues, were relatively less profitable.

It is possible that firms connected to main banks enjoyed the bank support when issuing bonds. ${ }^{41}$ There is evidence that banks acted as "custodians" during the 1980s for their client firms (however, banks were legally prevented from moving into the underwriting business until 1993). That said, it is still unclear as to why playing this role was in the bank's interest given that they directly competed with the bond market. Why would banks willingly back their clients that wanted to issue bonds? ${ }^{42}$ Much more plausible is the idea that bank-

\footnotetext{
${ }^{40}$ Weinstein and Yafeh (1998) used a similar analysis for the 1977-86 period. All regressions in tables 13 and 14 include unreported constant terms, and industry and year dummies.

${ }^{41}$ Diamond (1991), Chemmanur and Fulghieri (1994)

${ }^{42}$ Hall and Weinstein (2000) find no evidence that independent firms faced an interest premium on bond issues, even though they did not have the backing of a main bank.
} 
affiliated firms, although less profitable, found the costs of bond financing less than the costs associated with maintaining their traditional bank ties. Once deregulation gave these firms access to alternative financing sources, they exercised their new bargaining power over their banks. This left banks little choice but to back their clients' bond issues, or risk loosing them as clients altogether.

\subsection{Cash Flow Sensitivity-Keiretsu Division}

This section presents evidence on cash flow sensitivity for Keiretsu and independent firms after controlling for external credit opportunities. As a starting point, table 15 presents the simple division based on group membership alone. First, $Q$ was larger and more significant for group firms in the fixed-effects regression. However, when decomposed into its fundamental and non-fundamental parts in the GMM regression, only the non-fundamental part remained significant for group firms, while only the fundamental part was significant for independent firms. This suggests that investment of group firms was less tied to fundamentals during the asset appreciation period. Second, the difference in cash flow sensitivity between group and independent firms was statistically insignificant. All robustness checks described above yield similar results.

Table 16 repeats the above regressions after crossing the bond eligibility division with membership in a Keiretsu. As above, $Q$ was more significant for group firms in the fixedeffects regression, but considerably larger and more significant for independent firms when decomposed, which again suggests that investment of bank-affiliated firms was relatively loosely tied to fundamentals. Cash flow sensitivity was smallest for GR firms, and the difference over IR firms was everywhere significant. The story is reversed, however, for bond eligible firms. Sensitivity was largest for GU firms, and the difference over the IU coefficient is statistically significant. Eligibility implied higher sensitivity for both independent and group firms (consistent with the results of the last section), but the within-group difference was much larger for group firms. That is, Keiretsu member firms displayed a much larger spread in sensitivity. Mature and healthy firms with strong bank ties and bond market access relied on internal funds more than independent firms.

As a robustness check, in table 17 cash flow is separated into negative and positive observations, and a separate coefficient is estimated for each. The same pattern emerged, and the differences in the IR/GR groups and the GU/IU groups were again statistically 
significant (with the exception of the GR/IR difference in the GMM regression). These same sets of regressions were repeated using the robustness checks described in section 4 , and have been omitted to save space.

One point that needs to be revisited is the potential criticism that cash flow sensitivity merely proxys for profit opportunities not captured by $Q$. This issue was raised in section 4 in light of the finding that $\mathrm{U}$ firms, which had relatively high profit rates, displayed the highest investment-cash flow sensitivity. Here, eligible group firms (GU firms) had consistently lower profit rates than did the corresponding independent firms, yet had higher cash flow sensitivity than independent eligible firms (IU firms). This is a reversal of the supposed direction of this specification error, and makes it difficult to conclude that the "proxying" effect drove the results of section 4 .

In table 18 a separate coefficient is estimated for each of the four time periods. Since the bond eligibility criteria were lifted in 1990, presumably all firms faced similar financing options after this date. This would suggest that the differences in cash flow sensitivity between IR/GR firms and GU/IU firms present in the 1980s should be smaller in the 1990s. The coefficients on cash flow were everywhere smallest for GR firms (and only marginally significant using GMM), while those for IR firms are larger and significant. For all firm groups, sensitivity seems to have decreased from the 1982-87 period to the 1994-96 period. However, in all cases the same pattern emerges. GU firms again displayed the highest sensitivity whereas GR firms had the lowest. Note, however, that the difference in sensitivity between IR/GR firms and GU/IU firms was generally significant in the 1980s (particularly in the 1982-87 period before the first relaxation of the bond criteria), but not in the 1990s. As shown in figure 8, and in tables 13 and 14, the difference in profit rates between group and independent firms that was present in the 1980s disappeared in the 1990s.

Finally, figures 10 and 11 present the coefficients on CF1 in yearly cross sectional OLS regressions of investment on $P R A T$, price adjusted $Q$ and $Q$ squared, a dummy for bond issues, cash flow defined as $C F 1$, and a full set of industry dummies. Because land was such an important element in the asset appreciation of the 1980s, establishing that the above pattern is robust to its inclusion and exclusion is vital. In figure 10, the dependent variable, $I / K$, excludes land and the numerator of $Q$ is adjusted to reflect this (as in previous regressions). In the bottom panel, $I / K$ includes the investment and the stock of land (market value). In both figures, the sensitivity coefficient is largest for group unrestricted firms in 
the 1980s and smallest for group unrestricted. However, after 1987 when the eligibility criteria were relaxed, the differences across the four groups disappear. ${ }^{43}$ Note that the spread in sensitivity in the 1980s when land is included appears larger than when excluded, particularly in the early years. This contrasts with the results from table 11 where it was shown that the difference across the bond eligibility groups remained significant in the 1990s.

The results of this section show that those firms that were known to face financing constraints in the bond market again displayed lower sensitivity. However, this effect was exacerbated if the firm was also a member of a Keiretsu group. Rather than conclude that firms enjoyed a net benefit from relationship banking, I offer this as evidence in support of the predatory view, since sensitivity was highest for eligible, bank-affiliated firms.

\section{Conclusion}

If close bank ties are costly for mature and healthy firms, should we still expect banks to facilitate lower cash flow sensitivity? This study presents evidence on this issue for a sample of Japanese manufacturing firms over the last 20 years. Using the bond issuing criteria that were in place in the 1980s as a firm sorting criteria, I first demonstrate that investment-cash flow sensitivity was smallest for firms that were restricted from issuing bonds. This result is robust to several econometric specifications, measures of cash flow, and corrections for negative cash flow observations.

On the face of it, this finding is at odds with standard predictions in the cash flow literature; given that bond-eligible firms should face lower financing constraints, these firms should also display the lowest cash flow sensitivity. Finding the opposite suggests either cash flow sensitivity analysis is inappropriate because the monotonicity hypothesis as formulated by FHP88 and KZ97 is not satisfied, or other firm characteristics not controlled for in the standard investment-cash flow equation drive the results.

Large banks have historically been at the center of the Japanese financial system, precisely because of the legal restrictions on alternative financing sources. Many have argued that long-term banking ties, or "main banking" in the case of Japan, allows debt holders access to inside information about the investment opportunities facing the firm. This effectively

\footnotetext{
${ }^{43}$ The pattern shown in these figures is surprisingly robust. The inclusion/exclusion of $Q$, the addition of bank debt/TL and outstanding bonds/TL and their squares, and the inclusion of various corporate governance measures used in the profitability and probit regressions, firm size, and other profitability measures did not substantially change the results.
} 
allows client firms to stay on their first best investment path even when internal funds are insufficient. Recent research, however, has uncovered a dark side to Japanese relationship banking practices. Consistent with this, the results presented here suggest that banks did provide relatively easy access to financing (as evidenced by low sensitivity measures for bank dependent firms), but may have extracted rents in the process. This prompted bond-eligible firms to shift toward alternative financing sources at the earliest opportunity. 
Table 1: Example Bond Issue Criteria

Table presents minimum approval criteria for domestic issuance of secured convertible bonds and secured strait bonds for selected years. Criteria are taken from Kaneko and Battaglini (1990) and Karp and Koike (1990). A firm wishing to issue bonds in period $t$ must have met the below criteria in period $t-1$.

\begin{tabular}{|c|c|c|c|}
\hline \multicolumn{4}{|c|}{ October 1976-July 1987 Criteria for Domestic Secured Convertible Bonds } \\
\hline \multirow[t]{2}{*}{ Performance Standards } & \multicolumn{3}{|c|}{ Issuer's Book Equity } \\
\hline & 3-6 Billion Yen & 6-10 Billion Yen & $>10$ Billion Yen \\
\hline Book Equity/Paid in Capital & NA & 1.50 & 1.20 \\
\hline Book Equity/Total Assets & NA & 0.2 & 0.15 \\
\hline Operational Profit/Total Assets & NA & 0.05 & 0.04 \\
\hline Earnings per share (yen) & NA & 7.00 & 7.00 \\
\hline Dividends per share (yen) & NA & 5.00 & 5.00 \\
\hline Approval Criteria & NA & EPS, DPS & EPS, DPS \\
\hline & NA & and at least & and at least \\
\hline & NA & two of other & two of other \\
\hline & NA & three criteria & three criteria \\
\hline
\end{tabular}

\begin{tabular}{|l|l|l|l|}
\hline July 1987-May 1989 Criteria for Domestic Secured Convertible Bonds \\
\hline Performance Standards & Issuer's Book Equity & > \\
\hline & $3-6$ Billion Yen & 6 -10 Billion Yen & Billion Yen \\
\hline \multirow{2}{*}{ Book Equity/Paid in Capital } & 2.00 & 1.50 & 1.20 \\
Book Equity/Total Assets & 0.15 & 0.12 & 0.10 \\
Operational Profit/Total Assets & 0.07 & 0.06 & 0.05 \\
Earnings per share (yen) & 7.00 & 7.00 & 7.00 \\
Dividends per share (yen) & 5.00 & 5.00 & 5.00 \\
\hline \multicolumn{5}{|l|}{} \\
\hline Approval Criteria & EPS, DPS & EPS, DPS & EPS, DPS \\
& and at least & and at least & and at least \\
& two of other & two of other & two of other \\
& three criteria & three criteria & three criteria \\
\hline
\end{tabular}

\begin{tabular}{|c|c|c|c|}
\hline \multicolumn{4}{|c|}{ July 1987-May 1989 Criteria for Domestic Secured Strait Bonds } \\
\hline \multirow{2}{*}{ Performance Standards } & \multicolumn{3}{|c|}{ Issuer's Book Equity } \\
\hline & 3-6 Billion Yen & 6-10 Billion Yen & $>10$ Billion Yen \\
\hline Book Equity/Paid in Capital & 3.00 & 1.50 & 1.20 \\
\hline Book Equity/Total Assets & 0.30 & 0.12 & 0.10 \\
\hline Operational Profit/Total Assets & 0.08 & 0.06 & 0.05 \\
\hline Interest Coverage & 3.00 & 1.20 & 1.00 \\
\hline Dividends per share (yen) & $\begin{array}{l}\text { at least } 5 \text { yen } \\
\text { per share for } \\
\text { past } 3 \text { years }\end{array}$ & $\begin{array}{l}\text { at least } 4 \text { yen } \\
\text { per share for } \\
\text { past } 3 \text { years or } 5 \\
\text { yen previous year }\end{array}$ & $\begin{array}{l}\text { at least } 3 \text { yen } \\
\text { per share for } \\
\text { past } 3 \text { years or } 4 \\
\text { yen previous year }\end{array}$ \\
\hline Approval Criteria & \multicolumn{3}{|c|}{$\begin{array}{l}\text { If firm has no bonds outstanding, then DPS } \\
\text { and at least } 3 \text { of other } 4 \text { criteria satisfied. } \\
\text { If firm has outstanding bonds: (a) if DPS met in } \\
\text { last } 3 \text { years then only } 1 \text { remaining criteria } \\
\text { satisfied; (b) if DPS met in previous year, } \\
\text { then } 2 \text { of remaining } 4 \text { criteria satisfied. }\end{array}$} \\
\hline
\end{tabular}


Table 2: Why Did Firms Fail the Bond Criteria?

\begin{tabular}{|c|c|c|c|c|c|}
\hline$F Y$ & SIZE & $E P S$ & $C A P . R A T$ & $\overline{D P S}$ & Total Failures \\
\hline 80 & 221 & 26 & 4 & 9 & 260 \\
\hline 81 & 204 & 27 & 8 & 4 & 243 \\
\hline 82 & 184 & 39 & 5 & 5 & 233 \\
\hline 83 & 178 & 55 & 5 & 4 & 242 \\
\hline 84 & 172 & 55 & 4 & 2 & 236 \\
\hline 85 & 159 & 43 & 5 & 5 & 212 \\
\hline 86 & 145 & 52 & 7 & 7 & 211 \\
\hline 87 & 138 & 31 & 6 & 8 & 183 \\
\hline 88 & 68 & 75 & 7 & 10 & 160 \\
\hline 89 & 59 & 27 & 9 & 14 & 109 \\
\hline
\end{tabular}

Table 3: Bond Issue Criteria and Actual Bond Issues

Table presents the incidence of bond issues (convertible, strait, and warrant) by year and firm group. Firm groups are determined using the minimum approval criteria for domestic issuance of secured convertible bonds and secured strait bonds taken from Kaneko and Battaglini (1990) and Karp and Koike (1990). A firm wishing to issue bonds in period $t$ must have met these criteria in period $t-1$. $\mathrm{R}$ firms were eligible at most one period between 1980-90, $\mathrm{S}$ firms were eligible $2 \sim 4$ periods, and $\mathrm{U}$ firms were eligible 5 or more periods.

\begin{tabular}{|c|c|c|c|c|c|c|c|c|c|}
\hline & \multicolumn{2}{|c|}{ Restricted Firms } & \multicolumn{3}{c|}{ Semi-Res. Firms } & \multicolumn{3}{c|}{ Unrestricted Firms } \\
\hline$F Y$ & No Issue & Issue & Total & No Issue & Issue & Total & No Issue & Issue & Total \\
\hline 80 & 112 & 4 & 116 & 100 & 5 & 105 & 190 & 35 & 225 \\
81 & 107 & 9 & 116 & 91 & 14 & 105 & 166 & 59 & 225 \\
82 & 109 & 7 & 116 & 94 & 11 & 105 & 173 & 52 & 225 \\
83 & 108 & 8 & 116 & 97 & 8 & 105 & 159 & 66 & 225 \\
84 & 112 & 4 & 116 & 92 & 13 & 105 & 144 & 81 & 225 \\
85 & 111 & 5 & 116 & 89 & 16 & 105 & 145 & 80 & 225 \\
86 & 108 & 8 & 116 & 80 & 25 & 105 & 133 & 92 & 225 \\
87 & 112 & 4 & 116 & 82 & 23 & 105 & 140 & 85 & 225 \\
88 & 111 & 5 & 116 & 69 & 36 & 105 & 129 & 96 & 225 \\
89 & 99 & 17 & 116 & 72 & 33 & 105 & 128 & 97 & 225 \\
90 & 85 & 31 & 116 & 78 & 27 & 105 & 170 & 55 & 225 \\
91 & 90 & 26 & 116 & 63 & 42 & 105 & 137 & 88 & 225 \\
92 & 101 & 15 & 116 & 86 & 19 & 105 & 178 & 47 & 225 \\
93 & 104 & 12 & 116 & 92 & 13 & 105 & 180 & 45 & 225 \\
94 & 106 & 10 & 116 & 92 & 13 & 105 & 191 & 34 & 225 \\
95 & 105 & 11 & 116 & 90 & 15 & 105 & 188 & 37 & 225 \\
96 & 102 & 14 & 116 & 89 & 16 & 105 & 165 & 60 & 225 \\
\hline Obs. & 1,782 & 190 & 1,972 & 1,456 & 329 & 1,785 & 2,716 & 1,109 & 3,825 \\
\hline
\end{tabular}


Table 4: Sample Statistics for Bond Eligibility Division Table presents statistics on a sample of 446 manufacturing firms split by the number of
times the firm was eligible to issue bonds from $1980-1990$. Firms eligible at most one
time are restricted (R Firms), firms eligible $2 \sim 4$ times are semi-restricted (S Firms),
and firms eligible 5 or more times are unrestricted (U Firms). There are 116 R Firms,
$105 \mathrm{~S}$ Firms, and 225 U Firms.

\begin{tabular}{|c|l|c|c|c|c|}
\hline$I / K$ & & $1980-87$ & $1988-90$ & $1991-93$ & $1994-96$ \\
\hline R Firms & Mean & 0.089 & 0.133 & 0.130 & 0.074 \\
& Median & 0.071 & 0.103 & 0.102 & 0.062 \\
& Std. Dev. & 0.084 & 0.113 & 0.110 & 0.079 \\
\hline S Firms & Mean & 0.117 & 0.151 & 0.127 & 0.086 \\
& Median & 0.097 & 0.125 & 0.101 & 0.068 \\
& Std. Dev. & 0.097 & 0.120 & 0.104 & 0.094 \\
\hline U Firms & Mean & 0.144 & 0.176 & 0.138 & 0.087 \\
& Median & 0.124 & 0.155 & 0.117 & 0.072 \\
& Std. Dev. & 0.099 & 0.103 & 0.098 & 0.068 \\
\hline
\end{tabular}

\begin{tabular}{|c|l|c|c|c|c|}
\hline$Q$ & & $1980-87$ & $1988-90$ & $1991-93$ & $1994-96$ \\
\hline R Firms & Mean & 0.701 & 4.096 & 1.841 & 0.560 \\
& Median & 0.494 & 3.121 & 1.120 & 0.480 \\
& Std. Dev. & 2.248 & 4.465 & 3.596 & 2.822 \\
\hline S Firms & Mean & 1.284 & 4.147 & 1.651 & 0.768 \\
& Median & 0.631 & 3.284 & 1.146 & 0.570 \\
& Std. Dev. & 2.891 & 4.017 & 3.175 & 2.318 \\
\hline U Firms & Mean & 2.017 & 4.249 & 1.361 & 0.532 \\
& Median & 1.123 & 3.218 & 0.841 & 0.525 \\
& Std. Dev. & 3.405 & 4.945 & 3.709 & 2.724 \\
\hline
\end{tabular}

\begin{tabular}{|c|l|c|c|c|c|}
\hline Cash Flow $/ K$ & & $1980-87$ & $1988-90$ & $1991-93$ & $1994-96$ \\
\hline R Firms & Mean & 0.161 & 0.268 & 0.184 & 0.151 \\
& Median & 0.154 & 0.249 & 0.181 & 0.165 \\
& Std. Dev. & 0.150 & 0.161 & 0.160 & 0.169 \\
\hline S Firms & Mean & 0.238 & 0.296 & 0.217 & 0.187 \\
& Median & 0.215 & 0.274 & 0.195 & 0.188 \\
& Std. Dev. & 0.140 & 0.207 & 0.259 & 0.134 \\
\hline U Firms & Mean & 0.331 & 0.380 & 0.240 & 0.227 \\
& Median & 0.299 & 0.342 & 0.233 & 0.225 \\
& Std. Dev. & 0.171 & 0.187 & 0.163 & 0.186 \\
\hline
\end{tabular}

\begin{tabular}{|c|l|c|c|c|c|}
\hline Op. Prof $/ K$ & & $1980-87$ & $1988-90$ & $1991-93$ & $1994-96$ \\
\hline R Firms & Mean & 0.171 & 0.300 & 0.194 & 0.089 \\
& Median & 0.152 & 0.256 & 0.138 & 0.086 \\
& Std. Dev. & 0.219 & 0.246 & 0.254 & 0.218 \\
\hline S Firms & Mean & 0.288 & 0.318 & 0.205 & 0.145 \\
& Median & 0.242 & 0.276 & 0.144 & 0.110 \\
& Std. Dev. & 0.247 & 0.311 & 0.379 & 0.209 \\
\hline U Firms & Mean & 0.400 & 0.395 & 0.194 & 0.204 \\
& Median & 0.311 & 0.311 & 0.146 & 0.160 \\
& Std. Dev. & 0.321 & 0.352 & 0.252 & 0.223 \\
\hline
\end{tabular}


Table 5: Sample Statistics for Bond Eligibility Division

Table presents statistics on a sample of 446 manufacturing firms split by the number of times the firm was eligible to issue bonds from 1980-1990. Firms eligible at most one time are restricted ( $R$ Firms), firms eligible $2 \sim 4$ times are semi-restricted (S Firms), and firms eligible 5 or more times are unrestricted (U Firms). There are 116 R Firms, 105 S Firms, and 225 U Firms.

\begin{tabular}{|c|l|c|c|c|c|}
\hline Real Sales & (in Y10,000) & $1980-87$ & $1988-90$ & $1991-93$ & $1994-96$ \\
\hline R Firms & Mean & 5310 & 5994 & 6544 & 6411 \\
& Median & 1483 & 1882 & 2012 & 1947 \\
& Std. Dev. & 13555 & 14559 & 15820 & 16084 \\
\hline S Firms & Mean & 8992 & 9792 & 10316 & 10167 \\
& Median & 2328 & 3125 & 3359 & 3233 \\
& Std. Dev. & 27900 & 27366 & 27801 & 26842 \\
\hline U Firms & Mean & 15098 & 21496 & 24151 & 25996 \\
& Median & 6320 & 9586 & 10892 & 10850 \\
& Std. Dev. & 30385 & 42493 & 48159 & 55141 \\
\hline
\end{tabular}

\begin{tabular}{|c|l|c|c|c|c|}
\hline Sales Growth & & $1980-87$ & $1988-90$ & $1991-93$ & $1994-96$ \\
\hline R Firms & Mean & 0.028 & 0.078 & -0.011 & 0.005 \\
& Median & 0.024 & 0.064 & -0.013 & 0.002 \\
& Std. Dev. & 0.125 & 0.117 & 0.097 & 0.089 \\
\hline S Firms & Mean & 0.053 & 0.075 & -0.002 & 0.020 \\
& Median & 0.050 & 0.061 & -0.002 & 0.015 \\
& Std. Dev. & 0.120 & 0.097 & 0.094 & 0.087 \\
\hline U Firms & Mean & 0.072 & 0.080 & -0.003 & 0.033 \\
& Median & 0.062 & 0.066 & 0.000 & 0.024 \\
& Std. Dev. & 0.102 & 0.082 & 0.084 & 0.082 \\
\hline
\end{tabular}

\begin{tabular}{|c|l|c|c|c|c|}
\hline Total Assets & (in Y10,000) & $1980-87$ & $1988-90$ & $1991-93$ & $1994-96$ \\
\hline R Firms & Mean & 7071 & 7465 & 8420 & 7964 \\
& Median & 1376 & 1760 & 1909 & 1885 \\
& Std. Dev. & 22420 & 21970 & 24830 & 22908 \\
\hline \multirow{2}{*}{ S Firms } & Mean & 13504 & 14391 & 15556 & 14761 \\
& Median & 1978 & 2962 & 3328 & 3319 \\
& Std. Dev. & 48389 & 44874 & 47133 & 44123 \\
\hline U Firms & Mean & 15733 & 24232 & 27437 & 28018 \\
& Median & 5837 & 10158 & 11234 & 11642 \\
& Std. Dev. & 35128 & 49227 & 55156 & 55824 \\
\hline
\end{tabular}

\begin{tabular}{|c|l|c|c|c|c|}
\hline Bank Debt/Tot. Lia. & & $1980-87$ & $1988-90$ & $1991-93$ & $1994-96$ \\
\hline R Firms & Mean & 0.441 & 0.389 & 0.389 & 0.417 \\
& Median & 0.447 & 0.381 & 0.387 & 0.432 \\
& Std. Dev. & 0.175 & 0.176 & 0.181 & 0.189 \\
\hline S Firms & Mean & 0.378 & 0.298 & 0.300 & 0.313 \\
& Median & 0.402 & 0.297 & 0.292 & 0.307 \\
& Std. Dev. & 0.174 & 0.175 & 0.182 & 0.196 \\
\hline U Firms & Mean & 0.214 & 0.148 & 0.189 & 0.200 \\
& Median & 0.176 & 0.102 & 0.153 & 0.151 \\
& Std. Dev. & 0.181 & 0.149 & 0.171 & 0.185 \\
\hline
\end{tabular}


Table 6: Cash Flow Sensitivity, Pooled Sample, 1980-90

Table presents results on the standard cash flow equation using OLS, firm fixed-effects, and Arellano-Bond GMM estimation. The dependent variable is $I / K$. CONST is the target investment rate, $Q$ is the coefficient on Tobin's $Q$ and is the inverse of the adjustment cost parameter, $Q^{n f}$ is the coefficient on the non-fundamental portion of $Q, L A G I K$ is the coefficient on lagged $I / K$, $P R A T$ is the coefficient on the price ratio, and $C F$ is the coefficient on cash flow. Industry and time dummies are included in the OLS regression, and time dummies in the fixed-effects and GMM regressions. The $t$ statistics (OLS, FE) and $z$ statistics (GMM) are in parentheses, and are calculated with heteroskedasticity consistent standard errors (for OLS and GMM). The superscripts $a, b$, and $c$ denote significance at the $.01, .05$, and .1 levels of significance, respectively. The $p-$ values of the Sargan and the $M$ test (for second order serial correlation) are presented for the GMM regression. The sample period is $1980-90$.

\begin{tabular}{|l|c|c|c|}
\hline Parameters & OLS & Fixed Effects & First Differenced GMM \\
\hline CONST & .089 & .1255 & .0038 \\
LAGIK & $(3.49)^{a}$ & $(5.63)^{a}$ & $(.667)$ \\
& & & .0358 \\
$Q$ & & & $(1.37)$ \\
& .0001 & .002 & .0055 \\
$Q^{n f}$ & $(.168)$ & $(5.2)^{a}$ & $(2.49)^{b}$ \\
& & & .0005 \\
PRAT & -.0236 & -.0458 & $(.304)$ \\
& $(-1.79)^{c}$ & $(-3.11)^{a}$ & -.0807 \\
CF & .2143 & .2113 & $(-1.90)^{c}$ \\
& $(14.46)^{a}$ & $(19.45)^{a}$ & .3701 \\
$R^{2}$ Within & & .146 & $(7.77)^{a}$ \\
$R^{2}$ Between & & .334 & \\
$R^{2}$ All & .207 & .188 & .02 \\
\hline Sargan Test & & & .91 \\
M Test & & & \\
\hline
\end{tabular}

\begin{tabular}{|l|c|c|c|}
\hline Parameters & OLS & Fixed Effects & First Differenced GMM \\
\hline CONST & .0932 & .1255 & .0018 \\
& $(3.68)^{a}$ & $(5.67)^{a}$ & $(.317)$ \\
LAGIK & & & .0415 \\
& & & $(1.58)$ \\
& -.0001 & .0017 & .0053 \\
& $(-.209)$ & $(4.31)^{a}$ & $(2.44)^{b}$ \\
$Q^{n f}$ & & & -.0004 \\
& & & $(-.24)$ \\
PRAT & -.0232 & -.0452 & -.0786 \\
& $(-1.77)^{c}$ & $(-3.1)^{a}$ & $(-1.91)^{c}$ \\
CF & .1638 & .1593 & .2591 \\
& $(9.27)^{a}$ & $(12.83)^{a}$ & $(4.31)^{a}$ \\
CFxELIG & .0602 & .1001 & .1558 \\
& $(4.97)^{a}$ & $(8.5)^{a}$ & $(3.35)^{a}$ \\
\hline$R^{2}$ Within & & .159 & \\
$R^{2}$ Between & & .346 & .03 \\
$R^{2}$ All & .214 & .197 & .81 \\
\hline Sargan Test & & & \\
M Test & & & \\
\hline
\end{tabular}


Table 7: CF Sensitivity, Bond Elig. Division, 1980-90

Table presents results on the standard cash flow equation using OLS, firm fixed-effects, and Arellano-Bond GMM estimation. The dependent variable is $I / K$. CONST is the target investment rate, $Q$ is the coefficient on Tobin's $Q$ and is the inverse of the adjustment cost parameter, $Q^{n f}$ is the coefficient on the non-fundamental portion of $Q$, $L A G I K$ is the coefficient on lagged $I / K, P R A T$ is the coefficient on the price ratio, and $C F$ is the coefficient on cash flow. Industry and time dummies are included in the OLS regression, and time dummies in the fixed-effects and GMM regressions. The $t$ statistics (OLS, FE) and $z$ statistics (GMM) are in parentheses, and are calculated with heteroskedasticity consistent standard errors (for OLS and GMM). The superscripts $a$, $b$, and $c$ denote significance at the $.01, .05$, and .1 levels of significance, respectively. The $p$-values of the Sargan and the $M$ test (for second order serial correlation) are presented for the GMM regression. The sample period is 1980-90.

\begin{tabular}{|l|r|r|r|r|r|}
\hline OLS & \multicolumn{7}{|c|}{ All Firms } & R Firms & S Firms & U Firms & U-R Difference \\
\hline Parameters & .089 & .1227 & .1178 & .0673 & \\
& $(3.49)^{a}$ & $(2.74)^{a}$ & $(1.91)^{c}$ & $(1.93)^{c}$ & \\
$Q$ & .0001 & -.0002 & .0016 & -.0007 & \\
PRAT & $(.168)$ & $(-.334)$ & $(1.74)^{c}$ & $(-1.36)$ & \\
& -.0236 & -.0353 & -.0384 & -.0127 & \\
CF & $(-1.79)^{c}$ & $(-1.53)$ & $(-1.24)$ & $(-.68)$ & .1015 \\
& .2143 & .1345 & .1775 & .236 & $(3.42)^{a}$ \\
\hline$R^{2}$ & $(14.46)^{a}$ & $(5.5)^{a}$ & $(3.7)^{a}$ & $(14.05)^{a}$ & .175 \\
\hline
\end{tabular}

\begin{tabular}{|l|r|r|r|r|r|}
\hline \multicolumn{6}{|l|}{ Fixed Effects } \\
\hline Parameters & All Firms & R Firms & S Firms & U Firms & U-R Difference \\
\hline CONST & .1255 & .1473 & .1882 & .0418 & \\
& $(5.63)^{a}$ & $(3.08)^{a}$ & $(4.05)^{a}$ & $(1.41)$ & \\
$Q$ & .002 & .0005 & .0029 & .0011 & \\
PRAT & $(5.2)^{a}$ & $(.55)$ & $(3.08)^{a}$ & $(2.18)^{b}$ & \\
& -.0458 & -.0546 & -.0823 & -.0186 & \\
CF & $(-3.11)^{a}$ & $(-1.74)^{c}$ & $(-2.64)^{a}$ & $(-.963)$ & .2676 \\
& .2113 & .1047 & .1345 & .3723 & $(10.72)^{a}$ \\
\hline$R^{2}$ Within & $(19.42)^{a}$ & $(5.91)^{a}$ & $(6.11)^{a}$ & $(21.18)^{a}$ & \\
$R^{2}$ Between & .146 & .106 & .112 & .24 & \\
$R^{2}$ All & .334 & .144 & .23 & .231 & \\
\hline
\end{tabular}

\begin{tabular}{|l|r|r|r|r|r|}
\hline \multicolumn{7}{|l|}{ First Differenced GMM } \\
\hline Parameters & All Firms & R Firms & S Firms & U Firms & U-R Difference \\
\hline LAGIK & .0358 & .0571 & -.0305 & .0425 & \\
& $(1.37)$ & $(1.02)$ & $(-.5)$ & $(1.54)$ & \\
$Q$ & .0055 & .0073 & .0089 & .0074 & \\
$Q^{n f}$ & $(2.49)^{b}$ & $(2.35)^{b}$ & $(1.78)^{c}$ & $(3.19)^{a}$ & \\
& .0005 & -.0008 & -.0019 & .001 & \\
CF & $(.30)$ & $(-.39)$ & $(-.8)$ & $(.62)$ & .2286 \\
& .3701 & .1749 & .2478 & .4035 & $(2.68)^{a}$ \\
PRAT & $(7.77)^{a}$ & $(3.31)^{a}$ & $(2.37)^{b}$ & $(6.01)^{a}$ & \\
& -.0807 & -.0501 & -.1498 & -.0557 & \\
\hline Sargan Test & $(-1.9)^{c}$ & $(-.57)$ & $(-2.15)^{b}$ & $(-1.04)$ & \\
M Test & .02 & .991 & .999 & .471 & \\
\hline \multicolumn{7}{|c|}{} & .91 & .531 & .963 & .496 & \\
\hline
\end{tabular}


Table 8: CF Interacted with Bond Issue, Bond Elig. Division, 1980-90

\begin{abstract}
Table presents results on the standard cash flow equation using OLS, firm fixed-effects, and Arellano-Bond GMM estimation. The dependent variable is $I / K$. CONST is the target investment rate, $Q$ is the coefficient on Tobin's $Q$ and is the inverse of the adjustment cost parameter, $Q^{n f}$ is the coefficient on the non-fundamental portion of $Q, L A G I K$ is the coefficient on lagged $I / K, P R A T$ is the coefficient on the price ratio, $C F$ is the coefficient on cash flow, and $C F x B O N D$ is the coefficient on cash flow crossed with a dummy for bond issues. Industry and time dummies are included in the OLS regression, and time dummies in the fixed-effects and GMM regressions. The $t$ statistics (OLS, FE) and $z$ statistics (GMM) are in parentheses, and are calculated with heteroskedasticity consistent standard errors (for OLS and GMM). The superscripts $a, b$, and $c$ denote significance at the $.01, .05$, and .1 levels of significance, respectively. The $p$ - values of the Sargan and the $M$ test (for second order serial correlation) are presented for the GMM regression. The sample period is $1980-90$.
\end{abstract}

\begin{tabular}{|c|c|c|c|c|c|}
\hline \multicolumn{6}{|l|}{ OLS } \\
\hline Parameters & All Firms & $R$ Firms & S Firms & U Firms & $U$-R Difference \\
\hline \multirow{2}{*}{$C O N S T$} & .0943 & .1259 & .1285 & .071 & \\
\hline & $(3.74)^{a}$ & $(2.81)^{a}$ & $(2.09)^{b}$ & $(2.05)^{b}$ & \\
\hline \multirow[t]{2}{*}{$Q$} & .0001 & 0 & .0015 & -.0006 & \\
\hline & $(.31)$ & $(-.039)$ & $(1.69)^{c}$ & $(-1.16)$ & \\
\hline \multirow[t]{2}{*}{$P R A T$} & -.024 & -.0374 & -.0417 & -.0122 & \\
\hline & $(-1.84)^{c}$ & $(-1.62)$ & $(-1.35)$ & $(-.68)$ & \\
\hline \multirow[t]{2}{*}{$C F$} & .1961 & .1316 & .1691 & .2202 & .0886 \\
\hline & $(13.15)^{a}$ & $(5.37)^{a}$ & $(3.62)^{a}$ & $(12.39)^{a}$ & $(2.93)^{a}$ \\
\hline \multirow[t]{2}{*}{$C F x B O N D$} & .0891 & .1462 & .12 & .071 & \\
\hline & $(6.88)^{a}$ & $(2.33)^{b}$ & $(3.11)^{a}$ & $(4.88)^{a}$ & \\
\hline$R^{2}$ & .222 & .157 & .189 & .233 & \\
\hline \multicolumn{6}{|l|}{ Fixed Effects } \\
\hline Parameters & All Firms & $R$ Firms & S Firms & U Firms & $U$-R Difference \\
\hline \multirow[t]{2}{*}{$C O N S T$} & .1268 & .1424 & .1865 & .0459 & \\
\hline & $(5.71)^{a}$ & $(2.99)^{a}$ & $(4.05)^{a}$ & $(1.55)$ & \\
\hline \multirow[t]{2}{*}{$Q$} & .0019 & .0006 & .0028 & .0011 & \\
\hline & $(4.95)^{a}$ & $(.76)$ & $(2.98)^{a}$ & $(2.13)^{b}$ & \\
\hline \multirow[t]{2}{*}{ PRAT } & -.0455 & -.0514 & -.0797 & -.0193 & \\
\hline & $(-3.11)^{a}$ & $(-1.64)^{c}$ & $(-2.58)^{a}$ & $(-1)$ & \\
\hline \multirow[t]{2}{*}{$C F$} & .1999 & .0999 & .1229 & .3596 & .2597 \\
\hline & $(18.22)^{a}$ & $(5.64)^{a}$ & $(5.6)^{a}$ & $(19.92)^{a}$ & $(10.27)^{a}$ \\
\hline \multirow[t]{2}{*}{$C F x B O N D$} & .066 & .1541 & .12 & .0327 & \\
\hline & $(6.6)^{a}$ & $(3.07)^{a}$ & $(4.45)^{a}$ & $(2.99)^{a}$ & \\
\hline$R^{2}$ Within & .154 & .114 & .129 & .243 & \\
\hline$R^{2}$ Between & .365 & .161 & .227 & .245 & \\
\hline$R^{2} A l l$ & .202 & .122 & .149 & .202 & \\
\hline \multicolumn{6}{|c|}{ First Differenced GMM } \\
\hline Parameters & All Firms & $R$ Firms & S Firms & U Firms & $U$-R Difference \\
\hline \multirow[t]{2}{*}{$L A G I K$} & .0338 & .0559 & -.0471 & .0406 & \\
\hline & $(1.3)$ & $(.99)$ & $(-.79)$ & $(1.49)$ & \\
\hline \multirow[t]{2}{*}{$Q$} & .0056 & .0082 & .0086 & .0076 & \\
\hline & $(2.5)^{b}$ & $(2.46)^{b}$ & $(1.78)^{c}$ & $(3.19)^{a}$ & \\
\hline \multirow[t]{2}{*}{$Q^{n f}$} & .0005 & -.0008 & -.0019 & .001 & \\
\hline & $(.33)$ & $(-.39)$ & $(-.8)$ & $(.6)$ & \\
\hline \multirow[t]{2}{*}{$C F$} & .3722 & .157 & .2347 & .4054 & .2484 \\
\hline & $(7.87)^{a}$ & $(3.06)^{a}$ & $(2.27)^{b}$ & $(6.72)^{a}$ & $(3.14)^{a}$ \\
\hline \multirow[t]{2}{*}{$C F x B O N D$} & -.0054 & .3272 & .0843 & -.0058 & \\
\hline & $(-.1)$ & $(2.56)^{b}$ & (1.08) & $(-.11)$ & \\
\hline \multirow[t]{2}{*}{$P R A T$} & -.0823 & -.0149 & -.1506 & -.0578 & \\
\hline & $(-1.94)^{c}$ & $(-.16)$ & $(-2.24)^{b}$ & $(-1.1)$ & \\
\hline Sargan Test & .03 & .89 & .75 & .499 & \\
\hline$M$ Test & .888 & .598 & .828 & .502 & \\
\hline
\end{tabular}


Table 9: Negative Cash Flow Observations, Bond Elig. Division

Table presents the number of negative cash flow observations by firm group. Cash Flow (CF1) is defined as after tax earnings minus dividends paid plus accounting depreciation.

\begin{tabular}{|c|r|r|r|r|}
\hline Fiscal Year & R Firms & S Firms & U Firms & Total \\
\hline 80 & 4 & 0 & 0 & 4 \\
81 & 7 & 4 & 0 & 11 \\
82 & 10 & 2 & 1 & 13 \\
83 & 10 & 1 & 0 & 11 \\
84 & 9 & 2 & 1 & 12 \\
85 & 11 & 0 & 0 & 11 \\
86 & 19 & 2 & 0 & 21 \\
87 & 4 & 1 & 0 & 5 \\
88 & 3 & 1 & 0 & 4 \\
89 & 0 & 0 & 0 & 0 \\
90 & 5 & 2 & 2 & 9 \\
91 & 3 & 4 & 5 & 12 \\
92 & 9 & 12 & 13 & 34 \\
93 & 12 & 4 & 14 & 30 \\
94 & 14 & 6 & 11 & 31 \\
95 & 15 & 7 & 12 & 34 \\
96 & 12 & 4 & 7 & 23 \\
\hline Total & 147 & 52 & 66 & 265 \\
\hline
\end{tabular}


Table 10: Negative CF Observations and Bond Elig. Division, 1980-90

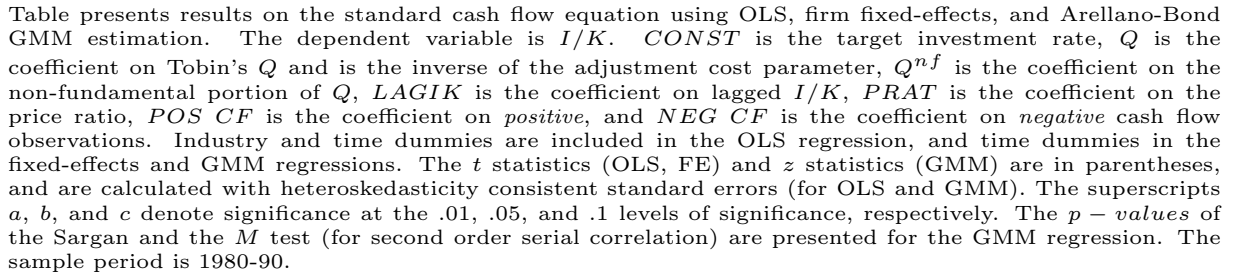
sample period is $1980-90$.

\begin{tabular}{|c|c|c|c|c|c|}
\hline \multicolumn{6}{|l|}{ OLS } \\
\hline Parameters & All Firms & $R$ Firms & S Firms & U Firms & $U-R$ Difference \\
\hline$C O N S T$ & $\begin{array}{l}.0724 \\
(2.9)^{a}\end{array}$ & $\begin{array}{r}.1044 \\
(2.31)^{b}\end{array}$ & $\begin{array}{r}.0831 \\
(1.42)\end{array}$ & $\begin{array}{l}.0653 \\
(1.9)^{c}\end{array}$ & \\
\hline \multirow[t]{2}{*}{$Q$} & -.0002 & -.0003 & .0011 & -.0007 & \\
\hline & $(-.65)$ & $(-.51)$ & $(1.29)$ & $(-1.4)$ & \\
\hline \multirow[t]{2}{*}{$P R A T$} & -.0178 & -.0287 & -.0262 & -.0118 & \\
\hline & $(-1.37)$ & $\begin{array}{r}(-1.25) \\
173\end{array}$ & $\begin{array}{r}(-.88) \\
2437\end{array}$ & $\begin{array}{r}(-.64) \\
0270\end{array}$ & \\
\hline POS CF & $\begin{array}{r}.2425 \\
(18.5)^{a}\end{array}$ & $\begin{array}{r}.173 \\
(4.94)^{a}\end{array}$ & $\begin{array}{r}.2437 \\
(6.25)^{a}\end{array}$ & $\begin{array}{r}.2379 \\
(13.98)^{a}\end{array}$ & $\begin{array}{r}.0649 \\
(1.67)^{c}\end{array}$ \\
\hline$N E G C F$ & $\begin{array}{r}-.026 \\
(-1.79)^{c}\end{array}$ & $\begin{array}{r}-.02 \\
(-.58)\end{array}$ & $\begin{array}{r}-.0264 \\
(-1.66)^{c}\end{array}$ & $\begin{array}{r}-.0356 \\
(-.39)\end{array}$ & \\
\hline$R^{2}$ & .217 & .157 & .196 & .219 & \\
\hline \multicolumn{6}{|c|}{ Fixed Effects } \\
\hline Parameters & All Firms & $R$ Firms & S Firms & U Firms & $U-R$ Difference \\
\hline \multirow[t]{2}{*}{$C O N S T$} & .1008 & .1357 & 158 & .0359 & \\
\hline & $(4.55)^{a}$ & $(2.85)^{a}$ & $(3.4)^{a}$ & $(1.21)$ & \\
\hline \multirow[t]{2}{*}{$Q$} & .0016 & .0004 & .0022 & .0011 & \\
\hline & $(4.08)^{a}$ & $(.51)$ & $(2.36)^{b}$ & $(2.13)^{b}$ & \\
\hline \multirow[t]{2}{*}{$P R A T$} & -.0408 & -.0541 & $\begin{array}{l}-.0736 \\
\end{array}$ & -.0164 & \\
\hline & $(-2.8)^{a}$ & $(-1.73)^{c}$ & $(-2.38)^{b}$ & $(-.85)$ & \\
\hline \multirow[t]{2}{*}{$P O S C F$} & .2763 & .1605 & .2146 & .3805 & \\
\hline & $(22.33)^{a}$ & $(7.11)^{a}$ & $(7.78)^{a}$ & $(21.42)^{a}$ & $(7.66)^{a}$ \\
\hline$N E G C F$ & $\begin{array}{r}-.0988 \\
(-3.17)^{a}\end{array}$ & $\begin{array}{r}-.093 \\
(-1.75)^{c}\end{array}$ & $\begin{array}{l}-.0347 \\
(-.83)\end{array}$ & $\begin{array}{r}-.277 \\
(-1.26)\end{array}$ & \\
\hline \multirow{2}{*}{$\begin{array}{l}R^{2} \text { Within } \\
R^{2} \text { Between }\end{array}$} & .167 & .118 & .131 & .243 & \\
\hline & .334 & .145 & 277 & .229 & \\
\hline$R^{2}$ All & .2 & .123 & .162 & .193 & \\
\hline \multicolumn{6}{|c|}{ First Differenced GMM } \\
\hline Parameters & All Firms & $R$ Firms & S Firms & U Firms & $U$-R Difference \\
\hline$L A G I K$ & $\begin{array}{l}.0342 \\
(135)\end{array}$ & $\begin{array}{l}.0551 \\
(101)\end{array}$ & $\begin{array}{l}-.0322 \\
(-55)\end{array}$ & $\begin{array}{l}.0416 \\
(1.51)\end{array}$ & \\
\hline \multirow[t]{2}{*}{$Q$} & .007 & .0094 & .0061 & .0075 & \\
\hline & $(3.45)^{a}$ & $(3.05)^{a}$ & $(1.48)$ & $(3.3)^{a}$ & \\
\hline \multirow[t]{2}{*}{$Q^{n f}$} & .0013 & -.0002 & -.0028 & 0009 & \\
\hline & $(.86)$ & $(-.13)$ & $(-1.24)$ & $(.52)$ & \\
\hline \multirow[t]{2}{*}{$P O S C F$} & 3859 & .2001 & .3733 & .3964 & .1963 \\
\hline & $(7.77)^{a}$ & $(3.04)^{a}$ & $(4.7)^{a}$ & $(6.41)^{a}$ & $(2.17)^{b}$ \\
\hline \multirow[t]{2}{*}{$N E G C F$} & -.2211 & -.1485 & .0395 & 1.4012 & \\
\hline & $(-1.32)$ & $(-1.15)$ & $(.42)$ & $(.8)$ & \\
\hline \multirow[t]{2}{*}{$P R A T$} & -.0471 & -.026 & -.1347 & -.0585 & \\
\hline & $(-1.11)$ & $(-.303)$ & $(-1.9)^{c}$ & $(-1.11)$ & \\
\hline \multirow{2}{*}{$\begin{array}{l}\text { Sargan Test } \\
M \text { Test }\end{array}$} & .05 & .999 & .97 & .439 & \\
\hline & .788 & .909 & .959 & .523 & \\
\hline
\end{tabular}


Table 11: CF Sensitivity by Period (Neg. Obs.), Bond Elig. Division, 1980-96

Table presents results on the standard cash flow equation using firm fixed-effects and Arellano-Bond GMM estimation. The dependent variable is $I / K$. CONST is the target investment rate, $Q$ is the coefficient on Tobin's $Q$ and is the inverse of the adjustment cost parameter, $Q^{n f}$ is the coefficient on the non-fundamental portion of $Q, L A G I K$ is the coefficient on lagged $I / K, P R A T$ is the coefficient on the price ratio, and POS CF is the coefficient on positive, and $N E G C F$ is the coefficient on negative cash flow (CF1). Time dummies are included in all regressions. The $t$ statistics (FE) and $z$ statistics (GMM) are in parentheses, and are calculated with heteroskedasticity consistent standard errors for GMM. The superscripts $a, b$, and $c$ denote significance at the .01 , .05 , and .1 levels of significance, respectively. The $p$-values of the Sargan and the $M$ test (for second order serial correlation) are presented for the GMM regression. The sample period is 1980-96.

\begin{tabular}{|c|c|c|c|c|c|}
\hline \multicolumn{6}{|l|}{ Fixed Effects } \\
\hline Parameters & All Firms & $R$ Firms & S Firms & U Firms & $U-R$ Difference \\
\hline \multirow[t]{2}{*}{$C O N S T$} & .1085 & .1163 & .1399 & .0754 & \\
\hline & $(8.3)^{a}$ & $(4.1)^{a}$ & $(4.9)^{a}$ & $(4.39)^{a}$ & \\
\hline \multirow[t]{2}{*}{$Q$} & .0013 & .0003 & .0019 & .001 & \\
\hline & $(4.08)^{a}$ & $(.364)$ & $(2.36)^{b}$ & $(2.43)^{b}$ & \\
\hline \multirow[t]{2}{*}{$P R A T$} & -.0491 & -.0429 & -.0703 & -.0379 & \\
\hline & $(-6.16)^{a}$ & $(-2.42)^{b}$ & $(-4.05)^{a}$ & $(-3.7)^{a}$ & \\
\hline \multirow{2}{*}{$P O S C F^{80-87}$} & .2939 & .1751 & .2744 & .3568 & .1817 \\
\hline & $(25.13)^{a}$ & $(6.4)^{a}$ & $(9.2)^{a}$ & $(22.91)^{a}$ & $(5.77)^{a}$ \\
\hline \multirow[t]{2}{*}{$P O S C F^{88-90}$} & .2412 & .1877 & .2072 & 2897 & .102 \\
\hline & $(15.63)^{a}$ & $(5.4)^{a}$ & $(5.42)^{a}$ & $(14.24)^{a}$ & $(2.53)^{b}$ \\
\hline \multirow[t]{2}{*}{$P O S C F^{91-93}$} & .1618 & .1184 & .0961 & .3128 & .1944 \\
\hline & $(9.89)^{a}$ & $(2.77)^{a}$ & $(3.89)^{a}$ & $(11.23)^{a}$ & $(3.81)^{a}$ \\
\hline \multirow[t]{2}{*}{$P O S C F^{94-96}$} & .1906 & .1462 & .1355 & .2831 & .1369 \\
\hline & $(9.39)^{a}$ & $(3.72)^{a}$ & $(2.63)^{a}$ & $(10.09)^{a}$ & $(2.84)^{a}$ \\
\hline \multirow[t]{2}{*}{$N E G C F^{80-87}$} & -.1645 & -.0896 & -.1386 & -.333 & \\
\hline & $(-3.52)^{a}$ & $(-1.57)$ & $(-1.21)$ & $(-1.29)$ & \\
\hline \multirow[t]{2}{*}{$N E G C F^{88-90}$} & -.0417 & -.0454 & -.0379 & .0108 & \\
\hline & $(-1.04)$ & $(-.31)$ & $(-.83)$ & $(.029)$ & \\
\hline \multirow[t]{2}{*}{$N E G C F^{91-93}$} & -.0081 & .0371 & .098 & -.1688 & \\
\hline & $(-.16)$ & $(.42)$ & $(.88)$ & $(-2.24)^{b}$ & \\
\hline \multirow[t]{2}{*}{$N E G C F^{94-96}$} & -.0084 & -.0633 & .2694 & -.0261 & \\
\hline & $(-.29)$ & $(-.82)$ & $(1.94)^{c}$ & $(-.83)$ & \\
\hline$R^{2}$ Within & 207 & .143 & .168 & .286 & \\
\hline$R^{2}$ Between & 268 & .12 & .152 & .2 & \\
\hline$R^{2} \mathrm{All}$ & .202 & .14 & .156 & .231 & \\
\hline \multicolumn{6}{|c|}{ First Differenced GMM } \\
\hline \multirow{3}{*}{$\begin{array}{l}\text { Parameters } \\
L A G I K\end{array}$} & All Firms & $R$ Firms & S Firms & U Firms & $U$-R Difference \\
\hline & .073 & .0561 & .063 & .0587 & \\
\hline & $(4.15)^{a}$ & $(1.59)$ & $(1.93)^{c}$ & $(2.7)^{a}$ & \\
\hline \multirow[t]{2}{*}{$Q$} & .0039 & .007 & .0043 & .0034 & \\
\hline & $(3)^{a}$ & $(2.33)^{b}$ & $(1.91)^{c}$ & $(2.18)^{b}$ & \\
\hline \multirow[t]{2}{*}{$Q^{n f}$} & -.0015 & -.001 & -.0025 & -.0006 & \\
\hline & $(-1.79)^{c}$ & $(-.8)$ & $(-1.68)^{c}$ & $(-.56)$ & \\
\hline \multirow[t]{2}{*}{ POS $C F^{80-87}$} & .3804 & .1926 & .4187 & .3902 & .1976 \\
\hline & $(9.5)^{a}$ & $(2.74)^{a}$ & $(6.53)^{a}$ & $(8.81)^{a}$ & $(2.32)^{b}$ \\
\hline \multirow[t]{2}{*}{$P O S C F^{88-90}$} & .3744 & .2803 & .3277 & .3413 & .0610 \\
\hline & $(5.91)^{a}$ & $(3.58)^{a}$ & $(2.23)^{b}$ & $(5.38)^{a}$ & $(.61)$ \\
\hline \multirow[t]{2}{*}{$P O S C F^{91-93}$} & .3254 & .0777 & .1502 & .412 & .3343 \\
\hline & $(3.89)^{a}$ & (1.03) & $(1.73)^{c}$ & $(5.66)^{a}$ & $(3.19)^{a}$ \\
\hline POS $C F^{94-96}$ & .3845 & .0963 & .1986 & .4322 & .3359 \\
\hline & $(6.75)^{a}$ & (1.58) & $(2.56)^{b}$ & $(6.12)^{a}$ & $(3.61)^{a}$ \\
\hline$N E G C F^{80-87}$ & -.2449 & -.142 & -.0216 & 7.2093 & \\
\hline & $(-1.04)$ & $(-1.06)$ & $(-.27)$ & $(1.25)$ & \\
\hline$N E G C F^{88-90}$ & -.0621 & .2072 & .0346 & -1.8103 & \\
\hline & $(-.42)$ & $(.62)$ & $(.28)$ & $(-.66)$ & \\
\hline$N E G C F^{91-93}$ & -.2262 & .1396 & .0086 & -.4182 & \\
\hline & $(1.9)^{c}$ & $(.9)$ & $(.06)$ & $(-2.24)^{b}$ & \\
\hline$N E G C F^{94-96}$ & -.0364 & -.0337 & .107 & -.0837 & \\
\hline & $(-.39)$ & $(-.31)$ & $(.76)$ & $(-1.08)$ & \\
\hline$P R A T$ & -.0831 & -.0813 & -.07 & -.0736 & \\
\hline & $(4.5)^{a}$ & $(-2.18)^{b}$ & $(-2.29)^{b}$ & $(-3.31)^{a}$ & \\
\hline Sargon Test & .99 & .988 & .97 & .967 & \\
\hline$M$ Test & .394 & .715 & .482 & .587 & \\
\hline
\end{tabular}


Table 12: Incidence and Size of Bond Issues by Eligible Firms

The statistics are calculated using all eligible firms in each year. The first two columns list the share of firms within each group that have a bond issue (either convertible, warrant, group, conditional on non-zero issue.

\begin{tabular}{|l|c|c||c|c||c|c|}
\hline & \multicolumn{2}{|c||}{ Pct. of Firms } & \multicolumn{2}{c||}{ Mean Issue } & \multicolumn{2}{c|}{ Median Issue } \\
\hline FY & Ind & Group & Ind & Group & Ind & Group \\
\hline 80 & 0.157 & 0.321 & 724.5 & 876.9 & 490.3 & 560.6 \\
81 & 0.325 & 0.466 & 823.9 & 1140.0 & 400.0 & 539.5 \\
82 & 0.225 & 0.433 & 1025.9 & 1275.6 & 376.1 & 625.2 \\
83 & 0.289 & 0.483 & 1186.2 & 1315.7 & 535.4 & 838.5 \\
84 & 0.370 & 0.511 & 1276.8 & 1555.9 & 590.1 & 940.6 \\
85 & 0.322 & 0.505 & 1236.6 & 1727.1 & 522.0 & 1023.2 \\
86 & 0.422 & 0.545 & 1434.1 & 1483.3 & 616.0 & 880.8 \\
87 & 0.310 & 0.556 & 1945.0 & 1475.5 & 974.4 & 1000.0 \\
88 & 0.410 & 0.512 & 2450.7 & 2342.5 & 1014.8 & 1305.3 \\
89 & 0.340 & 0.549 & 3963.0 & 3693.6 & 1431.7 & 1715.3 \\
90 & 0.257 & 0.370 & 1194.6 & 2235.6 & 505.6 & 1050.4 \\
\hline
\end{tabular}




\section{Table 13: Keiretsu Profitability Regressions}

Table presents results for OLS regressions. The dependent variables are Opp. Prof./TA, operating profits over total assets, and $E P S$, earnings per share. Bonds/TL is outstanding bonds divided by total liabilities, Tot. Debt/TL is outstanding bonds plus bank debt over total liabilities, Nom. K/Sales is the nominal capital stock divided by gross sales, $\ln$ (Sales) is the natural log of gross sales, SalesGrth is year-on-year growth in gross sales, Keiretsu is a dummy variable for Keiretsu membership, and Own Fin. Inst. Own. Indiv., Own Non Fin., Own. Top Ten is the percent of outstanding shares owned by financial institutions, individuals, and non-financial institutions, respectively. Own. Top Ten is cumulative ownership by the top ten shareholders. A constant term, industry, and time dummies are included in each regression but not reported. The $t$ statistics. A constant term, in $t$ statistics $a, b$, a d $c$ de

\begin{tabular}{|c|c|c|c|c|c|c|}
\hline \multirow{3}{*}{$\begin{array}{l}\text { OLS: 1980-90 } \\
\text { parameters } \\
\text { Bonds } / T L\end{array}$} & \multicolumn{6}{|c|}{ Dependent Variables } \\
\hline & \multicolumn{3}{|c|}{ Opp. Prof./TA } & \multicolumn{3}{|c|}{$E P S$} \\
\hline & $\begin{array}{l}-.0031 \\
(-.73)\end{array}$ & & & $\begin{array}{r}6.3581 \\
(1.7)^{c}\end{array}$ & & \\
\hline Tot. Debt/TL & & $\begin{array}{r}-.0581 \\
(-19.88)^{a}\end{array}$ & $\begin{array}{r}-.0597 \\
(-19.5)^{a}\end{array}$ & & $\begin{array}{r}-45.35 \\
(-10.5)^{a}\end{array}$ & $\begin{array}{r}-47.55 \\
(-9.71)^{a}\end{array}$ \\
\hline Nom.K/Sales & & & $\begin{array}{r}-.003 \\
(-.31)\end{array}$ & & & $\begin{array}{r}21.1301 \\
(2.27)^{b}\end{array}$ \\
\hline$(\text { Nom.K/Sales })^{2}$ & & & $\begin{array}{r}.012 \\
(1.24)\end{array}$ & & & $\begin{array}{l}-13.7717 \\
(-1.88)^{c}\end{array}$ \\
\hline $\ln ($ Sales $)$ & -.0009 & -.0016 & -.0016 & 1.6437 & 1.2712 & 1.3046 \\
\hline & $(-1.54)$ & $(-2.79)^{a}$ & $(-2.9)^{a}$ & $(3.53)^{a}$ & $(2.82)^{a}$ & $(2.91)^{a}$ \\
\hline SalesGrth. & $\begin{array}{r}.1272 \\
(16.56)^{a}\end{array}$ & $\begin{array}{r}.1123 \\
-(150) a\end{array}$ & .1134 & 51.5298 & 40.0705 & 41.777 \\
\hline & $(16.56)^{a}$ & $(15.59)^{a}$ & $(15.57)^{a}$ & $(8.09)^{a}$ & $(6.1)^{a}$ & $(6.53)^{a}$ \\
\hline Keiretsu & -.0049 & -.0023 & -.0024 & -7.2082 & -5.3256 & -5.3856 \\
\hline & $(-4.48)^{a}$ & $(-2.16)^{b}$ & $(-2.21)^{b}$ & $(-8.72)^{a}$ & $(-6.78)^{a}$ & $(-6.89)^{a}$ \\
\hline Own. Top Ten & .0072 & -.0029 & -.0014 & 15.3022 & 6.7252 & 8.068 \\
\hline & $(.81)$ & $(-.35)$ & $(-.17)$ & $(2.24)^{b}$ & $(.95)$ & $(1.15)$ \\
\hline Own. Indiv. & $\begin{array}{r}-.0564 \\
(-483)^{a}\end{array}$ & $\begin{array}{r}-.0645 \\
(-604)^{a}\end{array}$ & $\begin{array}{r}-.0649 \\
(-606)^{a}\end{array}$ & -3.0519 & -9.9059 & -9.7731 \\
\hline Own Fin Inst & $(-4.83)^{a}$ & $(-6.04)^{a}$ & $(-6.06)^{a}$ & $\begin{array}{r}(-.39) \\
-138283\end{array}$ & $(-1.29)$ & $\begin{array}{l}(-1.27) \\
-5.7498\end{array}$ \\
\hline Wh. I the Ithat. & $(-5.3)^{a}$ & $\begin{array}{r}-.0501 \\
(-4.92)^{a}\end{array}$ & $\begin{array}{r}-.0503 \\
(-4.93)^{a}\end{array}$ & $\begin{array}{l}-13.8283 \\
(-2.34)^{b}\end{array}$ & $\begin{array}{l}-5.8417 \\
(-1.13)\end{array}$ & $\begin{array}{l}-5.7498 \\
(-1.11)\end{array}$ \\
\hline Own. Non Fin. & $\begin{array}{r}-.073 \\
(-6.27)^{a}\end{array}$ & $\begin{array}{r}-.0666 \\
(-6.18)^{a}\end{array}$ & $\begin{array}{r}-.0673 \\
(-6.22)^{a}\end{array}$ & $\begin{array}{l}-16.6126 \\
(-2.75)^{a}\end{array}$ & $\begin{array}{l}-11.7136 \\
(-2.16)^{b}\end{array}$ & $\begin{array}{l}-12.0825 \\
(-2.21)^{b}\end{array}$ \\
\hline Psudo $R^{2}$ & .224 & .286 & .286 & .06 & .119 & .121 \\
\hline
\end{tabular}

\begin{tabular}{|l|r|r|r|r|r|r|}
\hline OLS: 1991-96 & \multicolumn{6}{|c|}{ Dependent Variables } \\
\hline parameters & \multicolumn{3}{|c|}{ Opp. Prof./TA } & \multicolumn{3}{c|}{ EPS } \\
\hline Bonds/TL & -.0074 .9 .9249 & & \\
Tot. Debt/TL & $(-1.92)^{c}$ & & & $(-1.8)^{c}$ & -66.2198 & -62.7434 \\
& & -.0497 & -.0427 & & $(-10.84)^{a}$ & $(-10.48)^{a}$ \\
Nom.K/Sales & & $(-14.75)^{a}$ & $(-12.48)^{a}$ & & -31.6799 \\
& & & -.0471 & & & $(-2.79)^{a}$ \\
Nom.K/Sales $)^{2}$ & & & $(-4.82)^{a}$ & & & 17.0205 \\
& & & .0189 & & & $(1.84)^{c}$ \\
ln(Sales $)$ & .0015 & .0012 & $(2.27)^{b}$ & & & .887 \\
& $(2.1)^{b}$ & $(1.75)^{c}$ & $(1.36)$ & $(1.9)^{c}$ & $(1.34)$ & $(1.17)$ \\
SalesGrth. & .1172 & .1097 & .1019 & 98.6679 & 88.626 & 84.5285 \\
& $(11.5)^{a}$ & $(11.11)^{a}$ & $(10.58)^{a}$ & $(5.9)^{a}$ & $(5.59)^{a}$ & $(5.36)^{a}$ \\
Keiretsu & -.002 & .0005 & .0006 & -5.7437 & -2.4252 & -2.3368 \\
& $(-1.6)$ & $(.38)$ & $(.53)$ & $(-3.46)^{a}$ & $(-1.62)$ & $(-1.57)^{a}$ \\
Own. Top Ten & .0385 & .0269 & .0205 & 17.7555 & 2.0404 & -1.2701 \\
& $(3.55)^{a}$ & $(2.62)^{a}$ & $(2.03)^{b}$ & $(1.31)$ & $(.16)$ & $(-.1)$ \\
Own. Indiv. & -.0712 & -.0657 & -.0726 & -90.5014 & -83.4626 & -87.4238 \\
& $(-4.87)^{a}$ & $(-4.87)^{a}$ & $(-5.48)^{a}$ & $(-5.32)^{a}$ & $(-5.53)^{a}$ & $(-5.8)^{a}$ \\
Own. Fin. Inst. & -.0764 & -.0635 & -.0677 & -78.4117 & -61.0793 & -63.8497 \\
& $(-5.41)^{a}$ & $(-4.99)^{a}$ & $(-5.38)^{a}$ & $(-4.55)^{a}$ & $(-4.02)^{a}$ & $(-4.2)^{a}$ \\
Own. Non Fin. & -.0967 & -.0843 & -.0864 & -80.7858 & -64.3379 & -65.6266 \\
& $(-7.37)^{a}$ & $(-7.18)^{a}$ & $(-7.45)^{a}$ & $(-4.82)^{a}$ & $(-4.28)^{a}$ & $(-4.38)^{a}$ \\
\hline Psudo R ${ }^{2}$ & .232 & .292 & .315 & .095 & .166 & .169 \\
\hline
\end{tabular}




\section{Table 14: Bond Issue Probit Regressions}

Table presents results for probit regressions where the dependent variable is a dummy for bond issues. Semi - Res is a dummy for the Semi-Restricted, and Unrestricted a dummy for the unrestricted firm group. $\ln$ (Sales) is the natural $\log$ of gross sales, Bonds $/ T L$ is outstanding bonds divided by total liabilities, Oper.Prof./PK is operating profits normalized by the nominal capital stock, and Own Fin. Inst., Own. Indiv., Own Non Fin., Own. Top Ten is the percent of outstanding shares owned by financial institutions, individuals, and non-financial institutions, respectively. Own. Top Ten is cumulative ownership by the top ten shareholders. A constant term, industry, and time dummies are included in each regression, but not reported. The $z$ statistics are in parentheses, and are calculated with heteroskedasticity consistent standard errors. The superscripts $a, b$, and $c$ denote significance 01,05, an 1 the 01,

\begin{tabular}{|l|r|r|r|r|}
\hline \multicolumn{5}{|c|}{ Probit Regression: Bond Issue Dummy } \\
\hline Parameters & \multicolumn{2}{|c|}{$1980-90$} & \multicolumn{2}{|c|}{$1991-96$} \\
\hline Semi-Res & .2589 & .2608 & -.1018 & -.0913 \\
Unrestricted & $(3.34)^{a}$ & $(3.30)^{a}$ & $(-1.04)$ & $(-0.92)$ \\
& -.0026 & -.0235 & -.5698 & -.557 \\
Keiretsu & $(-0.03)$ & $(-0.30)$ & $(-5.34)^{a}$ & $(-5.09)^{a}$ \\
& .2954 & .2517 & .089 & .082 \\
$\ln$ Sales $)$ & $(5.65)^{a}$ & $(4.68)^{a}$ & $(1.31)$ & $(1.20)$ \\
& .3391 & .2662 & .2943 & .309 \\
Bonds/TL & $(15.57)^{a}$ & $(9.87)^{a}$ & $(10.23)^{a}$ & $(8.72)^{a}$ \\
& 5.589 & 5.484 & 3.796 & 3.826 \\
Oper.Prof./PK & $(21.07)^{a}$ & $(20.36)^{a}$ & $(17.50)^{a}$ & $(17.08)^{a}$ \\
& $(5.18)^{a}$ & .444 & .4877 & .578 \\
Own. Fin. Inst. & & .0919 & $(3.70)^{a}$ & $(4.22)^{a}$ \\
& & $(0.22)^{a}$ & & 1.124 \\
Own. Indiv. & & -.893 & & $(1.58)$ \\
& & $(-2.19)^{b}$ & & $(2.47)^{b}$ \\
Own. Non Fin. & & .658 & & 1.31 \\
& & $(1.70)^{c}$ & & $(1.86)^{c}$ \\
Own. Top Ten & & -1.868 & & -.962 \\
& & $(-5.17)^{a}$ & & $(-1.69)^{c}$ \\
\hline Psudo R ${ }^{2}$ & .333 & .338 & .265 & .272 \\
\hline
\end{tabular}


Table 15: CF Sensitivity, Keiretsu Division, 1980s

Table presents results on the standard cash flow equation using OLS, firm fixed-effects, and Arellano-Bond GMM estimation. The dependent variable is $I / K$. CONST is the target investment rate, $Q$ is the coefficient on Tobin's $Q$ and is the inverse of the adjustment cost parameter, $Q^{n f}$ is the coefficient on the non-fundamental portion of $Q, L A G I K$ is the coeffiparameter, $Q$ is the coefficient on the non-fundamental portion of $Q, L A G I K$ is the coefficient on lagged $I / K, P R A T$ is the coefficient on the price ratio, and $C F$ is the coefficient on cash flow. Industry and time dummies are included in the OLS regression, and time dummies in the fixed-effects and GMM regressions. The $t$ statistics (OLS, FE) and $z$ statistics (GMM) are in parentheses, and are calculated with heteroskedasticity conce at the $.01, .05$, and .1 levels of significance, respectively. The $p$-values of the Sargan and the $M$ test (for second order serial correlation) are presented for the GMM regression. The sample period is $1980-90$

\begin{tabular}{|c|c|c|c|}
\hline \multicolumn{4}{|l|}{ OLS } \\
\hline Parameters & Independent & Bank Group & Ind.-Grp. Diff. \\
\hline \multirow[t]{2}{*}{$C O N S T$} & .0925 & .0842 & \\
\hline & $(2.53)^{a}$ & $(2.37)^{a}$ & \\
\hline \multirow[t]{2}{*}{$Q$} & -.0002 & .0008 & \\
\hline & $(-.41)$ & $(1.28)$ & \\
\hline \multirow[t]{2}{*}{$P R A T$} & -.0204 & -.0273 & \\
\hline & $(-1.07)$ & $(-1.49)$ & \\
\hline \multirow[t]{2}{*}{$C F$} & .2091 & .2185 & -.009 \\
\hline & $(10.26)^{a}$ & $(10.69)^{a}$ & $(-.33)$ \\
\hline$R^{2}$ & .192 & .246 & \\
\hline \multicolumn{4}{|c|}{ Fixed Effects } \\
\hline Parameters & Independent & Bank Group & Ind.-Grp. Diff. \\
\hline \multirow[t]{2}{*}{$C O N S T$} & .1325 & .1263 & \\
\hline & $(3.97)^{a}$ & $(4.31)^{a}$ & \\
\hline \multirow[t]{2}{*}{$Q$} & .0014 & .0034 & \\
\hline & $(2.81)^{a}$ & $(5.32)^{a}$ & \\
\hline \multirow[t]{2}{*}{$P R A T$} & -.0445 & -.0542 & \\
\hline & $(-2.05)^{b}$ & $(-2.75)^{a}$ & \\
\hline \multirow[t]{2}{*}{$C F$} & .2162 & .2031 & .013 \\
\hline & $(15.01)^{a}$ & $(12.06)^{a}$ & $(.593)$ \\
\hline$R^{2}$ Within & .135 & .173 & \\
\hline$R^{2}$ Between & .316 & .334 & \\
\hline$R^{2} A l l$ & .175 & .207 & \\
\hline \multicolumn{4}{|c|}{ First Differenced GMM } \\
\hline Parameters & Independent & Bank Group & Ind.-Grp. Diff. \\
\hline \multirow[t]{2}{*}{$L A G I K$} & .0268 & .0404 & \\
\hline & $(.85)$ & $(.98)$ & \\
\hline \multirow[t]{2}{*}{$Q$} & .0102 & .0023 & \\
\hline & $(3.47)^{a}$ & $(.9)$ & \\
\hline \multirow[t]{2}{*}{$Q^{n f}$} & .0009 & .0028 & \\
\hline & $(.54)$ & $(1.62)$ & \\
\hline \multirow[t]{2}{*}{$C F$} & .2752 & .3069 & -.032 \\
\hline & $(4.68)^{a}$ & $(4.51)^{a}$ & \\
\hline \multirow[t]{2}{*}{$P R A T$} & .0005 & -.1856 & \\
\hline & $(.01)$ & $(-3.63)^{a}$ & \\
\hline \multirow{2}{*}{$\begin{array}{l}\text { Sargon Test } \\
M \text { Test }\end{array}$} & .098 & .369 & \\
\hline & .882 & .889 & \\
\hline
\end{tabular}




\section{Table 16: CF Sensitivity, Keiretsu X Bond Elig. Division, 1980s}

Table presents results on the standard cash flow equation using OLS, firm fixed-effects, and Arellano-Bond GMM estimation. The dependent variable is $I / K . C O N S T$ is the target investment rate, $Q$ is the coefficient on $Q$ and is the inverse of the adjustment cost parameter, $Q^{n f}$ is the coefficient on the non-fundamental portion of $Q, L A G I K$ is the coefficient on lagged $I / K, P R A T$ is the coefficient on the price ratio, and $C F$ is the coefficient on cash flow. Industry and time dummies are included in the OLS regression, and time dummies in the fixed-effects and GMM is the coefficient on cash flow. Industry and time dummies are included in the OLS regression, and time dummies in the fixed-effects and GMM
regressions. The $t$ statistics (OLS, FE) and $z$ statistics (GMM) are in parentheses, and are calculated with heteroskedasticity consistent standard regressions. The $t$ statistics (OLS, FE) and $z$ statistics (GMM) are in parentheses, and are calculated with heteroskedasticity consistent standard errors (for OLS and GMM). The superscripts $a, b$, and $c$ denote significance at the $.01, .05$, and . .1 levels of significance, respectively. The
$p$-values of the Sargan and the $M$ test (for second order serial correlation) are presented for the GMM regression. The sample period is $1980-90$.

\begin{tabular}{|c|c|c|c|c|c|c|c|c|}
\hline OLS & \multicolumn{3}{|c|}{ Independent } & \multicolumn{3}{|c|}{ Bank Group } & \multicolumn{2}{|c|}{ Difference } \\
\hline Parameters & Restricted & Semi-Res. & Unrestricted & Restricted & Semi-Res. & Unrestricted & $I R-G R$ & $I U-G U$ \\
\hline$C O N S T$ & .0525 & .2197 & .0693 & .1184 & .0131 & .0685 & & \\
\hline & $(.86)$ & $(2.36)^{b}$ & (1.35) & $(1.83)^{c}$ & $(.17)$ & $(1.45)$ & & \\
\hline$Q$ & -.0004 & .001 & -.0008 & -.0002 & .0034 & -.0006 & & \\
\hline & $(-.48)$ & $(.88)$ & $(-1.41)$ & $(-.15)$ & $(2.17)^{b}$ & $(-.66)$ & & \\
\hline$P R A T$ & .0024 & -.0942 & -.0048 & -.0384 & .0102 & -.0312 & & \\
\hline & $(.08)$ & $(-1.95)^{c}$ & $(-.18)$ & $(-1.08)$ & $(.26)$ & $(-1.26)$ & & \\
\hline$C F$ & .1781 & .1704 & .211 & .0932 & .1892 & .31 & .0849 & -.099 \\
\hline & $(4.82)^{a}$ & $(2.74)^{a}$ & $(10.51)^{a}$ & $(2.83)^{a}$ & $(3.24)^{a}$ & $(11.19)^{a}$ & $(1.72)^{c}$ & $(-2.89)^{a}$ \\
\hline$R^{2}$ & .185 & .184 & .19 & .171 & .202 & .297 & & \\
\hline
\end{tabular}

\begin{tabular}{|c|c|c|c|c|c|c|c|c|}
\hline Fixed Effects & \multicolumn{3}{|c|}{ Independent } & \multicolumn{3}{|c|}{ Bank Group } & \multicolumn{2}{|c|}{ Difference } \\
\hline Parameters & Restricted & Semi-Res. & Unrestricted & Restricted & Semi-Res. & Unrestricted & $I R-G R$ & $I U-G U$ \\
\hline$C O N S T$ & .122 & .2709 & .0488 & .1552 & .0751 & .0203 & & \\
\hline & $(1.68)^{c}$ & $(4.05)^{a}$ & $(1.08)$ & $(2.51)^{b}$ & (1.17) & $(.53)$ & & \\
\hline$Q$ & -.0012 & .003 & .0008 & .0026 & .0034 & .0019 & & \\
\hline & $(-1.04)$ & $(2.57)^{a}$ & $(1.26)$ & $(2.11)^{b}$ & $(2.12)^{b}$ & $(2.36)^{b}$ & & \\
\hline PRAT & -.0374 & -.1309 & -.01 & -.0622 & -.022 & -.0295 & & \\
\hline & $(-.8)$ & $(-2.86)^{a}$ & $(-.35)$ & $(-1.49)$ & $(-.53)$ & $(-1.16)$ & & \\
\hline$C F$ & .1528 & .1111 & .327 & .0605 & .1897 & .4913 & .0923 & -.1643 \\
\hline & $(5.42)^{a}$ & $(4.28)^{a}$ & $(14.88)^{a}$ & $(2.78)^{a}$ & $(4.29)^{a}$ & $(16.15)^{a}$ & $(2.59)^{a}$ & $(-4.38)^{a}$ \\
\hline$R^{2}$ Within & .137 & .107 & .206 & .108 & .157 & .323 & & \\
\hline$R^{2}$ Between & .228 & .192 & .178 & .015 & .307 & .314 & & \\
\hline$R^{2} A l l$ & .15 & .123 & .159 & .078 & .185 & .26 & & \\
\hline
\end{tabular}

\begin{tabular}{|c|c|c|c|c|c|c|c|c|}
\hline GMM & \multicolumn{3}{|c|}{ Independent } & \multicolumn{3}{|c|}{ Bank Group } & \multicolumn{2}{|c|}{ Difference } \\
\hline Parameters & Restricted & Semi-Res. & Unrestricted & Restricted & Semi-Res. & Unrestricted & $I R-G R$ & $I U-G U$ \\
\hline$L A G I K$ & .0643 & -.1185 & .0316 & -.0065 & .0301 & -.0168 & & \\
\hline & $(.86)$ & $(-1.74)^{c}$ & $(.87)$ & $(-.09)$ & $(.34)$ & $(-.47)$ & & \\
\hline$Q$ & .0115 & .0103 & .0108 & .0067 & .0094 & .0014 & & \\
\hline & $(2.35)^{b}$ & $(1.82)^{c}$ & $(3.53)^{a}$ & $(1.57)$ & $(1.65)^{c}$ & $(.51)$ & & \\
\hline$Q^{n f}$ & -.0019 & -.0009 & .0007 & .0024 & -.0002 & .0047 & & \\
\hline & $(-.89)$ & $(-.37)$ & $(.4)$ & $(.98)$ & $(-.06)$ & $(2.58)^{a}$ & & \\
\hline$C F$ & .1792 & .1544 & .3262 & .048 & .3175 & .5285 & .1312 & -.2023 \\
\hline & $(3.03)^{a}$ & $(1.68)^{c}$ & $(4.74)^{a}$ & $(2.02)^{b}$ & $(3.13)^{a}$ & $(7.78)^{a}$ & $(2.06)^{b}$ & $(-2.09)^{b}$ \\
\hline PRAT & .093 & -.2147 & -.0019 & -.1443 & -.0319 & -.1338 & & \\
\hline & $(.91)$ & $(-2.19)^{b}$ & $(-.03)$ & $(-1.54)$ & $(-.44)$ & $(2.19)^{b}$ & & \\
\hline Sargon Test & .915 & .899 & .947 & .97 & .988 & .911 & & \\
\hline$M$ Test & .99 & .373 & .865 & .644 & .968 & .363 & & \\
\hline
\end{tabular}


Table 17: CF Sensitivity (Neg. Obs.), Keiretsu X Bond Elig. Division, 1980s

Table presents results on the standard cash flow equation using OLS, firm fixed-effects, and Arellano-Bond GMM estimation. The dependent variable is $I / K$. CONST is the target investment rate, $Q$ is the coefficient on $Q$ and is the inverse of the adjustment cost parameter, $Q^{n f}$ is the coefficient on the non-fundamental portion of $Q, L A G I K$ is the coefficient on lagged $I / K, P R A T$ is the coefficient on the price ratio, $P O S C F$ is the coefficient on positive, and NEG CF is the coefficient on negative cash flow. Industry and time dummies are included in the OLS regression, and time dummies in the fixed-effects and GMM regressions. The $t$ statistics (OLS, FE) and $z$ statistics (GMM) are in parentheses, and are calculated with heteroskedasticity consistent standard errors (for OLS and GMM). The superscripts $a, b$, and $c$ denote significance at the $.01, .05$, and .1 levels of significance, respectively. The $p-$ values of the Sargan and the $M$ test (for second order serial correlation) are presented for the GMM regression. The sample period is 1980-90.

\begin{tabular}{|l|r|r|r|r|r|r|r|r|}
\hline OLS & \multicolumn{3}{|c|}{ Independent } & \multicolumn{3}{|c|}{ Bank Group } & \multicolumn{2}{|c|}{ Difference } \\
\hline Parameters & Restricted & Semi-Res. & Unrestricted & Restricted & Semi-Res. & Unrestricted & IR-GR & \multicolumn{1}{l|}{ IU-GU } \\
\hline CONST & .0416 & .1501 & .0665 & .0945 & .0142 & .0672 & \\
& $(.68)$ & $(1.7)^{c}$ & $(1.3)$ & $(1.42)$ & $(.18)$ & $(1.42)$ & \\
$Q$ & -.0004 & .0004 & -.0009 & -.0003 & .0033 & -.0006 & \\
& $(-.56)$ & $(.34)$ & $(-1.46)$ & $(-.26)$ & $(2.13)^{b}$ & $(-.65)$ & \\
PRAT & .0048 & -.0647 & -.0035 & -.0281 & .0087 & -.0306 & \\
& $(.16)$ & $(-1.4)$ & $(-.13)$ & $(-.78)$ & $(.22)$ & $(-1.24)$ & .3112 & .08 \\
POS CF & .2121 & .2707 & .213 & .1322 & .1944 & -.098 \\
& $(4.19)^{a}$ & $(5.32)^{a}$ & $(10.45)^{a}$ & $(2.56)^{b}$ & $(3.09)^{a}$ & $(11.12)^{a}$ & $(1.11)$ & $(-2.87)^{a}$ \\
NEG CF & -.0334 & -.038 & -.0698 & -.0192 & .0898 & .0921 & & \\
& $(-.43)$ & $(-2.46)^{b}$ & $(-1.48)$ & $(-.52)$ & $(1.87)^{c}$ & $(1.41)$ & & \\
\hline$R^{2}$ & .191 & .22 & .191 & .178 & .203 & .298 & & \\
\hline
\end{tabular}

\begin{tabular}{|l|r|r|r|r|r|r|r|r|}
\hline Fixed Effects & \multicolumn{3}{|c|}{ Independent } & \multicolumn{3}{|c|}{ Bank Group } & \multicolumn{2}{c|}{ Difference } \\
\hline Parameters & Restricted & Semi-Res. & Unrestricted & Restricted & Semi-Res. & Unrestricted & \multicolumn{1}{c|}{ IR-GR } & IU-GU \\
\hline CONST & .1108 & .2161 & .0417 & .1451 & .0792 & .0133 & & \\
& $(1.53)$ & $(3.21)^{a}$ & $(.92)$ & $(2.35)^{b}$ & $(1.23)$ & $(.35)$ & \\
$Q$ & -.001 & .0021 & .0008 & .0025 & .0033 & .002 & \\
& $(-.93)$ & $(1.83)^{c}$ & $(1.19)$ & $(2.01)^{b}$ & $(2.03)^{b}$ & $(2.4)^{b}$ & \\
PRAT & -.0385 & -.1079 & -.0072 & -.0606 & -.028 & -.0268 & \\
& $(-.83)$ & $(-2.37)^{b}$ & $(-.25)$ & $(-1.46)$ & $(-.67)$ & $(-1.06)$ & .103 & -.169 \\
POS CF & .2084 & .208 & .3344 & .1054 & .2129 & .5029 & .103 \\
& $(6.06)^{a}$ & $(5.95)^{a}$ & $(15.1)^{a}$ & $(3.59)^{a}$ & $(4.59)^{a}$ & $(16.27)^{a}$ & $(2.28)^{b}$ & $(-4.43)^{a}$ \\
NEG CF & -.1497 & -.0358 & -.3126 & -.0572 & -.1249 & -.2205 & & \\
& $(-1.34)$ & $(-.81)$ & $(-1.11)$ & $(-1.02)$ & $(-.63)$ & $(-.62)$ & \\
\hline$R^{2}$ Within & .148 & .131 & .209 & .116 & .163 & .326 & & \\
$R^{2}$ Between & .191 & .282 & .173 & .027 & .28 & .314 & \\
$R^{2}$ All & .156 & .168 & .158 & .088 & .183 & .261 & \\
\hline
\end{tabular}

\begin{tabular}{|l|r|r|r|r|r|r|r|r|}
\hline GMM & \multicolumn{3}{|c|}{ Independent } & \multicolumn{3}{|c|}{ Bank Group } & \multicolumn{2}{c|}{ Difference } \\
\hline Parameters & Restricted & Semi-Res. & Unrestricted & Restricted & Semi-Res. & Unrestricted & IR-GR & IU-GU \\
\hline LAGIK & .06 & -.1199 & .0295 & -.0072 & .0351 & -.0191 & \\
& $(.8)$ & $(-1.82)^{c}$ & $(.82)$ & $(-.11)$ & $(.4)$ & $(-.53)$ & \\
$Q$ & .0119 & .0061 & .0108 & .0074 & .0099 & .0019 & \\
& $(2.43)^{b}$ & $(1.24)$ & $(3.49)^{a}$ & $(1.71)^{c}$ & $(1.76)^{c}$ & $(.69)$ & \\
$Q^{n f}$ & -.002 & -.0012 & .0003 & .0028 & .0004 & .0046 & \\
& $(-.94)$ & $(-.47)$ & $(.17)$ & $(1.14)$ & $(.12)$ & $(2.54)^{b}$ & \\
POS CF & .172 & .3009 & .3061 & .185 & .2955 & .5162 & -.013 & \\
& $(2.39)^{b}$ & $(3.01)^{a}$ & $(4.86)^{a}$ & $(2.42)^{a}$ & $(2.86)^{a}$ & $(7.4)^{a}$ & $(-.12)$ & $(-2.24)^{b}$ \\
NEG CF & .0616 & -.0028 & 3.3625 & -.1851 & .129 & 1.3402 & & \\
& $(.313)$ & $(-.05)$ & $(1.06)$ & $(-1.73)^{c}$ & $(.34)$ & $(.76)$ & \\
PRAT & .0919 & -.1773 & -.013 & -.1318 & -.034 & -.1373 & & \\
& $(.91)$ & $(-1.71)^{c}$ & $(-.18)$ & $(-1.43)$ & $(-.47)$ & $(2.25)^{b}$ & \\
\hline Sargon Test & .9 & .886 & .983 & .94 & .867 & .92 & & \\
M Test & .998 & .383 & .935 & .737 & .715 & .061 & \\
\end{tabular}


Table 18: CF Sensitivity by Period, Keiretsu X Bond Elig. Division

Table presents results on the standard cash flow equation using OLS, firm fixed-effects, and Arellano-Bond GMM estimation. The dependent variable is $I / K$. CONST is the target investment rate, $Q$ is the coefficient on $Q$ and is the inverse of the adjustment cost parameter, $Q^{n f}$ is the coefficient on the non-fundamental portion of $Q, L A G I K$ is the coefficient on lagged $I / K, P R A T$ is the coefficient on the price ratio, and $C F$ is the coefficient on cash flow. Industry and time dummies are included in the OLS regression, and time dummies in the fixed-effects and GMM regressions. The $t$ statistics (OLS, FE) and $z$ statistics (GMM) are in parentheses, and are calculated with heteroskedasticity consistent standard errors (for OLS and GMM). The superscripts $a, b$, and $c$ denote significance at the $.01, .05$, and .1 levels of significance, respectively. The $p$-values of the Sargan and the $M$ test (for second order serial correlation) are presented for the GMM regression. The sample period is $1980-96$.

\begin{tabular}{|l|r|r|r|r|r|r|r|r|}
\hline OLS & \multicolumn{3}{|c|}{ Independent } & \multicolumn{3}{c|}{ Bank Group } & \multicolumn{2}{c|}{ Difference } \\
\hline Parameters & Restricted & Semi-Res. & Unrestricted & Restricted & Semi-Res. & Unrestricted & \multicolumn{1}{c|}{ IR-GR } & IU-GU \\
\hline CONST & .1062 & .2022 & .151 & .1448 & .1333 & .1 & \\
& $(2.93)^{a}$ & $(4.55)^{a}$ & $(5.27)^{a}$ & $(2.94)^{a}$ & $(2.52)^{b}$ & $(3.82)^{a}$ & \\
$Q$ & -.001 & 0 & -.0005 & .0007 & .003 & .0001 & \\
& $(-1.3)$ & $(-.04)$ & $(-1.05)$ & $(.84)$ & $(2.2)^{b}$ & $(.18)$ & \\
PRAT & -.0284 & -.0932 & -.0478 & -.043 & -.0475 & -.0458 & \\
& $(-1.51)$ & $(-4.13)^{a}$ & $(-3.17)^{a}$ & $(-1.86)^{c}$ & $(-1.83)^{c}$ & $(-3.5)^{a}$ & .1069 & -.0952 \\
$C F^{80-87}$ & .1921 & .2942 & .2201 & .0852 & .1744 & .3153 & .1069 \\
& $(4.53)^{a}$ & $(5.37)^{a}$ & $(10.22)^{a}$ & $(2.43)^{b}$ & $(3.04)^{a}$ & $(11.45)^{a}$ & $(1.94)^{c}$ & $(-2.72)^{a}$ \\
$C F^{88-90}$ & .1912 & .0837 & .1786 & .1062 & .2128 & .2606 & .085 & -.0820 \\
& $(2.603)^{a}$ & $(1.385)$ & $(5.829)^{a}$ & $(1.376)$ & $(1.852)^{c}$ & $(3.517)^{a}$ & $(.8)$ & $(-.08)$ \\
$C F^{91-93}$ & .1516 & .0884 & .1298 & .0401 & .0739 & .1838 & .1115 & -.0540 \\
& $(2.19)^{b}$ & $(1.35)$ & $(3.93)^{a}$ & $(.78)$ & $(1.16)$ & $(3.15)^{a}$ & $(1.29)$ & $(-.8)$ \\
$C F^{94-96}$ & .0905 & .1654 & .0806 & .1081 & .1543 & .1105 & -.0176 & -.0299 \\
& $(3.35)^{a}$ & $(3.21)^{a}$ & $(3.54)^{a}$ & $(1.79)^{c}$ & $(1.75)^{c}$ & $(2.2)^{b}$ & $(-.27)$ & $(-.54)$ \\
\hline$R^{2}$ & .172 & .193 & .249 & .174 & .167 & .283 & & \\
\hline
\end{tabular}

\begin{tabular}{|c|c|c|c|c|c|c|c|c|}
\hline Fixed Effects & \multicolumn{3}{|c|}{ Independent } & \multicolumn{3}{|c|}{ Bank Group } & \multicolumn{2}{|c|}{ Difference } \\
\hline Parameters & Restricted & Semi-Res. & Unrestricted & Restricted & Semi-Res. & Unrestricted & $I R-G R$ & $I U-G U$ \\
\hline CONST & .1275 & .1935 & .118 & .1388 & .1246 & .0501 & & \\
\hline & $(3.11)^{a}$ & $(4.94)^{a}$ & $(4.6)^{a}$ & $(3.61)^{a}$ & $(2.97)^{a}$ & $(2.1)^{b}$ & & \\
\hline$Q$ & -.0014 & .002 & .0011 & .0028 & .003 & .002 & & \\
\hline & $(-1.52)$ & $(2.11)^{b}$ & $(2.12)^{b}$ & $(2.69)^{a}$ & $(2.05)^{b}$ & $(2.9)^{a}$ & & \\
\hline$P R A T$ & -.043 & -.0986 & -.0448 & -.0503 & -.054 & -.0346 & & \\
\hline & $(-1.71)^{c}$ & $(-3.97)^{a}$ & $(-2.92)^{a}$ & $(-2.01)^{b}$ & $(-2.21)^{b}$ & $(-2.44)^{b}$ & & \\
\hline$C F^{80-87}$ & .1718 & .2481 & .2809 & .0537 & .1816 & .4101 & .1181 & -.1292 \\
\hline & $(5.2)^{a}$ & $(7.14)^{a}$ & $(14.61)^{a}$ & $(2.01)^{b}$ & $(3.88)^{a}$ & $(15.54)^{a}$ & $(2.78)^{a}$ & $(-3.96)^{a}$ \\
\hline$C F^{88-90}$ & .2073 & .074 & .2254 & .0937 & .2307 & .3749 & .1136 & -.1495 \\
\hline & $(4.57)^{a}$ & $(2.37)^{b}$ & $(9.58)^{a}$ & $(2.15)^{b}$ & $(3.59)^{a}$ & $(8.96)^{a}$ & $(1.8)^{c}$ & $(-3.12)^{a}$ \\
\hline$C F^{91-93}$ & .1719 & .0901 & .1889 & .0129 & .0748 & .2437 & .1590 & -.0548 \\
\hline & $(3.36)^{a}$ & $(3.43)^{a}$ & $(6.94)^{a}$ & $(.3)$ & $(1.41)$ & $(5.84)^{a}$ & $(2.38)^{b}$ & $(-1.1)$ \\
\hline$C F^{94-96}$ & .0718 & .1514 & .1198 & .0982 & .1658 & .1739 & -.0264 & -.0541 \\
\hline & $(1.51)$ & $(2.81)^{a}$ & $(5.36)^{a}$ & $(2.61)^{a}$ & $(2.42)^{b}$ & $(5.01)^{a}$ & $(-.43)$ & $(-1.31)$ \\
\hline$R^{2}$ Within & .159 & .174 & .264 & .145 & .154 & .306 & & \\
\hline$R^{2}$ Between & .147 & .152 & .195 & .006 & .209 & .232 & & \\
\hline$R^{2}$ All & .157 & .164 & .23 & .119 & .153 & .255 & & \\
\hline
\end{tabular}

\begin{tabular}{|c|c|c|c|c|c|c|c|c|}
\hline GMM & \multicolumn{3}{|c|}{ Independent } & \multicolumn{3}{|c|}{ Bank Group } & \multicolumn{2}{|c|}{ Difference } \\
\hline Parameters & Restricted & Semi-Res. & Unrestricted & Restricted & Semi-Res. & Unrestricted & $I R-G R$ & $I U-G U$ \\
\hline$L A G I K$ & .022 & .0311 & .0572 & .0259 & .0475 & .062 & & \\
\hline & $(.44)$ & $(.68)$ & $(2.1)^{b}$ & $(.73)$ & $(.98)$ & $(2.23)^{b}$ & & \\
\hline$Q$ & .0069 & .0062 & .0061 & .0076 & .0115 & .0046 & & \\
\hline & $(1.69)^{c}$ & $(2.49)^{b}$ & $(3.28)^{a}$ & $(2.39)^{b}$ & $(2.86)^{a}$ & $(2.06)^{b}$ & & \\
\hline$Q^{n f}$ & -.0025 & -.0013 & -.0003 & .0043 & .0022 & .0018 & & \\
\hline$C F^{80-87}$ & $\begin{array}{r}(-1.62) \\
2622\end{array}$ & $\begin{array}{r}(-.83) \\
2395\end{array}$ & $\begin{array}{r}(-.24) \\
2712\end{array}$ & $\begin{array}{r}(3.15)^{a} \\
084\end{array}$ & $\begin{array}{l}(.86) \\
3214\end{array}$ & $\begin{array}{r}(1.58) \\
4003\end{array}$ & 1782 & -1291 \\
\hline & $(4.03)^{a}$ & $(2.69)^{a}$ & $(5.75)^{a}$ & $(1.65)^{c}$ & $(3.64)^{a}$ & $(7.57)^{a}$ & $(2.16)^{b}$ & $(-1.82)^{c}$ \\
\hline$C F^{88-90}$ & .2897 & 1094 & .2387 & .1146 & .2753 & .3704 & .1751 & -.1317 \\
\hline & $(3.62)^{a}$ & (1.11) & $(4.06)^{a}$ & $(1.44)$ & $(3.45)^{a}$ & $(4.73)^{a}$ & $(1.55)$ & $(-1.35)$ \\
\hline$C F^{91-93}$ & .1879 & .1003 & .1961 & .101 & .0203 & .2277 & .0869 & -.0316 \\
\hline & $(2.45)^{b}$ & (1.5) & $(4.59)^{a}$ & $(1.81)^{c}$ & $(.35)$ & $(2.18)^{b}$ & $(.91)$ & $(-.28)$ \\
\hline$C F^{94-96}$ & .0854 & .1735 & .1691 & .0642 & .1514 & .1979 & .0212 & -.0288 \\
\hline & $(1.98)^{b}$ & $(2.66)^{a}$ & $(2.98)^{a}$ & $(.89)$ & $(1.69)^{c}$ & $(2.37)^{b}$ & $(.25)$ & $(-.29)$ \\
\hline$P R A T$ & $\begin{array}{l}-.0292 \\
(-.57)\end{array}$ & $\begin{array}{r}-.1342 \\
(-2.95)^{a}\end{array}$ & $\begin{array}{r}-.0993 \\
(-3.12)^{a}\end{array}$ & $\begin{array}{r}-.0978 \\
(-2.64)^{a}\end{array}$ & $\begin{array}{l}-.0329 \\
(-.82)\end{array}$ & $\begin{array}{r}-.0374 \\
(-1.56)\end{array}$ & & \\
\hline Sargon Test & .918 & .87 & .84 & .95 & .93 & .901 & & \\
\hline$M$ Test & .659 & .638 & .347 & .739 & .918 & .618 & & \\
\hline
\end{tabular}


Figure 1: Distribution of Net Real $I / K$

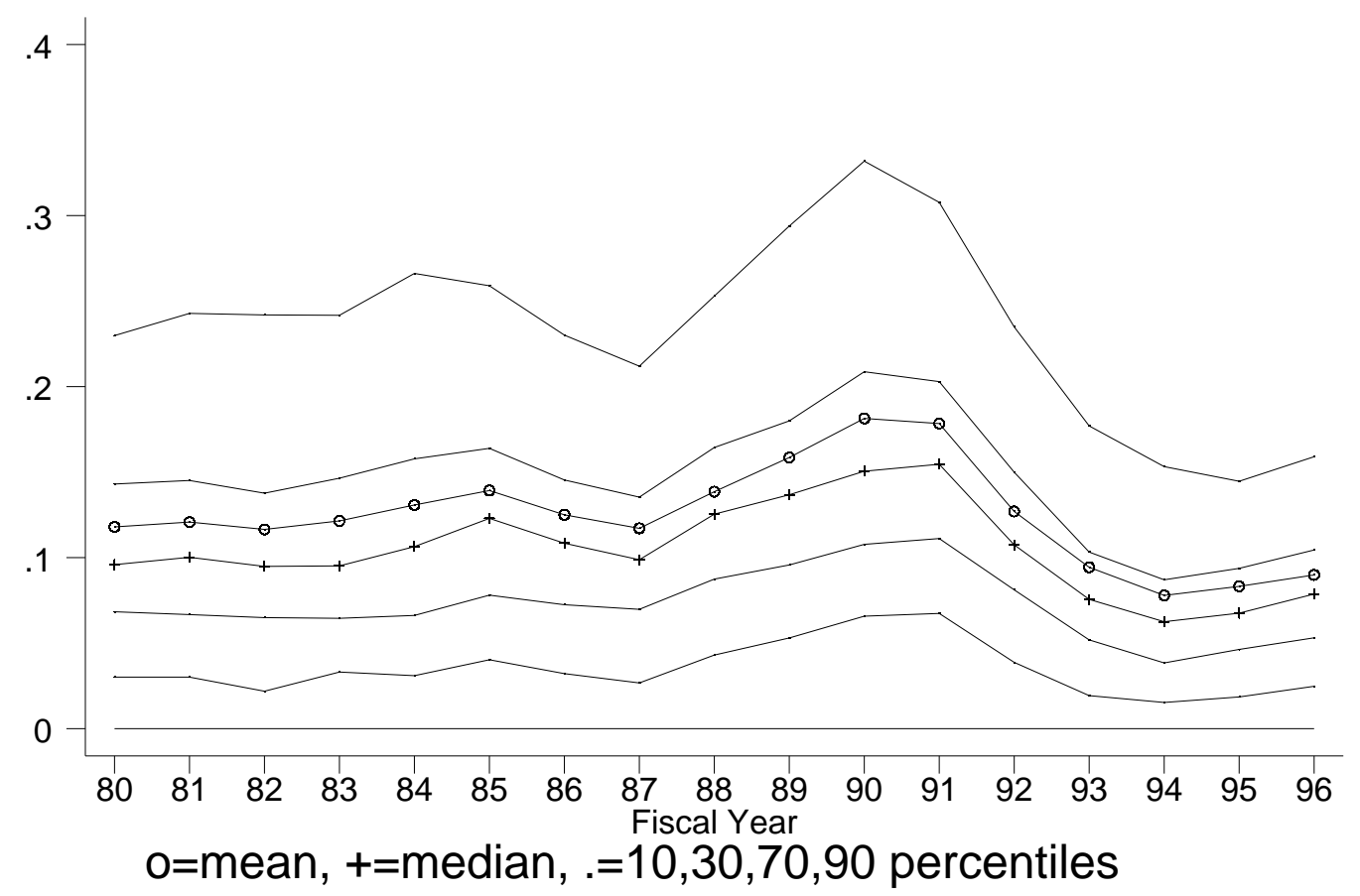

Figure 2: Distribution of Tobin's Average $Q$

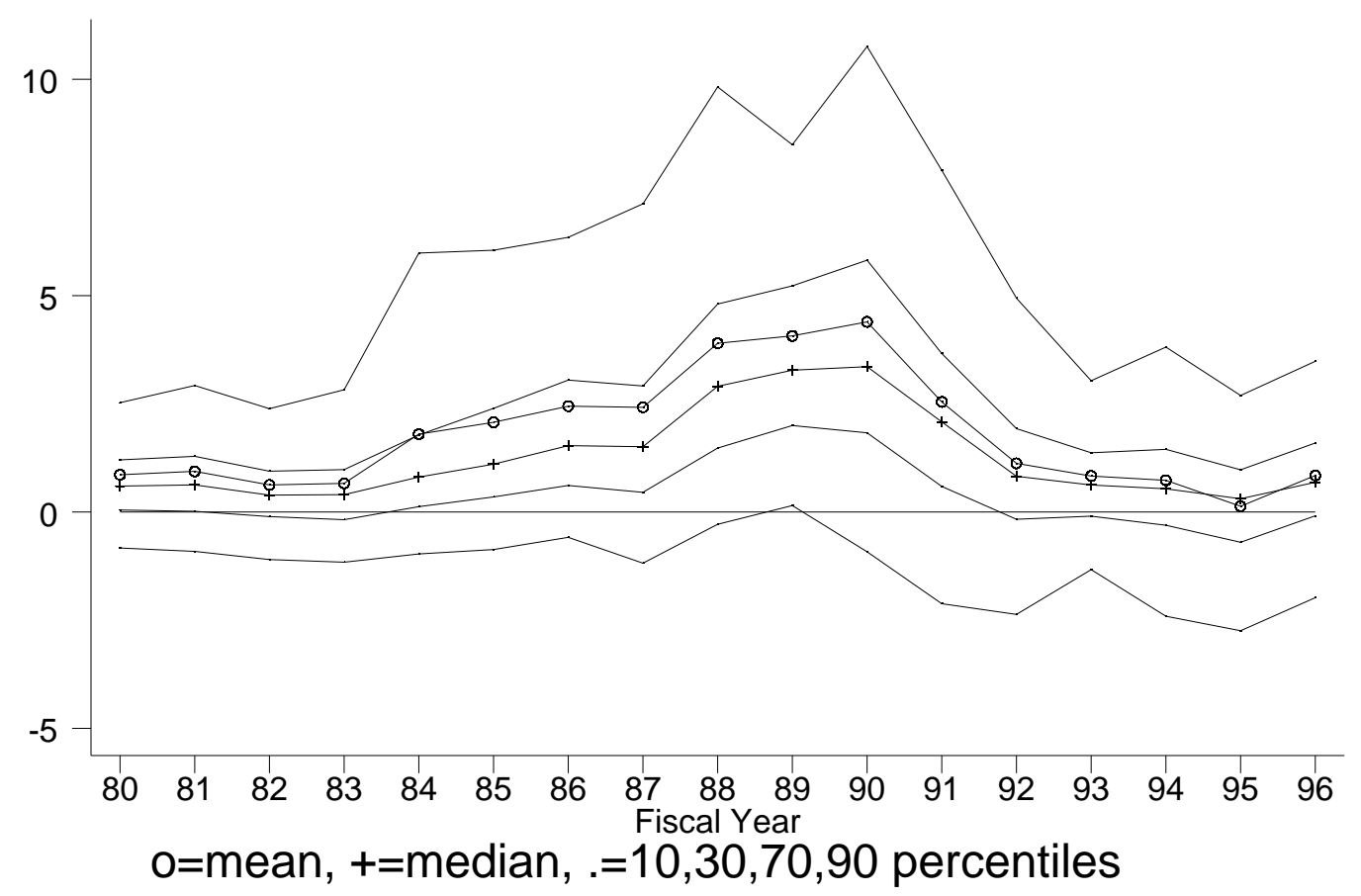


Figure 3: Distribution of Total Loan Growth From Domestic Banks

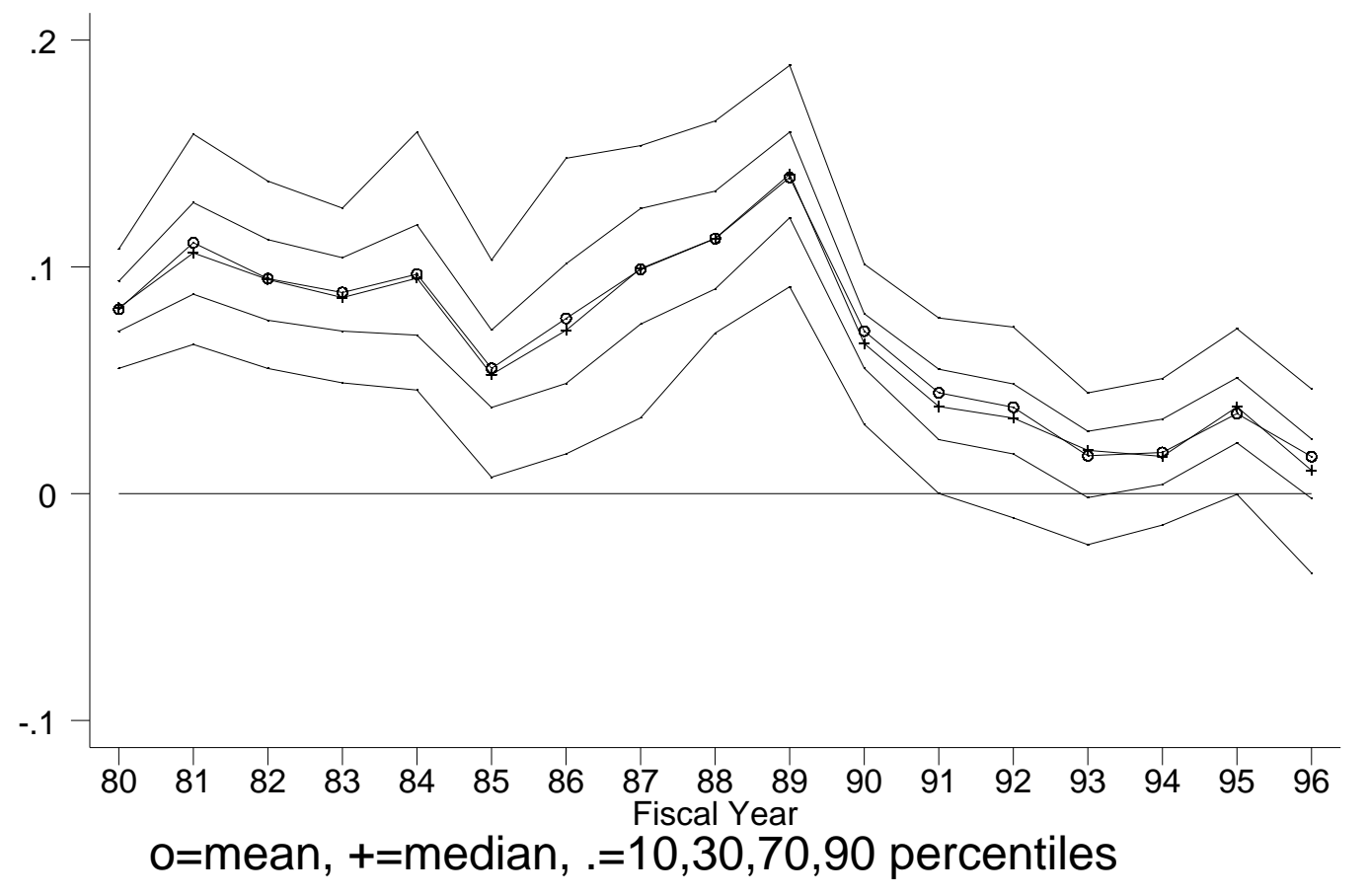


Figure 4: Mean Outstanding Bonds/TL

Figure displays the mean outstanding bonds divided by total liabilities for $\mathrm{R}, \mathrm{S}$, and $\mathrm{U}$ firm groups.

Restricted

Semi Restricted

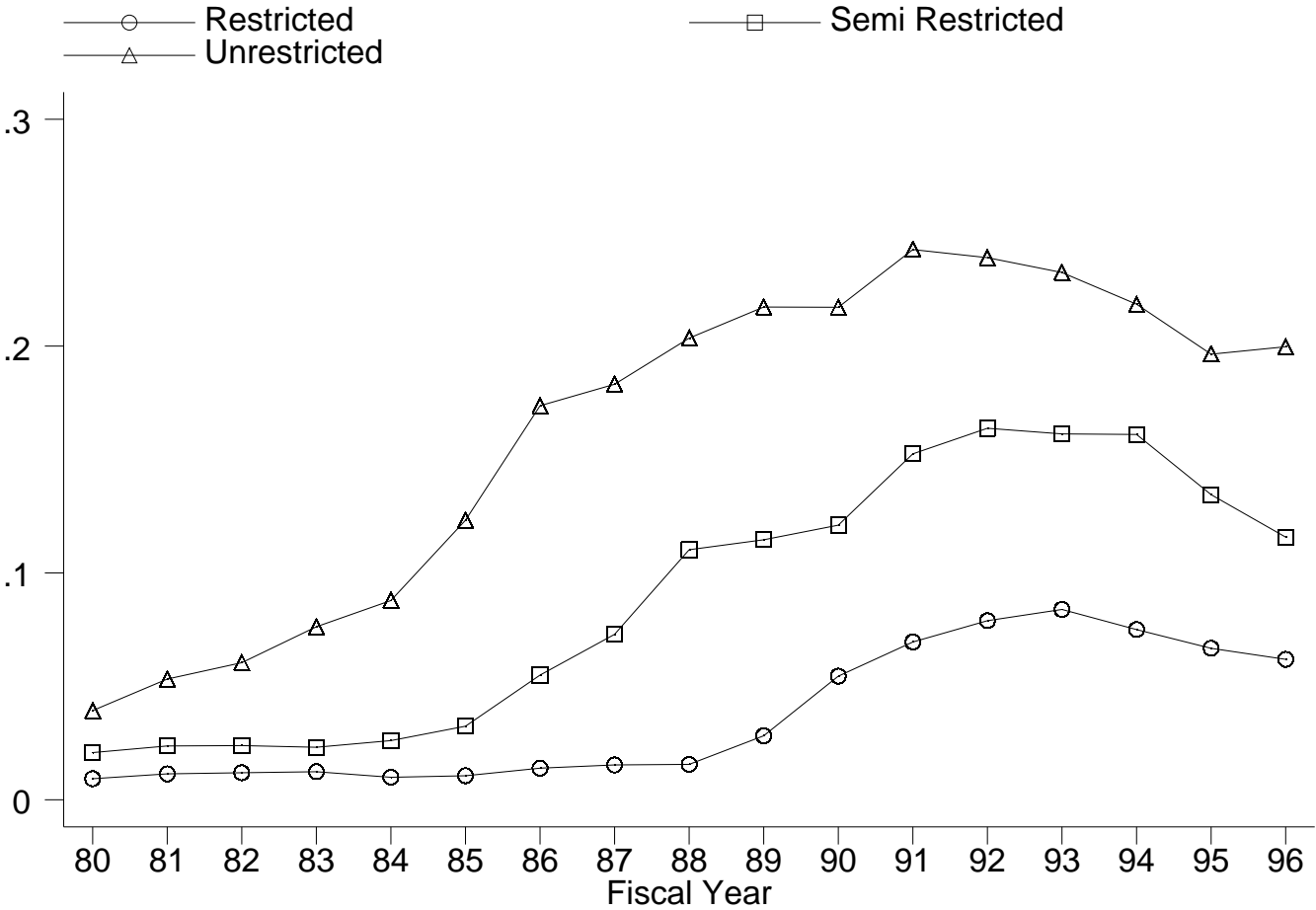

Figure 5: Mean Bank Debt/TL

Figure displays the mean total bank debt divided by total liabilities for $\mathrm{R}, \mathrm{S}$, and $\mathrm{U}$ firm groups.

Restricted

Semi Restricted

Unrestricted
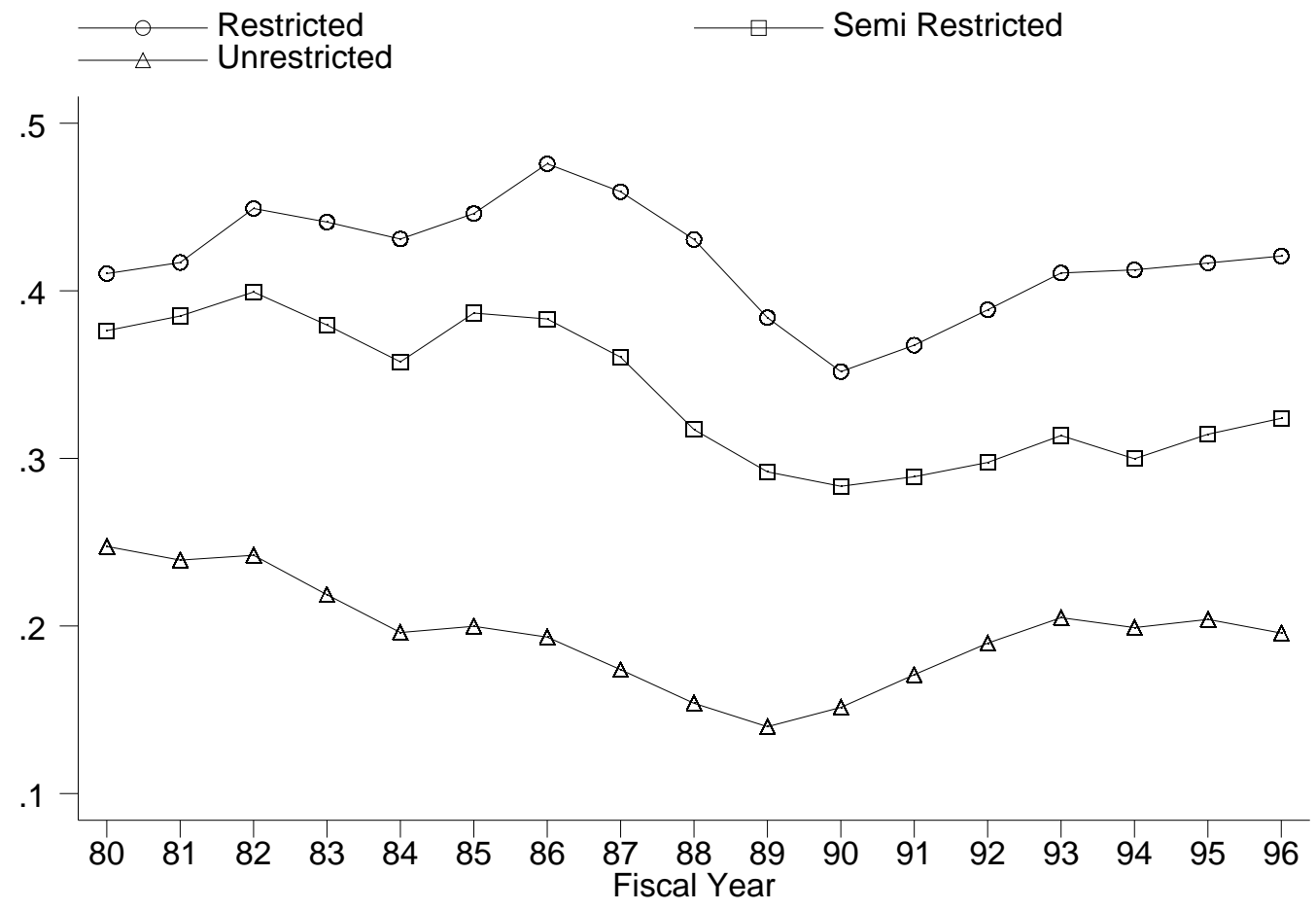
Figure 6: Mean Total Assets (Y10,000)

Figure displays the mean total assets (in Y10,000) for IR, IU, GR, and GU firm groups. Industry means are subtracted off to control for possible composition effects.

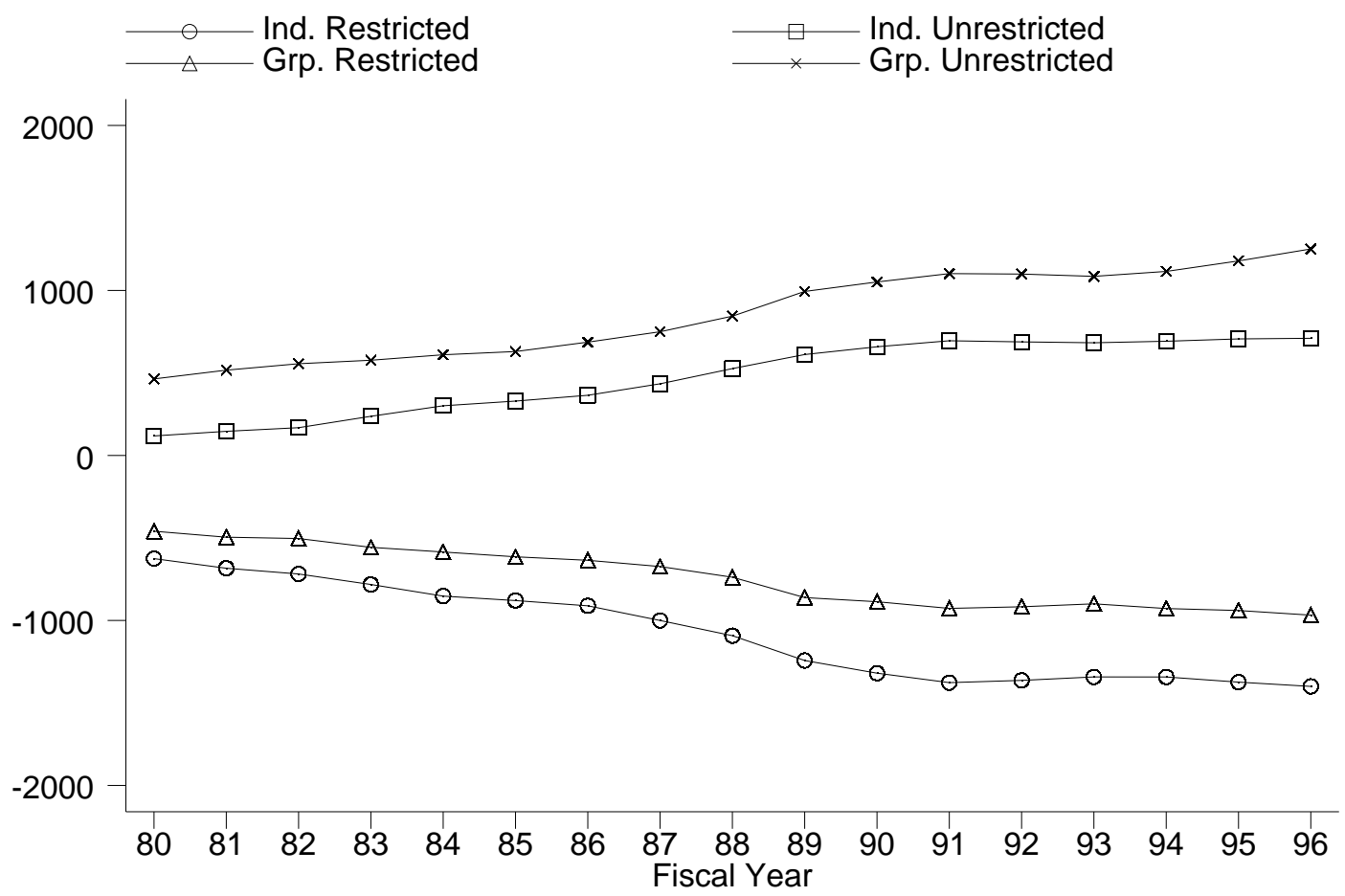

Figure 7: Mean Earnings per Share

Figure displays the mean earnings per share for IR, IU, GR, and GU firm groups. Industry means are subtracted off to control for possible composition effects.

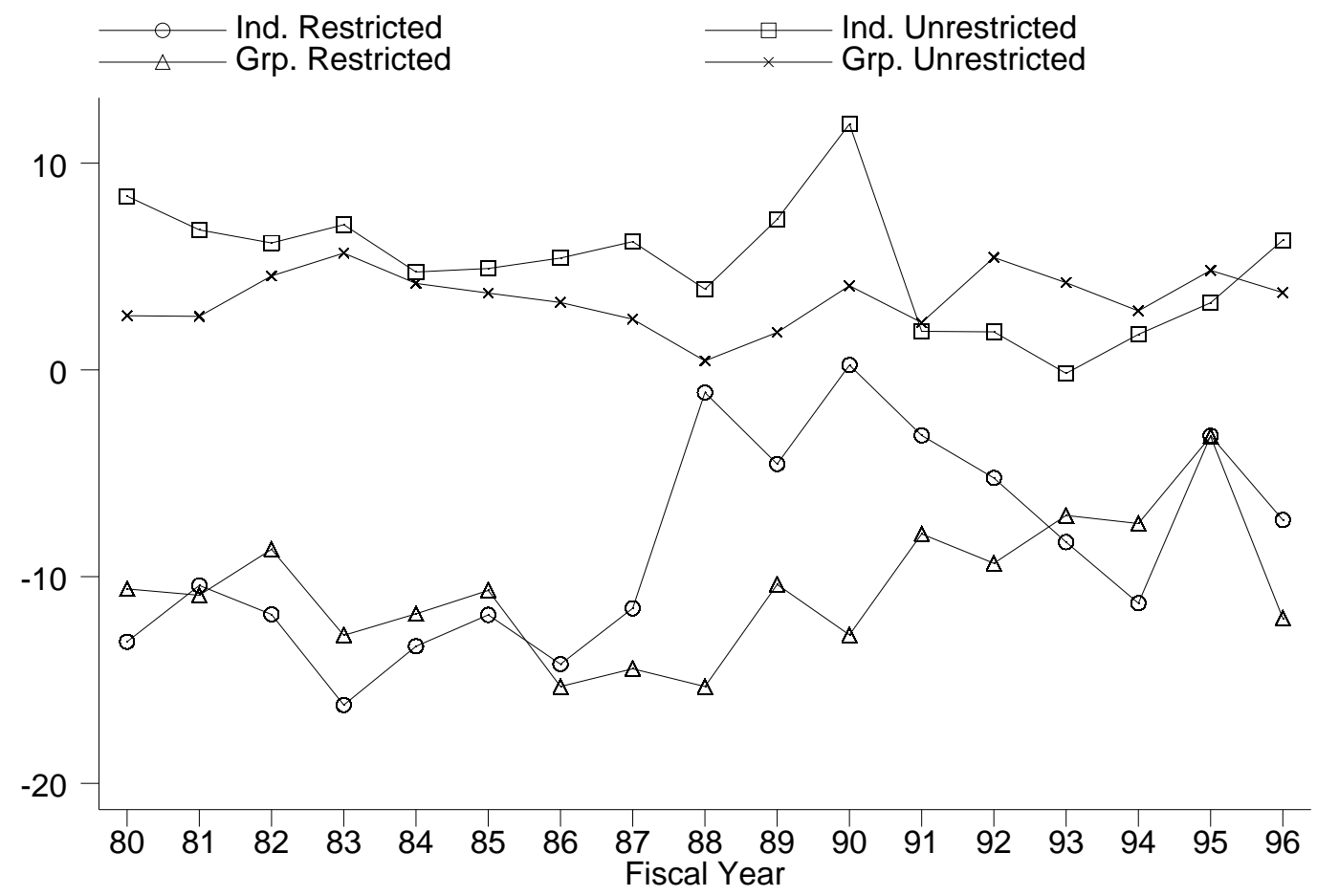


Figure 8: Mean Before-Tax Profits/TA

Figure displays the mean before tax profits divided by total assets for IR, IU, GR, and GU firm groups. Industry means are subtracted off to control for possible composition effects.

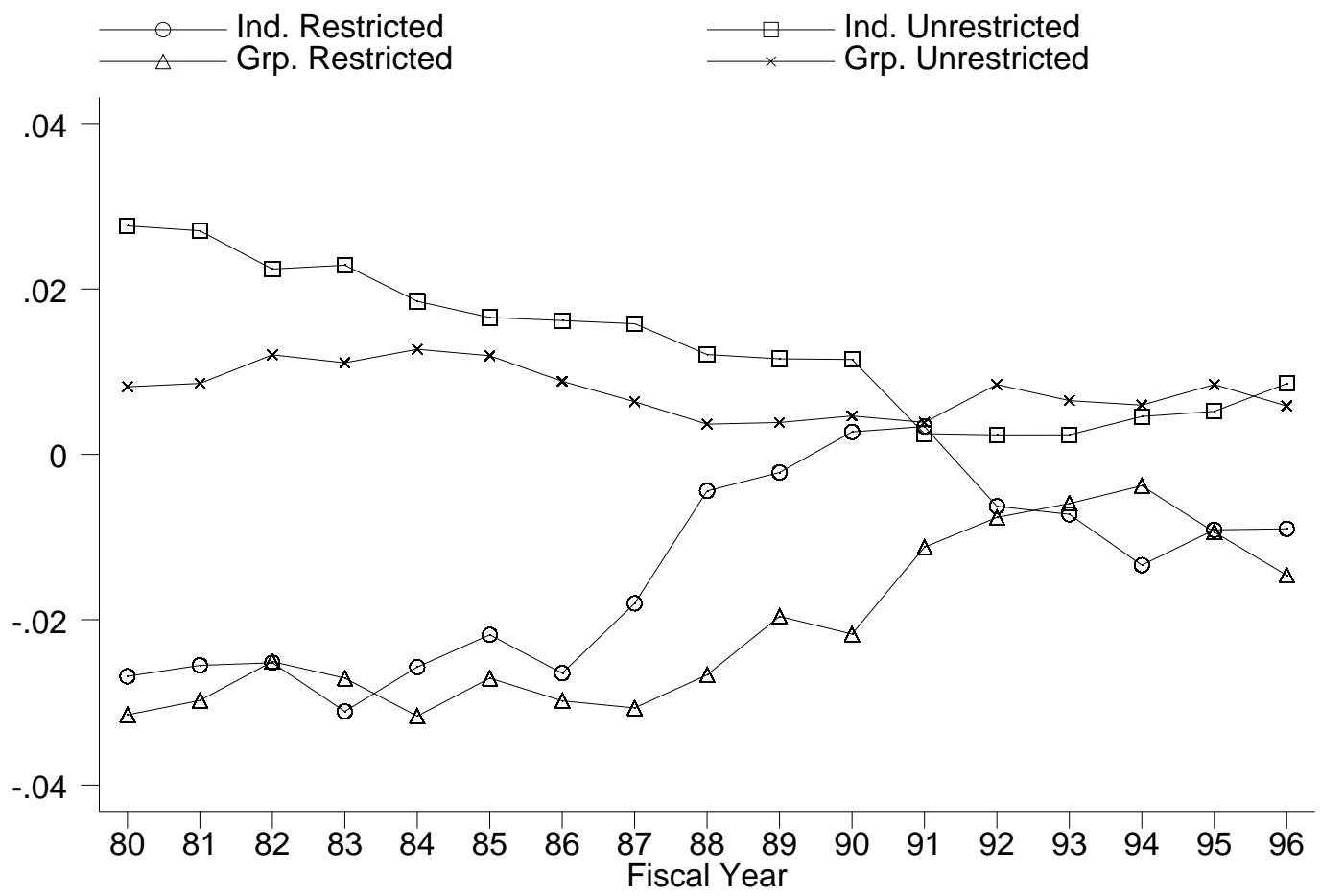

Figure 9: Mean Value Added/TA

Figure displays the mean value added for IR, IU, GR, and GU firm groups. Industry means are subtracted off to control for possible composition effects. Value added is calculated according to the method laid out in Keiei Bunseki Handbook (1987).

Ind. Restricted

Grp. Restricted

$\square$ Ind. Unrestricted

Grp. Unrestricted

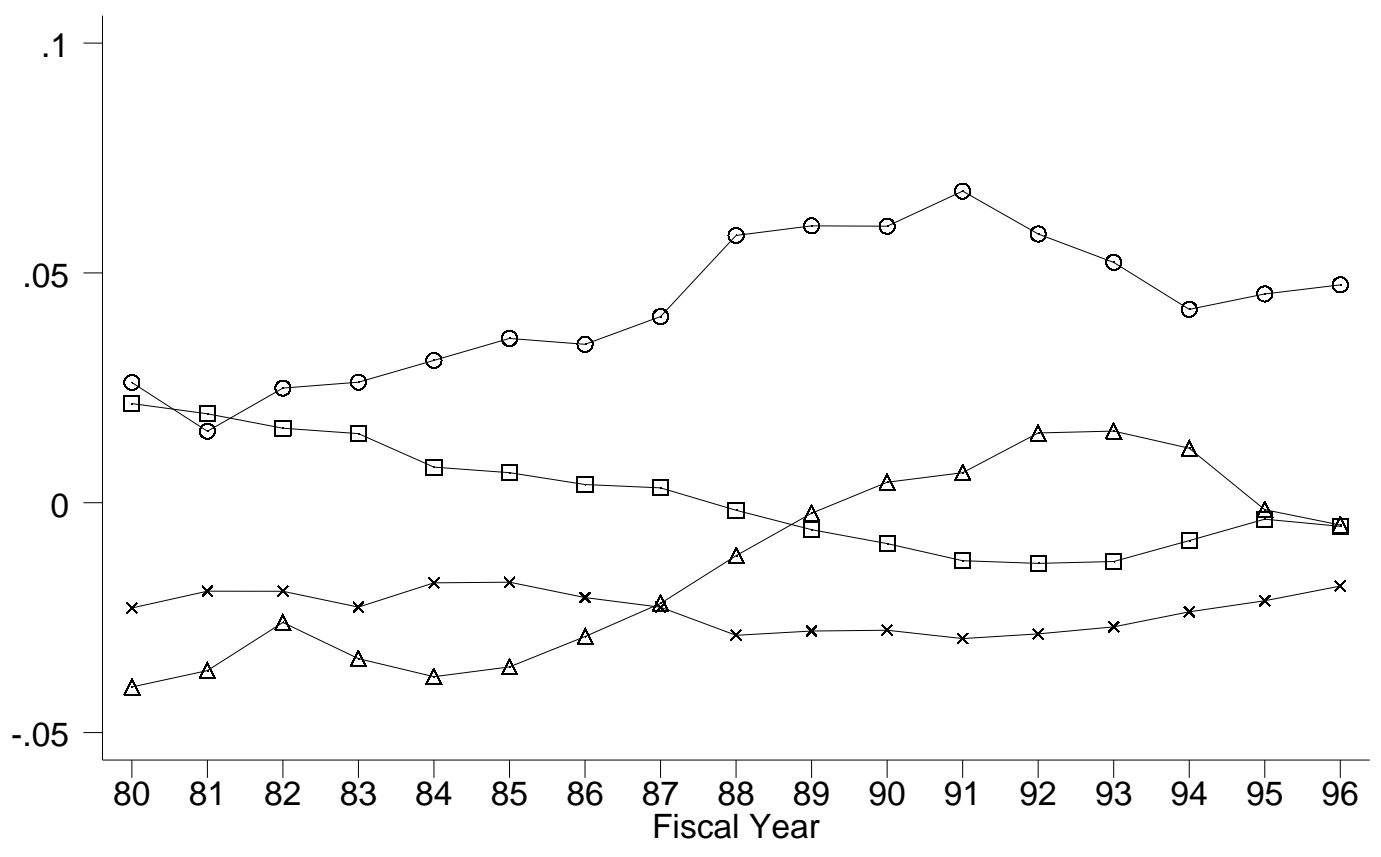


Figure 10: Year-by-Year Coefficients on CF1 (no land)

Figure displays the year-by-year coefficients on CF1 in OLS regressions of $I / K$ on $P R A T$, price adjusted $Q$ and $Q$ squared, a dummy for bond issues, cash flow defined as $C F 1$, and a full set of industry dummies. Investment does not include land and the numerator of $Q$ is adjusted to reflect this.

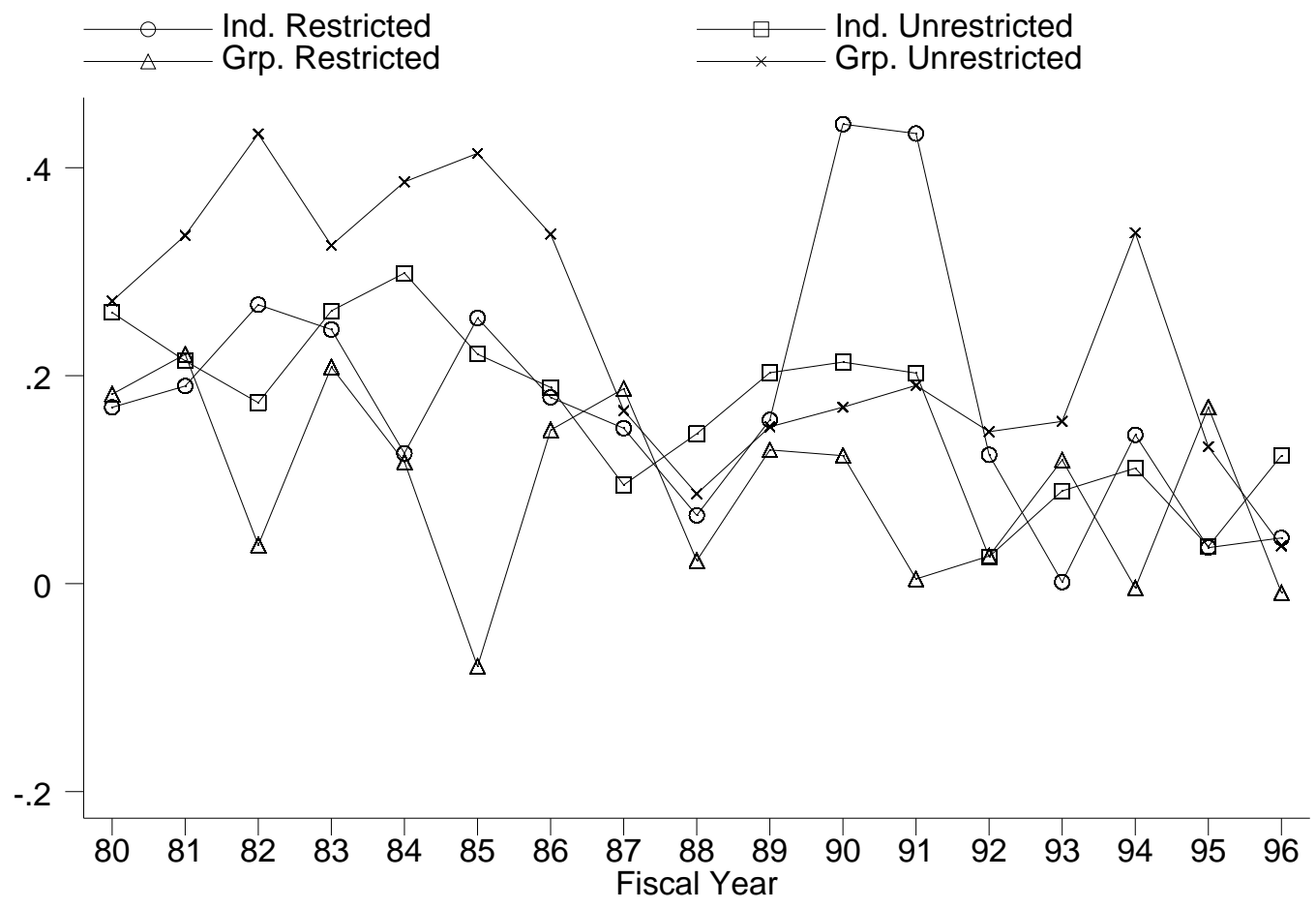

Figure 11: Year-by-Year Coefficients on CF1 (land)

Figure displays the year-by-year coefficients on CF1 in OLS regressions of $I / K$ on $P R A T$, price adjusted $Q$ and $Q$ squared, a dummy for bond issues, cash flow defined as $C F 1$, and a full set of industry dummies. The investment rate includes the market value of land.

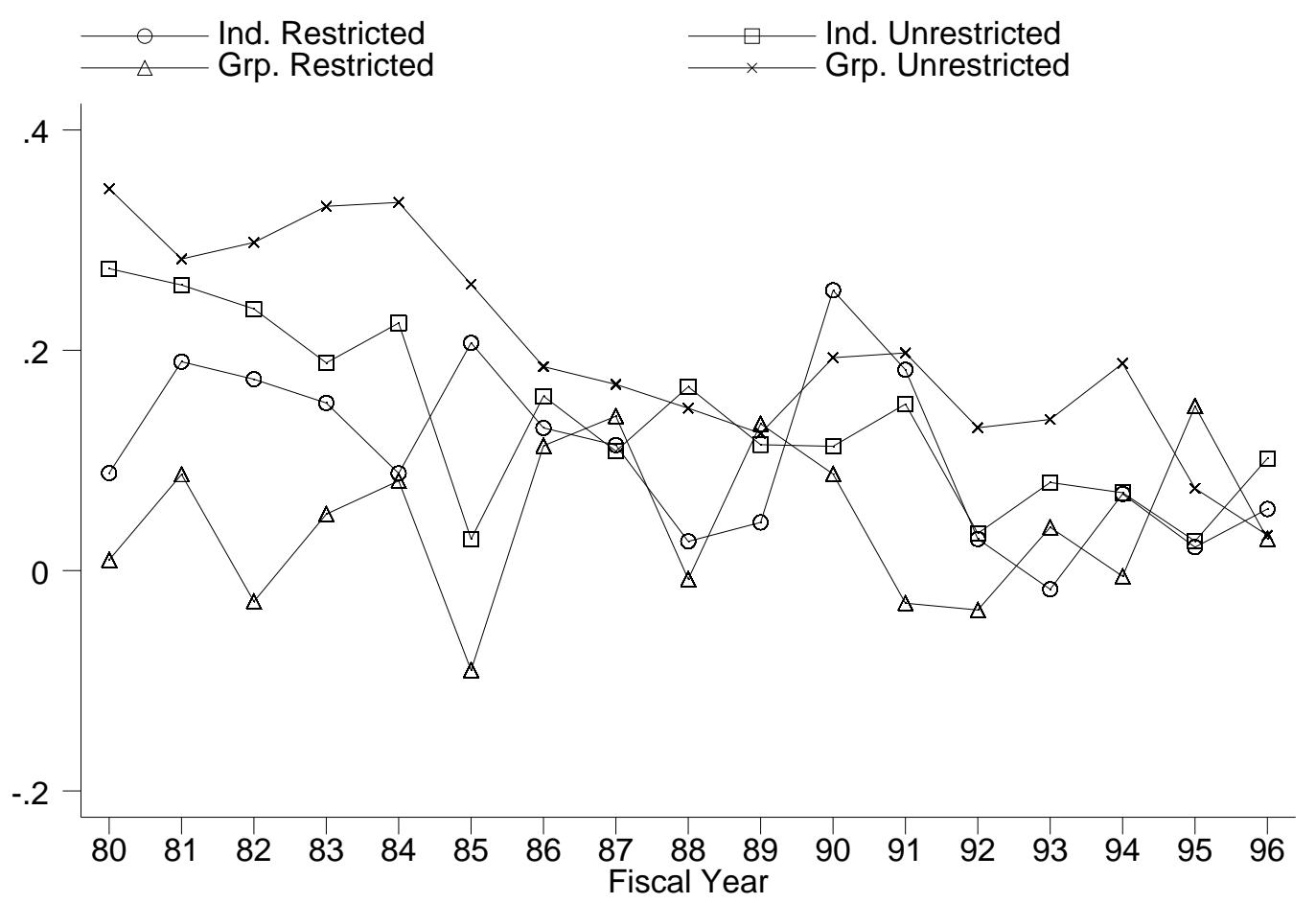




\section{References}

(1987): Keiei Bunseki HandobukkuNihon Shoken Keizai Kenkyujo-hen: Nihon Keizai Shinbunsha, Tokyo, Japan.

Abel, A., And J. Eberly (1996): "Investment and q with Fixed Costs: An Empirical Analysis," Working Paper: presented at NBER Economic Fluctuations Research Meeting.

Allayannis, G., And A. Mozumdar (2001): "The Investment-Cash Flow Sensitivity Puzzle: Can Negative Cash Flow Observations Explain It?," Virginia Tech Working Paper $98-5$.

Anderson, C. W., And A. K. Makhija (1999): "Deregulation, disintermediation, and the agency costs of debt: Evidence from Japan," Journal of Financial Economics, 51, 309-339.

Aoki, M. (1994): "Monitoring Characteristics of the Main Bank System: An Analytical and Developmental View," in The Japanese Main Bank System: Its Relevance for Developing and Transforming Economies, ed. by M. Aoki, and H. Patrick, pp. 109-141. Oxford University Press, Oxford.

Arellano, M., and S. Bond (1991): "Some tests of specification for panel data: Monte Carlo evidence and an application to employment equations," The Review of Economic Studies, 58, 277-297.

Beason, D. (1998): "Keiretsu affilitation and share price volatility in Japan," Pacific-Basin Finance Journal, 6, 27-43.

Bernanke, B., And M. Gertler (1989): "Agency Costs, net worth, and business fluctuations," American Economic Review, 79, 14-31.

(1990): "Financial Fragility and economic performance," Quarterly Journal of Economics, 105, 97-114.

Caves, R., And M. Uekusa (1976): Industrial Organization in Japan. The Brookings Institution, Washington D.C.

Chemmanur, T. J., and P. Fulghieri (1994): "Reputation, Renegotiation and the choice between bank loans and publically traded debt," Review of Financial Studies, 7, 475-506.

Chirinko, R., And H. Schaller (1995): "Why does liquidity matter in investment equations?," Journal of Money, Credit, and Banking, 27(2), 527-548.

Chirinko, R. S. (1993): "Business Fixed Investment Spending: Modeling Strategies, Empirical Results, and Policy Implications," Journal of Economic Literature, XXXI.

Cleary, S. (1999): "The Relationship between Firm Investment and Financial Status," The Journal of Finance, $\operatorname{LIV}(2), 673-692$. 
Cummins, J., K. Hassett, and S. Oliner (1999): "Investment Behavior, Observable Expectations, and Internal Funds," mimeo, New York University.

Erickson, T., And T. Whited (2000): "Measurment error and the relationship between investment and q," Journal of Political Economy, 108(5), 1027-1057.

Fazzari, S., G. Hubbard, and B. Petersen (1988): "Financing Constraints and Corporate Investment," Brookings Papers on Economic Activity, pp. 141-195.

(2000): "Investment-Cash flow sensitivities are useful: A comment on Kaplan and Zingales," Quarterly Journal of Economics, May, 695-705.

Gibson, M. S. (1995): "Can Bank Health affect Investment? Evidence from Japan," Journal of Business, 68, 281-308.

(1997): "More Evidence on the Link between Bank Health and Investment in Japan," Journal of the Japanese and International Economies, 11, 296-310.

Gilchrist, S., and C. Himmelberg (1998): "Investment: Fundamentals and Finance," NBER Macroeconomics Annual, pp. 223-62.

Goyal, V. K., and T. Yamada (2001): "Asset Price Bubbles, Investment, and Liquidity: Evidence from Japan," Working Paper, Department of Finance, Hong Kong University of Science and Technology.

Greenwald, B., J. Stiglitz, and A. Weiss (1984): "Information imperfections and macroeconomic fluctuations," American Economic Review, 74, 194-199.

Hall, B. J., And D. E. Weinstein (2000): "Main Banks, Creditor Concentration, and the Resolution of Financial Distress in Japan," in Finance, Governance, and Competitiveness in Japan, ed. by M. Aoki, and G. Saxonhouse, pp. 64-80. Oxford University Press, Oxford.

Hart, O., And J. Moore (1995): "Debt and Seniority: An Analysis of the role of hard claims on constraining management," American Economic Review, LXXXV, 567-585.

HAYASHI, F. (1982): "Tobin's marginal $q$ and average $q$ : A neoclassical interpretation," Econometrica, 50, 261-280.

(2000): "The Main Bank System and Corporate Investment: An Empirical Reassessment," in Finance, Governance, and Competitiveness in Japan, ed. by M. Aoki, and G. Saxonhouse, pp. 81-98. Oxford University Press, Oxford.

Hayashi, F., And T. Inoue (1991): "The Relation Between Firm Growth and $Q$ with Multiple Capital Goods: Theory and Evidence from Panel Data on Japanese Firms," Econometrica, 59(3), 731-53.

Horiuchi, A., F. Packer, And S. Fukuda (1988): "What Role Has the "Main Bank" Played in Japan?," Journal of the Japanese and International Economies, 2, 159-80. 
Hoshi, T. (2000): "The Main Bank System and Corporate Investment: Further robustness tests," in Finance, Governance, and Competitiveness in Japan, ed. by M. Aoki, and G. Saxonhouse, pp. 99-105. Oxford University Press, Oxford.

Hoshi, T., And A. Kashyap (1999): "The Japanese Banking Crisis: Where Did It Come From and How Will It End?," NBER Working Paper Series: Working Paper \#7250.

(2001): Corporate Financing and Governance in Japan: The Road to the Future. MIT Press.

Hoshi, T., A. Kashyap, and D. Scharfstein (1990): "The Role of Banks in Reducing the Costs of Financial Distress in Japan," Journal of Financial Economics, 27, 33-60.

- (1990b): "Bank Monitoring and Investment: Evidence from the Changing Structure of Japanese Corporate Banking Relationships," in Asymmetric Information, Corporate Finance, and Investment, ed. by G. Hubbard, pp. 105-26. University of Chicago Press.

(1991): "Corporate Structure, Liquidity, and Investment: Evidence from Japanese Industrial Groups," Quarterly Journal of Economics, 106.

(1993): "The Choice between Public and Private Debt: An Analysis of PostDeregulation Corporate Financing in Japan," NBER Working Paper Series: Working Paper \#4421.

Hubbard, R. G. (1998): "Capital-Market Imperfections and Investment," Journal of Economic Literature, XXXVI.

Jensen, M. (1986): "Agency Costs of free cash flow, corporate finance, and takeovers," American Economic Review, 76, 323-329.

Jensen, M., And W. Meckling (1976): "The theory of the firm: Managerial behaviour, agency costs, and ownership structure," Journal of Financial Economics, III, 305-360.

Kaneko, Y., and L. Battaglini (1990): "Yen-denominated Convertible Bonds," in The Japanese Bond Market: An Overview and Analysis, ed. by F. Fabozzi. McGraw Hill, London.

KAng, J.-K., AND A. Shivdasani (1999): "Alternative mechanisms for corporate governance in Japan: An analysis of independent and bank-affiliated firms," Pacific-Basin Finance Journal, 1(22), 1-22.

Kaplan, S. N. (1994): "Top Executive Rewards and firm performance: A comparison of Japan and the United States," Journal of Political Economy, 102, 510-46.

Kaplan, S. N., And B. A. Minton (1994): "Appointments of Outsiders to Japanese Boards: Determinants and Implications for Managers," Journal of Financial Economics, 36. 
Kaplan, S. N., and L. Zingales (1997): "Do Investment-Cash Flow Sensitivites Provide Useful Measures of Financing Constraints?," Quarterly Journal of Economics, CXII, 169215 .

(2000): "Investment-Cash flow sensitivities are not valid measures of financing constraints," Quarterly Journal of Economics, May, 707-712.

Karp, E., AND A. Kolke (1990): "The Japanese Corporate Bond Market," in The Japanese Bond Market: An Overview and Analysis, ed. by F. Fabozzi. McGraw Hill, London.

Laeven, L. (2001): "Financial Liberalization and Financing Constraints: Evidence from Panel Data on Emerging Economies," World Bank Working Paper, RePEc:wop:wobadc:2467.

Love, I. (2000): "Financial Development and Financing Constraints: International Evidence from the Structural Investment Model," Mimeograph, New York, Columbia University.

MaYer, C. (1990): "Financial Systems, corporate finance, and economic development," in Asymmetric Information, Corporate Finance and Investment, ed. by G. Hubbard. The University of Chicago Press, Oxford.

Miwa, Y., And J. M. Ramseyer (2001): "The Fable of the Keiretsu," Disussion Paper, Harvard University, CIRJE-F-109.

Morck, R., and M. Nakamura (1999): "Banks and Corporate Control in Japan," The Journal of Finance, $\operatorname{LIV}(1), 319-39$.

Morck, R., M. Nakamura, and A. Shivdasani (2000): "Banks, Ownership Structure, and Firm Value in Japan," Journal of Business, 73(4), 539-67.

Myers, S., And N. Majluf (1984): "Corporate financing and investment decisions when firms have information investors do not have," Journal of Financial Economics, 13, 187221.

Nakatani, I. (1984): "The Economic Role of Financial Corporate Grouping," in The Economic Analysis of the Japanese Firm, ed. by M. Aoki, pp. 227-258. Elsevier Science Publishers B.V.

Oliner, S., And G. Rudebusch (1992): "Sources of the financing hierarchy for business investment," Review of Economics and Statistics, 74, 643-654.

Ongena, S., and D. Smith (2000): "What Determines the Number of Bank Relationships? Cross-Country Evidence," Journal of Financial Intermediation, 9, 26-56.

Prowse, S. D. (1990): "Institutional Investment Patterns and Corporate Financial Behavior in the United States and Japan," Journal of Financial Economics, 27(1), 43-66.

(1992): "The Structure of Corporate Ownership in Japan," Journal of Finance, $47(3), 1121-40$. 
RAJAN, R. (1992): "Insiders and outsiders: The choice between relationship and arms length debt," Journal of Finance, 47, 1367-1400.

Schaller, H. (1993): "Asymmetric information, liquidity constraints, and Canadian investment," Canadian Journal of Economics, 26, 552-574.

SEKINE, T. (1999): "Firm Investment and Balance-Sheet Problems in Japan," International Monetary Fund Working Paper WP/99/111.

Sharpe, S. (1990): "Asymmetric Information, bank lending and implicit contracts: A stylized model of customer relationships," Journal of Finance, 45(1069-1087).

Sheard, P. (1989): "The Main Bank System and Corporate Monitoring and Control in Japan," Journal of Economic Behavior and Organization, 11.

Thakor, A. V. (1996): "Capital Requirements, Monetary Policy, and Aggregate Bank Lending: Theory and Empirical Evidence," Journal of Finance, 51(279-324).

Weinstein, D., And Y. YAfeh (1995): "Japan's Corporate Groups: Collusive or Competitive? An Empirical Investigation of Keiretsu Behavior," The Journal of Industrial Economics, XLIII(4).

(1998): "On the Costs of a Bank-Centered Financial System: Evidence from the Changing Main Bank Relations in Japan," The Journal of Finance, LIII(2). 